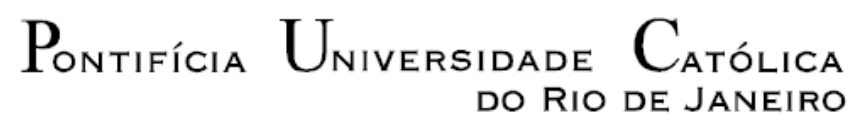

DO RIO DE JANEIRO

Gabriela Pinto Ribas

Planejamento Operacional de Refinarias

de Petróleo sob Incerteza

Tese de Doutorado

Tese apresentada ao Programa de Pós-Graduação em Engenharia de Produção da PUC-Rio como requisito parcial para obtenção do título de Doutor em Engenharia de Produção.

Orientador: Prof. Silvio Hamacher

Rio de Janeiro

Novembro de 2012 


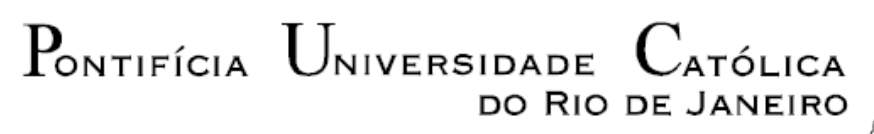

Gabriela Pinto Ribas

\title{
Planejamento Operacional de Refinarias de Petróleo sob Incerteza
}

Tese apresentada ao Programa de Pós-graduação em Engenharia de Produção do Departamento de Engenharia Industrial da PUC-Rio como requisito parcial para obtenção do título de Doutor em Engenharia de Produção.

$$
\begin{array}{r}
\text { D.Sc. Prof. Silvio Hamacher } \\
\text { Orientador } \\
\text { Departamento de Engenharia Elétrica - PUC-Rio }
\end{array}
$$

D.Sc. Prof. Alexandre Street

Departamento de Engenharia Industrial - PUC-Rio

D.Sc. Prof. Asgeir Tomasgard Norwegian University of Science and Technology - NTNU

D.Sc. Prof. Fernanda Raupp

Departamento de Engenharia Industrial - PUC-Rio

\author{
D.Sc. Paulo Ribas \\ PETROBRAS/CENPES \\ D.Sc. Prof. Virgilio Ferreira Filho \\ COPPE/UFRJ
}

Prof. José Eugênio Leal

Coordenador Setorial de Pós-graduação

do Centro Técnico Científico - PUC-Rio

Rio de Janeiro, 14 de novembro de 2012 
Todos os direitos reservados. É proibida a reprodução total ou parcial do trabalho sem autorização do autor, do orientador e da universidade.

\section{Gabriela Pinto Ribas}

Gabriela Ribas é formada em Engenharia de Produção pela PUC-Rio (2006) e obteve seu título de M.Sc. em Engenharia Elétrica com ênfase em Métodos de Apoio à Decisão também pela PUC-Rio (2008). Participou do grupo de consultores da Coppead durante o período de 2004/2006, tendo oportunidade de desenvolver projetos na área de logística, dentre os quais se destacam: previsão de vendas, roteirização e localização de centros de distribuição. Atualmente segue desenvolvendo pesquisas na área de modelagem matemática e otimização estocástica no Departamento de Engenharia Industrial pelo Núcleo de Excelência em Otimização.

Ficha Catalográfica

Ribas, Gabriela Pinto

Planejamento operacional de refinarias de petróleo sob incerteza / Gabriela Pinto Ribas; orientador: Silvio Hamacher. - 2012.

96 f. ; $30 \mathrm{~cm}$

Tese (doutorado) - Pontifícia Universidade Católica do Rio de Janeiro, Departamento de Engenharia Industrial, 2012.

Inclui bibliografia

1. Engenharia Industrial - Teses. 2. Refinaria. 3. Planejamento. 4. Programação estocástica. 5. Geração de cenários. I. Hamacher, Silvio. II. Pontifícia Universidade Católica do Rio de Janeiro. Departamento de Engenharia Industrial. III. Título. 


\section{Agradecimentos}

Ao orientador Silvio Hamacher, pela excelente orientação e pelos ensinamentos e aprimoramentos acadêmicos. Agradeço ainda por todas as oportunidades concedidas durante minha vida acadêmica e profissional.

Aos colegas do Núcleo de Excelência em Otimização (NExO), em especial a Adriana Leiras e Paula Nunes, pelas discussões e contribuições sobre os mais diversos temas relacionados a esta tese.

Ao Conselho Nacional de Desenvolvimento Científico e Tecnológico (CNPq) e à Pontifícia Universidade Católica do Rio de Janeiro (PUC-Rio), pelos auxílios concedidos e pelo ótimo ambiente de estudo. 


\section{Resumo}

Ribas, Gabriela Pinto; Hamacher, Silvio (Orientador). Planejamento Operacional de Refinarias de Petróleo Sob Incerteza. Rio de Janeiro, 2012. 96p. Tese de Doutorado - Departamento de Engenharia Industrial, Pontifícia Universidade Católica do Rio de Janeiro.

As companhias petrolíferas dedicam grande esforço para manter sua rentabilidade e melhorar sua eficiência, principalmente frente às incertezas presentes neste negócio. As empresas que pretendem manter a competitividade precisam planejar suas operações cada vez melhor e com maior segurança. Em face destas oportunidades e desafios, foi proposta no âmbito desta tese uma abordagem estocástica para o problema de planejamento operacional de refinarias. Neste sentido foi desenvolvido um modelo não-linear (NLP) de programação estocástica com dois estágios. O modelo proposto representa os processos de natureza não-linear presentes em uma refinaria, como as transformações químicas e o cálculo de qualidade dos derivados. Devido ao elevado nível de complexidade do problema NLP formulado, foram avaliados cinco métodos de solução associados aos principais solvers comerciais. Uma metodologia de geração de cenários e medidas de qualidade para árvore de cenários também foram definidas para representar adequadamente as incertezas presentes neste problema. A abordagem estocástica proposta neste trabalho foi avaliada considerando dados reais de uma refinaria brasileira. Os resultados finais desta pesquisa devem proporcionar avanços no processo de planejamento operacional de refinarias, explorando a técnica de programação não-linear (NLP) e os novos solvers disponíveis para problemas do tipo NLP. Pretende-se também gerar contribuições na área de programação estocástica, definindo medidas de qualidade para árvore de cenários que permitam uma melhor representação das incertezas e consequentemente um melhor uso da abordagem estocástica.

\section{Palavras-chave}

Refinaria; Planejamento; Programação Estocástica; Geração de Cenários. 


\section{Abstract}

Ribas, Gabriela Pinto; Hamacher, Silvio (Orientador). Oil Refinery Operational Planning Under Uncertainty. Rio de Janeiro, 2012. 96p. D.Sc. Thesis - Departamento de Engenharia Industrial, Pontifícia Universidade Católica do Rio de Janeiro.

Oil companies make a great effort to maintain profitability and improve efficiency, especially given the uncertainties present in this business. Companies that intend to remain competitive need to plan their operations better and with greater safety. In light of these opportunities and challenges, this thesis proposes a stochastic approach to the refinery operational planning problem. In this sense, a two-stage nonlinear stochastic programming model (NLP) developed. The proposed model is intended to adequately represent nonlinear processes encountered in a refinery, such as chemical transformations and calculations of the properties of the oil derivatives. Due to the high level of complexity of the NLP problem formulated, five solution methods associated with major commercial solvers were evaluated. A methodology for generating scenarios and quality measures for scenarios tree were also defined to properly represent the uncertainties present in this problem. The stochastic approach proposed in the present study was evaluated based on actual data from a Brazilian refinery. The final results of this research should provide advances in the processes of refinery operational planning exploiting the technique of nonlinear programming (NLP) and new solvers available for NLP-type problems. Another objective was to generate contributions in the field of stochastic programming by defining quality measures for scenario trees that allow a better representation of uncertainties and, consequently, better use of the stochastic approach.

\section{Keywords}

Oil Refinery; Planning; Stochastic Programming; Scenario Generation. 


\section{Sumário}

1 Introdução 10

1.1 Estrutura da Tese 13

2 Planejamento Operacional de Refinarias $\quad 14$

2.1 Atividade de Refino 14

2.2 Modelos de Planejamento Operacional de Refinarias 17

3 Otimização Sob Incerteza $\quad 22$

3.1 Modelo de Programação Estocástica de Dois Estágios 23

3.2 Métodos de Geração de Cenários $\quad 27$

3.3 Medidas de Qualidade para Árvore de Cenários 35

4 Metodologia $\quad 41$

5 Modelo Estocástico para o Planejamento Operacional de Refinaria 44

5.1 Modelo Matemático $\quad 45$

6 Método de Solução

6.1 Descrição das Refinarias $\quad 53$

6.2 Resultados dos Métodos de Solução 63

$\begin{array}{ll}7 \text { Resultados } & 69\end{array}$

7.1 Geração das Árvores de Cenários 69

7.2 Avaliação das Árvores de Cenários $\quad 74$

7.3 Resultados dos Métodos de Solução 83

8 Conclusão $\quad 86$

8.1 Trabalhos Futuros $\quad 88$

9 Referências bibliográficas $\quad 90$ 


\section{Lista de Figuras}

Figura 2.1: Cadeia de suprimentos de petróleo. .................................................... 15

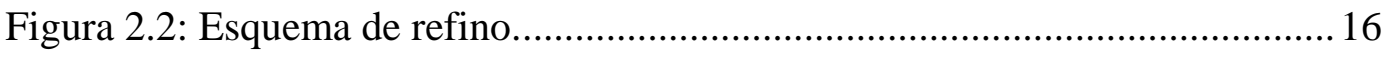

Figura 6.1: Esquema de Refino da Ref. Pequena................................................ 55

Figura 6.2: Esquema de Refino da Ref. Média.................................................... 58

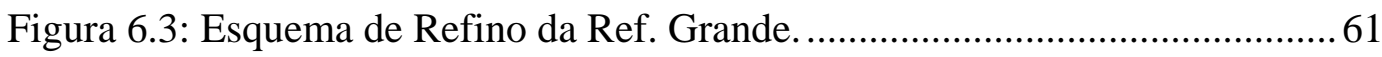

Figura 7.1: Histograma dos erros para os petróleos A, B e C.............................. 71 


\section{Lista de Tabelas}

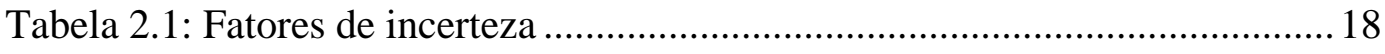

Tabela 2.2: Revisão da literatura na área de planejamento operacional de

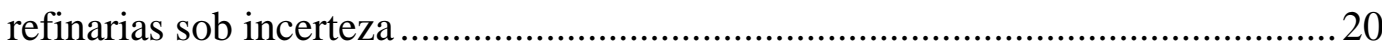

Tabela 3.1: Métodos de Geração de Cenários ....................................................... 29

Tabela 3.2: Modelo de Geração de Cenários - Conjuntos, Variáveis e Parâmetros.

32

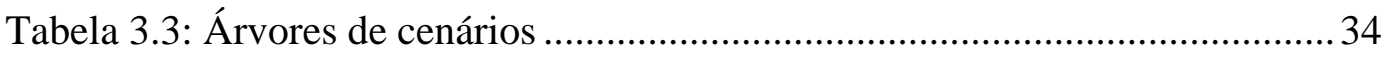

Tabela 3.4: Modelos de aproximação discreta. ..................................................... 35

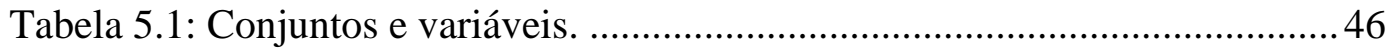

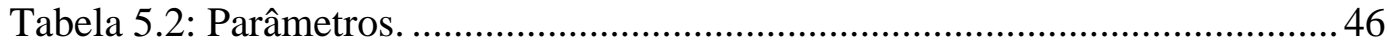

Tabela 6.1: Unidades de Processo da Ref. Pequena..............................................54

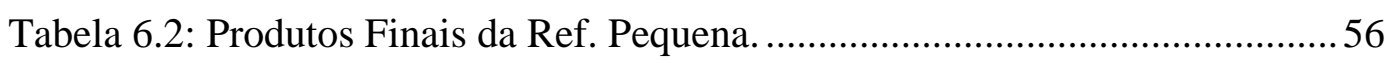

Tabela 6.3: Unidades de Processo da Ref. Média. .................................................5 57

Tabela 6.4: Produtos Finais da Ref. Média. ....................................................... 59

Tabela 6.5: Unidades de Processo da Ref. Grande................................................60

Tabela 6.6: Produtos Finais da Ref. Grande......................................................... 62

Tabela 6.7: Fornecimento de petróleo planejado (volume)................................... 63

Tabela 6.8: Descrição das refinarias brasileiras. .................................................... 64

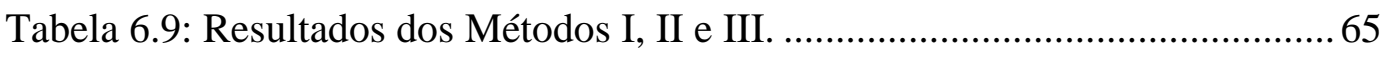

Tabela 6.10: Resultados dos Métodos I, II, III, IV e V......................................67

Tabela 7.1: Propriedades estatísticas das distribuições originais. .......................... 72

Tabela 7.2: Solução inicial - Aproximação discreta para os petróleos A, B e C...72

Tabela 7.3: Árvores de cenário - Método de Høyland e Wallace (2001).............. 73

Tabela 7.4: Árvores de cenário - Propriedades estatísticas. ................................ 74

Tabela 7.5: Fornecimento de petróleo (volume). .................................................. 75

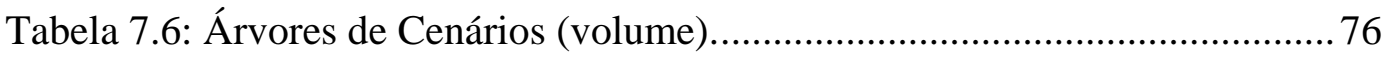

Tabela 7.7: Porte do Modelo Estocástico e Tempo Médio de Processamento...... 77

Tabela 7.8: Avaliação das Árvores com Três Cenários. ....................................... 78

Tabela 7.9: Avaliação das Árvores de Cenários com Tamanhos Diferentes......... 81

Tabela 7.10: Média das Medidas de Qualidade Normalizadas. ............................83

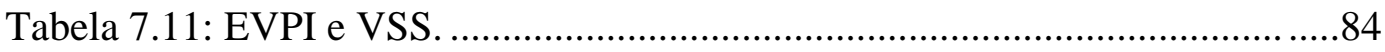




\section{1 \\ Introdução}

A indústria de refino de petróleo é a maior fonte de produtos energéticos no mundo, atendendo a 33,1\% da demanda total de energia do mundo (BEN, 2011). Em um ambiente de elevado consumo de derivados de petróleo, as companhias petrolíferas dedicam grande esforço para manter sua rentabilidade e melhorar sua eficiência, principalmente frente às constantes mudanças nas especificações dos combustíveis que têm por objetivo reduzir a emissão de poluentes causada por suas queimas. Além das questões ambientais, a indústria de petróleo precisa lidar com as incertezas presentes neste negócio e com a instabilidade econômica que afeta todos os setores econômicos. As empresas que pretendem manter a competitividade precisam planejar suas operações cada vez melhor e com maior segurança.

Dentro deste contexto, torna-se fundamental o desenvolvimento de ferramentas de apoio à decisão adequadas para o planejamento das operações de refino e que respondam tanto a questões de legislação ambiental quanto a questões de flexibilidade em um ambiente de incertezas. O uso de programação matemática nesta atividade tem se mostrado bastante promissor, com ganhos potenciais de US\$10,00 por tonelada de produto (Moro, 2003). Na literatura encontram-se diversos modelos de planejamento operacional testados em refinarias reais (Gao et al. 2008; Lakkhanawat e Bagajewicz, 2008; Li et al., 2008; Micheletto et al. 2007; Neiro e Pinto, 2004; Neiro e Pinto, 2005; Neiro e Pinto, 2006; Pongsakdi et al., 2006; Göthe-Lundgren et al., 2002; Pinto e Moro, 2000; Pinto et al., 2000; Moro et al., 1998). Apesar das significativas contribuições destes trabalhos, foram identificadas ainda oportunidades de melhoria nos modelos de planejamento operacional de refinaria, tanto em termos de modelagem matemática quanto do ponto de vista da aplicação. Shah et al. (2011) destacam possibilidades de melhorias através de uma modelagem mais acurada dos processos de refino de natureza não linear e da avaliação dos novos algoritmos disponíveis para resolução de problemas de programação não-linear (NLP). 
O tratamento adequado das incertezas presentes no problema de planejamento operacional de refinarias surge como mais uma oportunidade de avanço na área. Técnicas de otimização sob incerteza, como programação estocástica com dois estágios (Neiro e Pinto, 2005; Neiro e Pinto, 2006; Pongsakdi et al., 2006), programação probabilística (Li et al., 2008), programação robusta (Leiras et al., 2010) e programação fuzzy (Ravi e Reddy, 1998) já foram aplicadas neste tipo de problema. No entanto, a combinação de programação nãolinear com técnicas de otimização sob incerteza para resolver o problema de planejamento operacional de refinarias foi pouco explorada. Apenas Neiro e Pinto (2005, 2006) resolveram o modelo não-linear estocástico, todos os demais autores citados acima trabalharam com aproximações lineares.

A abordagem de otimização sob incerteza mais aplicada a problemas na indústria do petróleo é o modelo de programação estocástica de dois estágios (Leiras et al., 2011). O bom desempenho desta abordagem depende fortemente da capacidade de representar a incerteza, que neste tipo de modelo é captada através de cenários. Apesar de ser uma abordagem amplamente aceita, ela está suscetível a críticas, pois a modelagem estocástica sem uma árvore de cenários que traduza adequadamente as incertezas perde sua eficácia. Segundo Mitra (2006), ao incorporar pouca incerteza os modelos estocásticos são reduzidos a determinísticos. Por outro lado, incorporar arbitrariamente qualquer incerteza pode levar a soluções irreais ou irrelevantes. As principais referências de otimização sob incerteza na indústria do petróleo (Al-Othman et al., 2008; Dempster et al., 2000; Escudero et al., 1999; Khor et al., 2007; Lababidi et al., 2004; Liu e Sahinidis, 1996; Pongsakdi et al., 2006) não tratam a geração de cenários com a atenção devida e optam por usar a clássica metodologia média mais ou menos um desvio.

A geração de árvore de cenários tem papel fundamental para o bom desempenho do modelo de programação estocástica, porém pouco foi encontrado na literatura sobre como medir a influência da árvore de cenários na qualidade da solução do modelo matemático. Neste sentido destaca-se o trabalho de Kaut e Wallace (2003), que discute a qualidade do método de geração de cenários em função do resultado do modelo estocástico. Mesmo com esta relevante, porém isolada contribuição, ainda é preciso explorar melhor a relação entre a escolha da árvore de cenários e a solução do modelo estocástico. O presente trabalho propõe 
a seleção da árvore de cenários através de medidas de qualidade como etapa importante do processo de planejamento via modelos de programação estocástica. As medidas de qualidade pretendem avaliar a capacidade da árvore de cenários aproximar a solução do modelo de programação estocástica obtida com a distribuição completa do parâmetro estocástico, comparando as soluções do modelo de programação estocástica obtidas com a árvore de cenários e com a distribuição completa.

Em resumo, os gaps identificados na literatura em relação ao problema de planejamento operacional de refinarias são:

- Modelagem mais acurada dos processos de refino de natureza não linear;

- Avaliação dos novos solvers comerciais disponíveis para resolução de problemas de programação não-linear (NLP);

• Formulação estocástica do modelo de programação não-linear (NLP);

- Identificar incertezas relacionadas ao planejamento operacional de refinarias mais relevantes para realidade brasileira;

- Representação adequada das incertezas;

- Testar o modelo estocástico de programação não-linear em refinarias reais e completas.

O objetivo desta tese é propor uma abordagem estocástica para o problema de planejamento operacional de refinarias. A abordagem proposta se diferencia das demais encontradas na literatura, pois pretende cobrir os gaps listados acima. Para tanto, será desenvolvido um modelo não-linear de programação estocástica com dois estágios. O modelo proposto pretende representar adequadamente os processos de natureza não-linear presentes em uma refinaria, como as transformações químicas e o cálculo de qualidade dos derivados. Os principais solvers comerciais disponíveis no mercado para resolução de problemas do tipo NLP (KNITRO, SNOPT e CONOPT) serão testados. Uma metodologia de geração de cenários será definida para representar adequadamente a incerteza considerada no fornecimento de petróleo da refinaria. Após a geração de cenários, medidas de qualidade serão utilizadas para selecionar a árvore de cenários em função da solução do modelo estocástico. A abordagem estocástica proposta neste trabalho para o problema de planejamento operacional de refinarias será avaliada considerando dados reais de uma refinaria brasileira. 
Os resultados finais desta pesquisa devem proporcionar avanços no processo de planejamento operacional de refinarias, explorando a técnica de programação não-linear (NLP) e os novos solvers disponíveis para problemas do tipo NLP. Pretende-se também gerar contribuições na área de programação estocástica, definido medidas de qualidade para árvore de cenários que permitam uma melhor representação das incertezas e consequentemente um melhor uso da abordagem estocástica.

\section{1}

\section{Estrutura da Tese}

A presente tese está organizada em 9 Capítulos, incluindo este introdutório.

O Capítulo 2 apresenta formalmente o problema de planejamento operacional de refinarias. O capítulo continua com uma revisão de literatura sobre planejamento operacional de refinarias, incluindo abordagens propostas para o problema em estudo e oportunidades na área.

O Capítulo 3 apresenta os conceitos de otimização sob incerteza, sob a forma de uma revisão bibliográfica. Estes conceitos estão organizados em programação estocástica, métodos de geração de cenários e medidas de qualidade para avaliar árvores de cenários.

O Capítulo 4 descreve a metodologia utilizada nesta tese.

O Capítulo 5 apresenta a formulação do modelo matemático proposto. O Capítulo 6 define o método de solução e mostra os resultados de desempenho computacional do modelo matemático considerando dados reais das três refinarias nacionais.

O Capítulo 7 contém a descrição completa dos resultados referentes à geração e avalição das árvores de cenários e do modelo de programação estocástico.

O Capítulo 8 finaliza o trabalho com as conclusões e sugestões de continuação da pesquisa. 


\section{2 \\ Planejamento Operacional de Refinarias}

O Capítulo 2 está dividido em duas seções: (2.1) Atividade de Refino e (2.2) Modelos de Planejamento Operacional de Refinarias. A primeira seção apresenta todas as atividades que compõem a cadeia de suprimentos de petróleo e descreve com maior nível de detalhe a atividade de refino. A segunda seção foca nos modelos de planejamento operacional de refinarias encontrados na literatura, concluindo com as oportunidades de contribuição na área.

\section{1}

\section{Atividade de Refino}

As atividades que compõem a cadeia de suprimentos de petróleo são divididas em três grandes segmentos: upstream, midstream e downstream. O segmento de upstream compreende as atividades de exploração e produção do petróleo. O midstream é um segmento intermediário e consiste, basicamente, na atividade de refino, que compreende desde o transporte do petróleo do local de produção até a produção dos derivados nas refinarias, ficando as tarefas logísticas necessárias para transportar os produtos desde a refinaria até os pontos de consumo no segmento de downstream. A atividade de refino se insere dentro do segmento de midstream e representa um elo central da cadeia de petróleo unindo os segmentos de upstream e downstream, como ilustrado na Figura 2.1. 


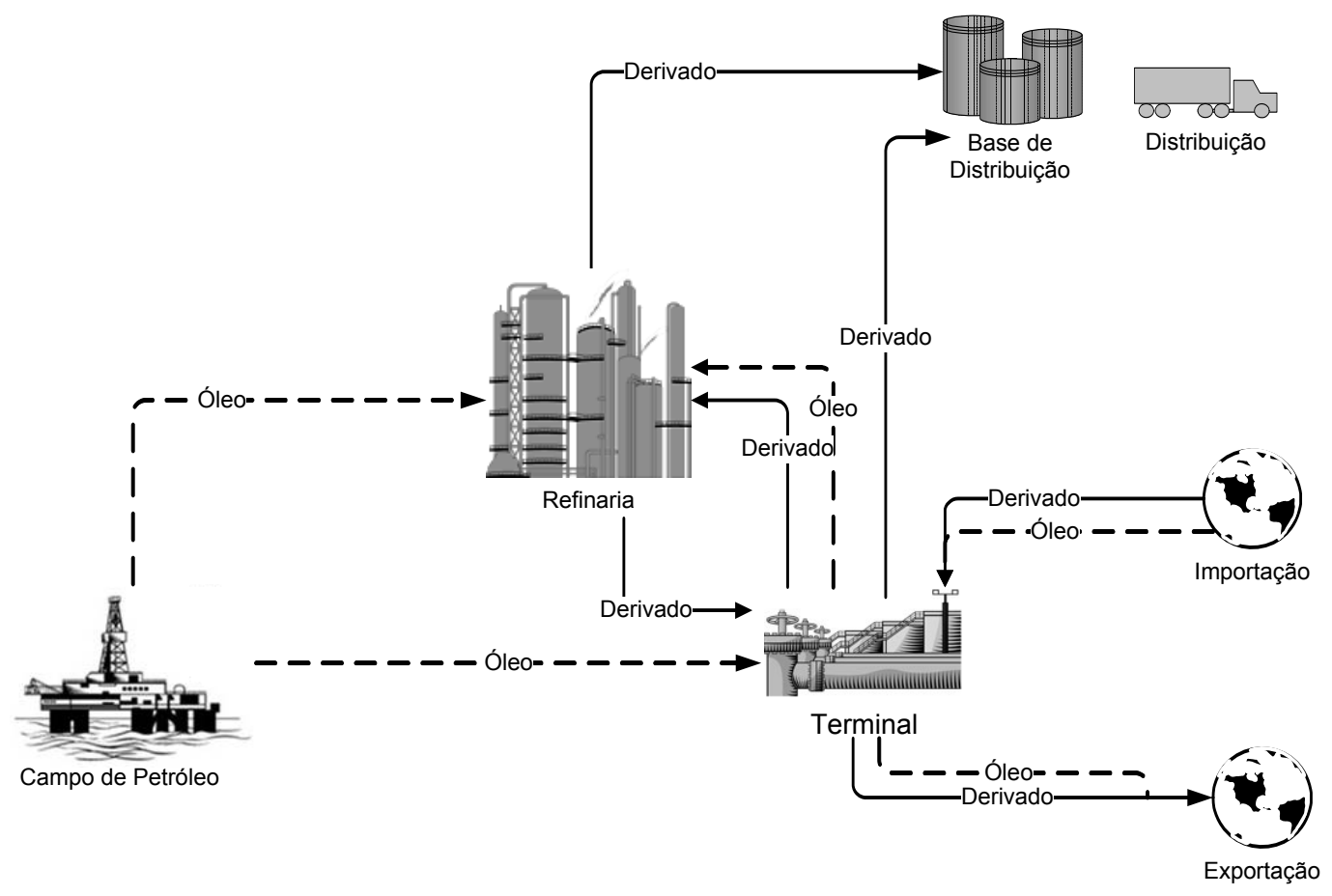

Figura 2.1: Cadeia de suprimentos de petróleo (Adaptado de Ribas et al., 2010).

A principal função de uma refinaria é transformar o óleo cru em produtos de maior valor agregado, com o objetivo de maximizar o seu lucro. A refinaria é composta por unidades de processo, tanques de armazenamento para produtos finais e intermediários, e dutos interligando todos estes componentes. $\mathrm{O}$ arranjo de todos os tanques e unidades de processo em uma refinaria é chamado de esquema de refino. A Figura 2.2 mostra o esquema de uma refinaria localizada no Brasil: 


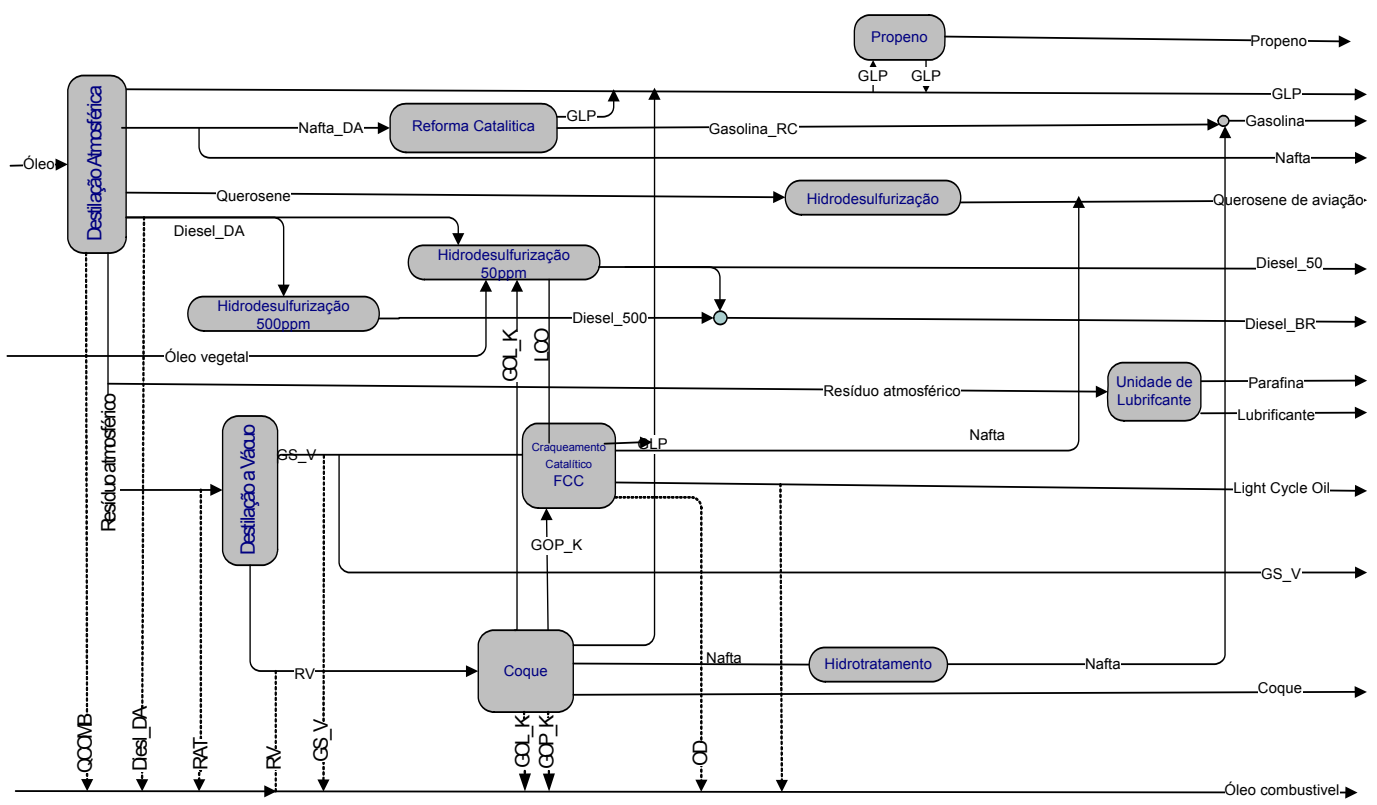

Figura 2.2: Esquema de refino (Adaptado de Ribas et al., 2010).

A refinaria produz frações leves (ex: Propeno, Gás liquefeito de Petróleo, Gasolina, Nafta), médias (ex: Querosene de aviação, Diesel) e pesadas (ex: Parafina, Lubrificantes, Light Cycle Oil, Gasóleo, Coque, Óleo Combustível), de acordo com a extensão e complexidade das suas cadeias de carbono. A refinaria transforma o óleo cru em produtos comercializáveis através de três processos principais: conversão, separação e tratamento. Os processos de separação (Destilação Atmosférica, Destilação a Vácuo) são projetados para separar o óleo em suas frações básicas ou processar uma fração previamente gerada para produzir um grupo específico de componentes. Dependendo dos objetivos de produção, diferentes processos de conversão e de tratamento são aplicados às frações de petróleo. Processos de conversão (Coque, Craqueamento Catalítico FCC, Reforma Catalítica) transformam uma fração em outra ou alteram a estrutura molecular de uma fração. Processos de tratamento (Hidrodesulfurização, Hidrotratamento) modifica a estrutura de produtos semi-acabados reduzindo ou removendo contaminantes (nitrogênio, enxofre e metais) de sua estrutura molecular. As refinarias possuem não somente unidades de processo, mas também tanques para armazenar e misturar produtos intermediários e dutos interligando todos os componentes. 


\section{2}

\section{Modelos de Planejamento Operacional de Refinarias}

O planejamento operacional da atividade de refino é a base para decisões de negócios com grande impacto sobre a rentabilidade da refinaria. Da necessidade de executar um planejamento operacional ótimo foram disponibilizados no mercado softwares comerciais com base em programação linear (LP) para o planejamento das atividades de produção de uma refinaria, tais como RPMS (1979) e PIMS (1993). A ferramenta PIMS oferece um módulo de programação não-linear (NLP), mas algumas companhias petrolíferas ainda utilizam a versão linear. Além dessas ferramentas comerciais, diversos autores propuseram abordagens LP para o planejamento operacional de refinarias (Gao et al., 2008; Zhang e Hua, 2007; Micheletto et al., 2007; Göthe-Lundgren et al., 2002; Ponnambalam et al., 2002; Zhang et al., 2001; Pinto e Moro, 2000). No entanto, a imprecisão causada por modelos lineares não rigorosos podem reduzir a rentabilidade global ou sacrificar a qualidade final dos derivados de petróleo (Shah et al., 2011).

Grandes avanços nesta área foram obtidos principalmente através do uso de programação não-linear. Alhajri et al.(2008) propõem uma representação mais precisa dos processos refino capaz de prever as variáveis operacionais, como temperaturas de corte na unidade de Destilação Atmosférica, e avaliar as propriedades dos produtos finais para atender a especificação de mercado. Elkamel et al. (2008) apresentam um modelo de programação não-linear inteiro misto (MINLP) para o planejamento da produção da refinaria que maximiza o lucro operacional enquanto reduz a emissão de CO2 a um determinado nível através de diferentes opções de mitigação. Zhang e Zhu (2006) implementaram uma estratégia de decomposição para tratar o problemas de planejamento em refinarias de grande porte. O problema é dividido em dois níveis, nível local (modelo mestre) e nível de processo (sub-modelos). O modelo mestre refere-se a problemas comuns entre os processos, como a atribuição de matérias-primas e utilidades (energia, gás, etc.), e os sub-modelos otimizam processos individuais que alimentam o modelo mestre. Este procedimento termina quando os critérios de convergência são atingidos. Além destes trabalhos destacam-se Li et al. (2005), Pinto et al. (2000), e Moro et al. (1998) que também formularam modelos de 
programação não-linear (PNL) para representar os processos de refino. No entanto suas aplicações foram restritas a apenas alguns processos, e não a refinaria completa.

Outro importante aspecto do problema de planejamento operacional de refinarias é a presença de incertezas. De acordo com Wendt et al. (2002) e Li et al. (2004), os fatores de incerteza podem ser classificados em: fatores exógenos e fatores endógenos. As incertezas exógenas são representadas por fatores externos que impactam o processo. Já os fatores endógenos representam a deficiência no completo conhecimento dos processos internos. Os fatores de incerteza endógenos e exógenos identificados e associados ao problema de planejamento de refinarias são apresentados na Tabela 2.1.

Tabela 2.1: Fatores de incerteza (baseado em Maiti et al., 2001; Liu e Sahinidis, 1997).

\begin{tabular}{l|l}
\hline \multicolumn{1}{c|}{ Fatores exógenos (externos) } & \multicolumn{1}{c}{ Fatores endógenos (internos) } \\
\hline \hline Disponibilidade de fontes de petróleo; & Propriedades de componentes; \\
$\begin{array}{l}\text { Tipos de petróleo disponíveis; } \\
\text { Dados econômicos sobre matéria-prima, produtos } \\
\text { acabados, utilidades e outros (preços, demandas e } \\
\text { custos de produção e distribuição); }\end{array}$ & Rendimentos de processos; \\
$\begin{array}{l}\text { Localização; } \\
\text { Orçamento de investimentos para expansão de } \\
\text { capacidade e compras de equipamentos; } \\
\text { Custos de investimentos de processos; } \\
\text { Questões políticas. }\end{array}$ & Opções de processamento e blending; \\
\hline
\end{tabular}

Park et al. (2010) desenvolveram um modelo integrado baseado em programação estocástica com dois estágios para o planejamento operacional e gestão de riscos financeiros de uma refinaria. Khor e Nguyen (2009) formularam um modelo de programação estocástica de dois estágios com uma estrutura de risco tratável na função objetivo. A abordagem de análise de cenário é adotada para representar incertezas em três tipos de parâmetros estocásticos: preço do petróleo e dos produtos comerciais, demanda e rendimento da produção. Li et al. (2008) propuseram um modelo de programação estocástica para o planejamento de produção da refinaria com demanda incerta representada por uma distribuição uniforme. O modelo é aproximado por funções lineares por parte e resolvido com programação linear. Pongsakdi et al. (2006) estudaram o problema estocástico com gerenciamento de risco financeiro feito através da medida de risco Value-atRisk (VaR). O objetivo foi determinar a compra ótima de petróleo e decidir sobre 
o nível de produção dado as previsões de demanda. Lakkhanawat e Bagajewicz (2008) abordam um problema similar.

Neiro e Pinto (2005) formularam um modelo estocástico não-linear inteiro misto (MINLP) para representar as operações de uma refinaria de petróleo. A incerteza é incorporada nos parâmetro de demanda, preço dos derivados e preço do petróleo. Este trabalho foi complementado em Neiro e Pinto (2006), onde a Decomposição Lagrangeana foi aplicada para reduzir o tempo de solução. Os trabalhos de Neiro e Pinto merecem especial atenção por combinarem programação não-linear inteira mista (MINLP) com otimização sob incerteza. O modelo de planejamento operacional para refinarias proposto nesta tese baseia-se no modelo de Neiro e Pinto (2005). A modelagem inicialmente proposta por Neiro e Pinto (2005) foi modificada de forma a incluir importantes aspectos do problema real de planejamento operacional de refinaria a serem discutidos no Capítulo 5.

Os artigos sobre planejamento operacional de refinaria sob incerteza estão resumidos na Tabela 2.2 segundo tipo de problema, abordagem de otimização sob incerteza e fatores de incerteza. 
PUC-Rio - Certificação Digital № 0821421/CA

Tabela 2.2: Revisão da literatura na área de planejamento operacional de refinarias sob incerteza (adaptado de Leiras et al., 2010).

\begin{tabular}{|c|c|c|c|c|c|c|c|c|c|c|c|c|c|c|c|c|}
\hline \multirow[b]{2}{*}{ Autor (ano) } & \multicolumn{4}{|c|}{ Tipo de Problema } & \multicolumn{6}{|c|}{ Abordagem de Otimização sob Incerteza } & \multicolumn{6}{|c|}{ Fatores de Incerteza } \\
\hline & $\varrho$ & 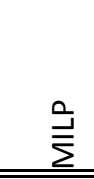 & 言 & $\stackrel{\text { 主 }}{\Sigma}$ & 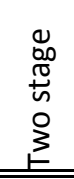 & 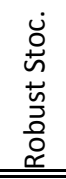 & 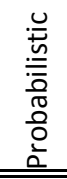 & 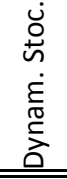 & $\begin{array}{l}\vec{n} \\
\stackrel{0}{0} \\
\stackrel{0}{0} \\
\end{array}$ & $\begin{array}{l}\vec{N} \\
\text { N } \\
\stackrel{1}{L} \\
\end{array}$ & $\begin{array}{l}\frac{\pi}{0} \\
\frac{0}{\pi} \\
\tilde{E} \\
\Phi \\
0 \\
\end{array}$ & 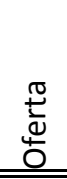 & 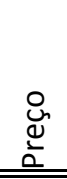 & 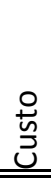 & 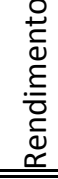 & 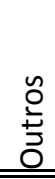 \\
\hline Park et al. (2010) & & & & & & $x$ & & & & & & & $x$ & & & \\
\hline Leiras et al . (2010) & $x$ & & & & & & & & $x$ & & $x$ & & $x$ & $x$ & $x$ & \\
\hline Khor e Nguyen (2009) & $x$ & & & & & $\mathrm{x}$ & & & & & $\mathrm{x}$ & & $x$ & $\mathrm{x}$ & $x$ & \\
\hline Lakkahanawat e Bagajewicz (2008) & $x$ & & & & & $x$ & & & & & $x$ & & $x$ & $x$ & & \\
\hline Li et al . (2008) & $\mathrm{x}$ & & & & & & $\mathrm{x}$ & & & & $x$ & & & & & \\
\hline Pongsakdi et al . (2006) & $\mathrm{x}$ & & & & & $\mathrm{x}$ & & & & & $\mathrm{x}$ & & $\mathrm{x}$ & & & \\
\hline Neiro e Pinto (2006) & & & & $x$ & & & & $\mathrm{x}$ & & & $x$ & & $x$ & & & \\
\hline Neiro e Pinto (2005) & & & & $x$ & & & & $x$ & & & $x$ & & $x$ & & & \\
\hline Ravi \& Reddy (1998) & $\mathrm{x}$ & & & & & & & & & $\mathrm{x}$ & & & & & & $\mathrm{x}$ \\
\hline
\end{tabular}


Analisando a Tabela 2.2 nota-se que poucos autores trataram incertezas geradas por fatores endógenos e, dentre os fatores exógenos, destacam-se demanda e preço. No que se refere ao problema brasileiro de planejamento operacional de refinarias, incertezas relacionadas à oferta de petróleo e disponibilidade de equipamentos são mais relevantes, uma vez que fatores exógenos, como demanda e preço, são relativamente estáveis no curto prazo (nível operacional) quando consideramos o mercado nacional.

Ainda com base na Tabela 2.2 é possível observar que apenas Neiro e Pinto (2005, 2006) apresentaram uma modelagem NLP para o problema estocástico, havendo espaço para novos trabalhos. É importante ressaltar também que em geral os trabalhos que propuseram modelos NLP consideram apenas parte da refinaria ou versões simplificadas da mesma, devido à dificuldade de resolver o problema de porte real. Shah et al. (2011) identificaram gaps similares na literatura, e destacam a necessidade de uma modelagem mais acurada dos processos de refino de natureza não-linear e de uma avaliação dos novos algoritmos disponíveis para resolução de problemas do tipo NLP. 


\section{Otimização Sob Incerteza}

A otimização estuda problemas do mundo real através de modelos matemáticos e algoritmos, comumente associados a parâmetros incertos, como oferta de matéria prima, demanda, custos e preços. Na literatura encontramos diversas abordagens para incorporar e tratar estas incertezas, podendo destacar programação robusta, programação fuzzy e programação estocástica.

A otimização robusta concentra-se em modelos que garantam a viabilidade da solução para os possíveis resultados dos parâmetros incertos. Segundo esta abordagem, o tomador de decisão aceita uma solução sub-ótima para garantir que, quando houver variações nos dados, a solução continua a ser viável e perto do ótimo. A técnica robusta foi inicialmente relatada por Soyster (1973), que propôs uma abordagem bem conservadora, onde todos os parâmetros aleatórios assumiam o valor do pior caso. Desde então, vários estudos têm estendido a abordagem de Soyster, como pode ser visto em Beyer e Sendhoff (2007). Ben-Tal e Nemirovski (1998, 1999, 2000), El-Ghaoui et al. (1998) e El-Ghaoui e Lebret (1997) apresentaram um método robusto menos conservador, introduzindo um termo não-linear na função objetivo. Bertsimas e $\operatorname{Sim}(2003,2004)$ propuseram um método que não aumenta a complexidade do problema original e permite que o grau de conservadorismo seja controlado pelo tomador de decisão.

A programação fuzzy baseia-se nos conceitos de lógica fuzzy, assumindo que a incerteza dos parâmetros presentes nos modelos matemáticos sejam representados por números fuzzy e as restrições por conjuntos fuzzy. Algumas violações de restrições são permitidas e o grau de satisfação associado a cada restrição é definido por uma função de pertinência (Sahinidis, 2004). A abordagem de programação fuzzy foi originalmente proposta por Bellmann e Zadeh (1970) e popularizado por Zimmermann (1991).

A programação estocástica trata de problemas de otimização com parâmetros que assumem uma distribuição de probabilidade discreta ou contínua e pode ser dividida em: 
- Modelos de recurso (recourse models): esta abordagem foi originalmente proposta por Dantzig (1955) e Beale (1955) para problemas de programação estocástica de dois estágios, podendo ser estendida para múltiplos estágios. Modelos de recurso usam ações corretivas para compensar a violação de restrições que surgiram após a realização de incertezas. Detalhes desta abordagem serão apresentados na seção 3.1.1.

- Modelos probabilísticos (chance-constrained programming): apresentados por Charnes e Cooper (1959), permitem que algumas restrições de segundo estágio sejam expressas em termos de declarações probabilísticas sobre as decisões de primeiro estágio. As ações corretivas presentes nos modelos de recurso são evitadas nesta abordagem, já que algumas restrições de segundo estágio podem ser violadas ao incorporarem uma medida de risco. Os modelos probabilísticos são particularmente úteis quando os custos e benefícios associados às decisões de segundo estágio são difíceis de serem avaliados.

Embora muitas abordagens tenham sido propostas para modelar incertezas, os modelos de programação estocástica provaram a sua flexibilidade e utilidade em diversas áreas da ciência (Shapiro et al., 2009). Como visto no capítulo anterior, o modelo estocástico de dois estágios vem sendo aplicada com sucesso nos problemas de planejamento de refinaria, e por isso foi a abordagem selecionada para o presente trabalho. A próxima seção descreve o modelo de programação estocástica de dois estágios e as medidas de comparação entre modelos determinísticos e estocásticos. O Capítulo 3 é finalizado com uma breve discussão sobre métodos de geração de cenários e a sua importância para o bom desempenho do modelo de programação estocástica.

\section{1}

\section{Modelo de Programação Estocástica de Dois Estágios}

O modelo de programação estocástica mais aplicado e estudado é o modelo de dois estágios (Shapiro e Philpott). O modelo de dois estágios, como o próprio nome sugere, divide as variáveis de decisão em dois estágios. As variáveis de primeiro estágio devem ser decididas antes da realização de incertezas. As variáveis de segundo estágio são utilizadas como medidas de correção contra 
qualquer inviabilidade que tenha surgido após a realização de incertezas. O modelo de programação estocástica de dois estágios pode ser formulado como:

$$
\operatorname{Min}_{x \in X}\left\{z(x)=c^{T} x+E_{\xi}[Q(x, \xi)]\right\} \quad \text { sujeito a } \quad A x \leq b \quad x \geq 0,
$$

onde $Q(x, \xi)$ é o valor ótimo do problema de segundo estágio:

$$
\underset{y}{\operatorname{Min}} q^{T} y \quad \text { sujeito a } \quad W y \leq h-T x \quad y \geq 0 .
$$

Nesta formulação, $x \in R^{n}$ é o vetor das variáveis de decisão de primeiro estágio, $c$, $A$ e $b$ são os dados associados ao problema de primeiro estágio, $y \in R^{m}$ é o vetor das variáveis de decisão de segundo estágio e $\xi=(q, T, W, h)$ contém os dados para o problema de segundo estágio que podem ser representados por variáveis aleatórias com distribuição de probabilidade conhecidas. Aqui assume-se que o vetor aleatório $\xi$ possui um número finito de realizações $\xi_{1} \ldots \xi_{s c}$ com as respectivas probabilidades $p_{1} \ldots p_{s c}$. Assim o valor esperado $E_{\xi}[Q(x, \xi)]$ pode ser escrito em função do somatório:

$$
E_{\xi}[Q(x, \xi)]=\sum_{s c=1}^{S C} p_{s c} Q_{s c}\left(x, \xi_{s c}\right) \text {. }
$$

Assumindo o modelo discreto, pode-se reescrever modelo de programação estocástica de dois estágios na forma:

$$
\operatorname{Min}_{x \in X}\left\{z(x)=c^{T} x+\sum_{s c=1}^{S C} p_{s c} Q_{s c}\left(x, \xi_{s c}\right)\right\} \quad \text { sujeito a } \quad A x \leq b \quad x \geq 0,
$$

onde $Q_{s c}\left(x, \xi_{s c}\right)$ é o valor ótimo do problema de segundo estágio para cada realização $s C=1, \ldots, S C$ :

$\underset{y}{\operatorname{Min}} q_{s c}{ }^{T} y_{s c}$ sujeito a $W y_{s c} \leq h_{s c}-T_{s c} x \quad y_{s c} \geq 0$.

No primeiro estágio é minimizado o custo de $c^{T} X$ mais o valor esperado do custo do problema de segundo estágio $\sum_{s c=1}^{S C} p_{s c} Q_{s c}\left(x, \xi_{s c}\right)$. No primeiro estágio deve ser tomada a decisão do tipo "aqui e agora” (here-and-now) do vetor $x$, antes da realização das incertezas representadas por $\xi_{s c}$ conhecido. A decisão de primeiro estágio $x$ depende apenas da informação disponível até aquele momento, este princípio é chamado de nonanticipativity constraint. No problema de dois estágios isto implica que a decisão $x$ independe das realizações do segundo 
estágio, sendo assim o vetor $x$ é o mesmo para todos os possíveis eventos que venham a ocorrer no segundo estágio do problema (Birge e Louveaux, 1997). No segundo estágio, onde as informações $\xi_{\text {sc }}$ já estão disponíveis, é tomada a decisão sobre o valor do vetor $y_{s c}$. A decisão tomada no problema de segundo estágio reflete o comportamento ótimo no momento em que a incerteza é revelada.

\subsection{1}

\section{Medidas de Comparação entre Modelos Determinísticos e Estocásticos}

Mesmo Segundo Birge e Louveaux (1997), o modelo estocástico geralmente é computacionalmente difícil de resolver. É comum optar pela solução de um modelo determinístico, usando a média das variáveis aleatórias ou resolvendo um problema determinístico para cada cenário. No intuito de comparar estas soluções determinísticas com a estocástica, Birge e Louveaux (1997) apresentam duas medidas: o valor esperado da informação perfeita e o valor da solução estocástica.

\section{Valor Esperado da Informação Perfeita}

O valor esperado da informação perfeita (Expected Value of Perfect Information - EVPI) mede o máximo montante que um tomador de decisão estaria disposto a pagar pela informação perfeita, isto é, o preço a pagar para conhecer as realizações futuras. Supondo que a incerteza seja representada por um número finito de cenários, sendo $\xi$ a variável aleatória cujas realizações correspondem aos vários cenários, define-se:

$$
\begin{aligned}
& \underset{x \in X}{\operatorname{Min}} z(x, \xi)=c^{T} x+\min \left\{q^{T} y \mid W y \leq h-T x, y \geq 0\right\} \\
& \text { s.a. } \quad A x \leq b, x \geq 0,
\end{aligned}
$$

como o problema associado a cada realização $\xi$. Assume-se que para todo $\xi$ existe pelo menos uma solução viável $x \in R^{n}$. Sejam $x^{*}(\xi)$ a solução ótima para o problema (3.6) e $z\left(x^{*}(\xi), \xi\right)$ o valor da função objetivo para cada cenário, é possível calcular a solução conhecida como espere-e-veja (wait-and-see - WS). A solução chamada de espere-e-veja corresponde ao valor ótimo do problema quando as realizações futuras de $\xi$ são conhecidas, isto é, o tomador de decisão 
pode esperar e ver o futuro antes de decidir. O valor esperado da solução espere-eveja é dado por:

$$
W S=E_{\xi}\left[\min _{x} z(x, \xi)\right]=E_{\xi}\left[z\left(x^{*}(\xi), \xi\right)\right] .
$$

Agora é possível comparar a solução WS com a solução aqui-e-agora (hereand-now) correspondente ao problema de recurso (Recourse Problem - RP) de dois estágios definido na seção anterior como (3.1), onde RP pode ser escrito na forma:

$$
R P=\min _{x} E_{\xi}[z(x, \xi)]
$$

com solução ótima $x^{*}$. A solução RP é definida como aqui-e-agora, pois a solução de primeiro estágio é decidida sem que se conheça as realizações futuras de $\xi$, isto é, a decisão é tomada no momento presente sem nenhum conhecimento sobre o futuro.

O valor esperado da informação perfeita é, por definição, a diferença entre as soluções espere-e-veja e aqui-e-agora:

$$
E V P I=|W S-R P| \text {. }
$$

O valor esperado da informação perfeita (EVPI) representa a diferença entre a solução obtida pelo agente com poder de predição perfeita (conhece os eventos futuros) e o agente que resolve o problema sob a hipótese de conhecer apenas a distribuição de probabilidade de $\xi$.

\section{Valor da Solução Estocástica}

Em alguns casos precificar o valor da informação perfeita não é a medida de comparação mais adequada, já que a solução espere-e-veja (WS) é impossível de ser realizada na prática. Nestes casos, outra opção consiste em utilizar a solução do problema determinístico associada à média das variáveis aleatórias para comparar com a solução estocástica. Assim, define-se por EV (Expected Value) a solução do problema para o cenário esperado (valor esperado de $\xi$ ):

$$
E V=\min _{x} z(x, \bar{\xi})
$$

onde $\bar{\xi}=E[\xi]$ e $x^{*}(\bar{\xi})$ é a solução ótima de EV.

Em seguida será definido o valor esperado do resultado (Expected Result of Expected Value Solution - EEV) usando a solução obtida com EV: 


$$
E E V=E_{\xi}\left[z\left(x^{*}(\bar{\xi}), \xi\right)\right]
$$

O EEV mede a performance da solução $x^{*}(\bar{\xi})$ para cada realização de $\xi$, permitindo que a decisão de segundo estágio seja feita de forma ótima em função de $x^{*}(\bar{\xi})$ e $\xi$. O valor da solução estocástica (Value of the Stochastic Solution VSS) fica então:

$$
V S S=|E E V-R P| \text {. }
$$

O valor da solução estocástica (VSS) pode ser interpretado como o benefício esperado do agente que considerou a incerteza dada por $\xi$, ou ainda, como a perda esperada do agente que optou pela modelagem determinística utilizando o valor esperado de $\xi(E[\xi]=\bar{\xi})$.

\section{2}

\section{Métodos de Geração de Cenários}

O problema de programação estocástica de dois estágios definido em 3.1, com exceção de casos triviais, não pode ser resolvido com distribuições contínuas, além disso, a maioria dos métodos de solução precisa que a incerteza seja representada por uma distribuição discreta. Sendo assim, uma questão importante para a resolução de modelos de programação estocástica consiste na aproximação do processo estocástico contínuo por uma árvore de cenários (Heitsch e Römisch, 2005). O resultado do modelo de programação estocástica depende fortemente da capacidade de representar adequadamente a incerteza, que é captada através de cenários. Segundo Mitra (2006), ao incorporar pouca incerteza os modelos estocásticos são reduzidos a determinísticos. Por outro lado, incorporar arbitrariamente qualquer incerteza pode levar a soluções irreais ou irrelevantes. Assim os métodos de geração cenários são de importância central para qualquer modelo de programação estocástica.

Cenários podem ser gerados usando vários métodos (Mitra, 2006):

- Estatísticos: são utilizados para determinar uma aproximação discreta (cenários) que melhor se ajuste a distribuição teórica dos dados. O ajuste é 
feito através dos valores de propriedades estatísticas da distribuição original, como momentos centrais e correlação.

Principais métodos: Moment matching e property matching; Análise das principais componentes (PCA); Regressão e suas variantes.

- Amostragem: tem como princípio fundamental tomar uma amostra de uma dada função densidade de probabilidade ( $f d p)$ onde os valores selecionados para representar a $f d p$ determinam os cenários e suas respectivas probabilidades.

Principais métodos: Monte Carlo, Bootstrap sampling, Markov Chain Monte Carlo sampling, Importance sampling, Internal sampling, Conditional sampling, Stratifield sampling.

- Simulação: envolvem a simulação de um processo matemático (por exemplo, movimento Browniano) onde números aleatórios são introduzidos em sua equação. O resultado fornece realizações da variável aleatória, usados como cenários.

Principais métodos: Simulação de processos estocásticos, Modelo de correção de erros, Vetor Auto-regressivo (VAR).

- Outros métodos de geração de cenário: Redes neurais, Clustering, Redução de cenários, Métodos híbridos.

A Tabela 3.1 lista alguns métodos de geração de cenários bem estabelecidos em diversos campos de aplicação. 
Tabela 3.1: Métodos de Geração de Cenários (adaptado de Di Domenica et al., 2009).

\begin{tabular}{|c|c|c|c|}
\hline Abordagem & Método & Campo de Aplicação & Referência \\
\hline \multirow[t]{3}{*}{ Estatística } & Moment matching & $\begin{array}{l}\text { Finanças, cadeia de } \\
\text { suprimentos, energia. }\end{array}$ & Keefer (1994) \\
\hline & Property matching & $\begin{array}{l}\text { Cadeia de suprimentos, } \\
\text { energia, meio ambiente. }\end{array}$ & $\begin{array}{l}\text { Høyland e Wallace } \\
\text { (2001) }\end{array}$ \\
\hline & $\begin{array}{l}\text { Analise das } \\
\text { principais } \\
\text { componentes (PCA) }\end{array}$ & Finanças. & Smith (2002) \\
\hline \multirow[t]{4}{*}{ Amostragem } & $\begin{array}{l}\text { Monte Carlo } \\
\text { sampling }\end{array}$ & $\begin{array}{l}\text { Finanças, cadeia de } \\
\text { suprimentos, energia. }\end{array}$ & Doucet et al. (2001) \\
\hline & Bootstrap sampling & Finanças. & Efron (1997) \\
\hline & $\begin{array}{l}\text { Markov Chain } \\
\text { Monte Carlo } \\
\text { sampling }\end{array}$ & $\begin{array}{l}\text { Finanças, cadeia de } \\
\text { suprimentos, energia. }\end{array}$ & $\begin{array}{l}\text { Jurrum e Sincler } \\
\text { (1996) }\end{array}$ \\
\hline & Internal sampling & Finanças. & $\begin{array}{l}\text { Dantzig e Infanger } \\
\text { (1992); Ermoliev e } \\
\text { Gaivoronski (1992) }\end{array}$ \\
\hline \multirow[t]{4}{*}{ Simulação } & ARMA & $\begin{array}{l}\text { Finanças, cadeia de } \\
\text { suprimentos, meio } \\
\text { ambiente. }\end{array}$ & Box e Jenkins (1976) \\
\hline & GARCH & $\begin{array}{l}\text { Finanças, cadeia de } \\
\text { suprimentos, meio } \\
\text { ambiente. }\end{array}$ & $\begin{array}{l}\text { Bollerslev (1986); } \\
\text { Engle (1982) }\end{array}$ \\
\hline & $\begin{array}{l}\text { Vetor Auto } \\
\text { regressivo (VAR) }\end{array}$ & $\begin{array}{l}\text { Finanças, cadeia de } \\
\text { suprimentos, meio } \\
\text { ambiente. }\end{array}$ & Fair e Shiller (1990) \\
\hline & $\begin{array}{l}\text { Movimento } \\
\text { Browniano } \\
\text { geométrico }\end{array}$ & Finanças, meio ambiente. & $\begin{array}{l}\text { Freedman (1983); } \\
\text { Bollerslev (1986) }\end{array}$ \\
\hline Outros & Redes neurais & $\begin{array}{l}\text { Cadeia de suprimentos, } \\
\text { energia, meio ambiente. }\end{array}$ & Bollerslev (1986) \\
\hline
\end{tabular}

Keefer (1994) apresenta e compara métodos com base em correspondência de momentos (Moment Matching) para aproximação de uma distribuição contínua por três pontos. A precisão destas aproximações são avaliadas em função da utilidade esperada e do equivalente certeza. Høyland e Wallace (2001) definem uma metodologia de geração de cenários que ajusta qualquer propriedade estatística (Property Matching). O ajuste das propriedades estatísticas é feito através de um modelo de programação não linear que minimiza a diferença entre as propriedades da distribuição original e da aproximação. Smith (2002) apresenta 
um tutorial sobre Principal Components Analysis (PCA) e introduz algumas aplicações do método.

O algoritmo de Monte Carlo apresenta diferentes variações e muitos métodos híbridos estão disponíveis para geração de cenários. O livro de Doucet et al. (2001) trata de simulação de Monte Carlo e suas principais variações, como Bootstrap e Markov Chain Monte Carlo. Referências mais específicas de Bootstrap sampling e Markov Chain Monte Carlo sampling são obtidas em Efron (1997) e Jurrum e Sincler (1996), respectivamente. Uma alternativa aos métodos de amostragem apresentados é o internal sampling, que amostra os cenários durante o procedimento de solução do problema de programação estocástica. Os métodos mais importantes deste tipo são: importance sampling com decomposição de Benders (L-shaped) (Dantzig e Infanger, 1992), e o método stochastic quasigradient (Ermoliev e Gaivoronski, 1992).

Nos métodos de simulação, os modelos mais utilizados para representar processos estocásticos são os modelos econométricos ARMA (Box \& Jenkins, 1976), GARCH (Bollerslev,1986; Engle, 1982) e VAR (Fair \& Shiller, 1990); e o movimento Browniano geométrico (Freedman, 1983; Bollerslev, 1986). A simulação não fornece diretamente uma árvore de cenários, o resultado é um conjunto de caminhos (paths), também denominado “fan”, onde um caminho completo define um cenário. A árvore de cenários é construída a partir do agrupamento destes caminhos feito através de clustering (para exemplo veja Gulpinar e Settergren, 2004). Aplicações deste método, muito utilizado na área de finanças, são descritas em Dempster e Thorlacius (1998) e Mulvey (1996), que usam modelos de simulação de processos estocásticos para representar variáveis econômicas e retorno de ações.

O método de geração de cenários é fundamental para o sucesso da abordagem de programação estocástica. No entanto, a maioria dos métodos só garante que a árvore de cenários gerada aproxima bem a distribuição original do parâmetro estocástico de interesse, e não verifica se a árvore aproxima bem o problema de programação estocástico. A segunda aproximação só pode ser verificada se o método de geração de cenários tivesse alguma interação com o modelo de programação estocástica, o que não acontece na maioria dos métodos. Os cenários gerados por métodos estatísticos, apesar de ajustarem bem as propriedades estatísticas da distribuição original, não garantem necessariamente 
um bom resultado do modelo de programação estocástica. Já os métodos por amostragem, em geral, selecionam os cenários antes da otimização, e por isso não garantem uma boa aproximação para a função objetivo do modelo estocástico. O método Internal sampling é a exceção, realizando a amostragem durante a execução do algoritmo de otimização, e gera, teoricamente, a árvore de cenários que otimiza o resultado do problema. O Internal sampling só pode ser aplicado em problemas resolvidos via métodos de decomposição, o que em muitos casos gera uma forte restrição ao uso deste método para amostragem. As principais referências no assunto (Dantzig e Infanger, 1992; Infanger, 1992; Infanger, 1994; Ermoliev e Gaivoronski, 1992) tratam apenas de problemas lineares. Da mesma forma que os outros métodos de geração de cenários, a simulação também não incorpora informações obtidas com a solução do modelo de programação estocástica.

O método de geração de cenários utilizado nesta tese é do tipo property matching e foi proposto por Høyland e Wallace (2001). Na seção 3.2.1 o método de Høyland e Wallace (2001) será apresentado em detalhe, bem como os motivos que levaram a sua escolha.

\subsection{1}

\section{Metodologia de Geração de Cenários}

Nos modelos de otimização sob incerteza, muitas vezes nos deparamos com o problema de representar as incertezas de forma adequada aos modelos matemáticos. Se as incertezas são expressas em termos de distribuições contínuas (univaridas ou multivariadas), ou uma distribuição discreta com muitos pontos, a solução normalmente utilizada é encontrar uma aproximação discreta com poucos pontos que sirva de entrada para o modelo, e que respeite propriedades estatísticas básicas da distribuição original.

A abordagem padrão definida por Keefer (1994) para aproximar uma distribuição contínua (ou discreta com muitos pontos) por uma distribuição discreta é a seguinte: (1) dividir a região onde está definida a distribuição contínua em intervalos, (2) selecionar um ponto que representa cada intervalo, e (3) atribuir uma probabilidade a cada ponto. Esta abordagem é uma solução simples e eficiente no caso de distribuições univariadas. No entanto a maioria dos 
problemas práticos envolve distribuição multivariada. Alguns autores, como Keefer (1994), tratam o caso de distribuição multivariada assumindo uma destas duas hipóteses: (1) as variáveis aleatórias são independentes ou (2) a distribuição de probabilidade conjunta é conhecida. Ambas as hipóteses dificilmente são verdadeiras em problemas reais. Em geral, a distribuição de probabilidade conjunta não é conhecida e/ou não se pode assumir independência, pois a correlação entre as variáveis tem efeito importante sobre a geração de cenários. Neste trabalho optou-se por utilizar um método de geração de cenários que forneça a distribuição de probabilidade conjunta com base na correlação entre as variáveis aleatórias. Para isto, foi utilizado o método de geração de cenários proposto por Høyland e Wallace (2001).

Høyland e Wallace (2001) apresentam um método baseado em programação não-linear (NLP) que pode ser usado para gerar um número limitado de cenários discretos que satisfazem propriedades estatísticas específicas. Os usuários são livres para especificar qualquer propriedade estatística que acharem relevante, mas os autores sugerem o uso dos quatro primeiros momentos centrais e da correlação. A ideia básica é minimizar alguma medida de distância entre as propriedades estatísticas dos resultados gerados e as propriedades especificadas.

A formulação do modelo proposto por Høyland e Wallace (2001) adaptado para o problema com dois estágios pode ser escrita como:

$$
\operatorname{Min} \sum_{i \in I} W_{i}\left(f_{i}\left(x_{v, s c}, p_{s c}\right)-T_{i}\right)^{2} \text { sujeito a } \sum_{s c \in S C} p_{s c}=1, p_{s c} \geq 0
$$

As definições dos conjuntos, variáveis e parâmetros do modelo (3.13) são apresentadas na Tabela 3.2.

Tabela 3.2: Modelo de Geração de Cenários - Conjuntos, Variáveis e Parâmetros.

\begin{tabular}{|c|c|c|c|}
\hline \multicolumn{2}{|l|}{ Conjuntos } & \multicolumn{2}{|l|}{ Variáveis } \\
\hline Variável aleatória $(v)$ & $v \in V$ & Valor da variável aleatório & $x_{v, s c}$ \\
\hline Cenário (sc) & $s c \in S C$ & Probabilidade & $p_{s c}$ \\
\hline Propriedade estatística (i) & $i \in I$ & Valor da propriedade estatística & $f_{i}\left(x_{v, s c}, p_{s c}\right)$ \\
\hline \multicolumn{4}{|c|}{ Parâmetros } \\
\hline Meta da propriedade estatística & $T_{i}$ & Peso para propriedade estatística & $W_{i}$ \\
\hline
\end{tabular}

Nesta formulação $\boldsymbol{p}_{\boldsymbol{s} \boldsymbol{c}}$ e $\boldsymbol{x}_{\boldsymbol{v}, \boldsymbol{s c}}$ são as variáveis de decisão. A variável $\boldsymbol{p}_{\boldsymbol{s c}}$ está associada aos valores de probabilidade para cada cenário sc que devem ser 
positivos e somar 1 . A variável $\boldsymbol{x}_{\boldsymbol{v}, \boldsymbol{s} \boldsymbol{c}}$ assume os valores nos pontos que compõem a distribuição aproximada, onde $\boldsymbol{v}$ indica a variável aleatória correspondente e $\boldsymbol{s} \boldsymbol{c}$ o cenário. $\boldsymbol{f}_{\boldsymbol{i}}\left(\boldsymbol{x}_{\boldsymbol{v}, \boldsymbol{s c}}, \boldsymbol{p}_{\boldsymbol{s c}}\right)$ é o valor da propriedade estatística $i$ calculada em função das variáveis $\boldsymbol{x}_{\boldsymbol{v}, \boldsymbol{s} \boldsymbol{c}}$ e $\boldsymbol{p}_{\boldsymbol{s} \boldsymbol{c}}$. O parâmetro $\boldsymbol{T}_{\boldsymbol{i}}$ corresponde às propriedades estatísticas $i$ da distribuição original e servem de meta para o problema. Através do parâmetro $\boldsymbol{W}_{\boldsymbol{i}}$ é possível associar pesos diferentes para cada propriedade estatística $i$. O objetivo é definir $\boldsymbol{x}_{\boldsymbol{v}, \boldsymbol{s c}}$ e $\boldsymbol{p}_{\boldsymbol{s c}}$, para que as propriedades estatísticas $\boldsymbol{f}_{\boldsymbol{i}}\left(\boldsymbol{x}_{\boldsymbol{v}, \boldsymbol{s c}}, \boldsymbol{p}_{\boldsymbol{s c}}\right)$ da distribuição aproximada correspondam (tão bem quanto possível) às propriedades estatísticas especificadas pelo parâmetro $\boldsymbol{T}_{\boldsymbol{i}}$. Isso é feito através da minimização de uma medida de distância (o quadrado da diferença) entre as propriedades estatísticas da distribuição construída $\boldsymbol{f}_{\boldsymbol{i}}\left(\boldsymbol{x}_{\boldsymbol{v}, \boldsymbol{s} \boldsymbol{c}}, \boldsymbol{p}_{\boldsymbol{s} \boldsymbol{c}}\right)$ e as propriedades estatísticas especificadas $\boldsymbol{T}_{\boldsymbol{i}}$ ponderada pelo peso $\boldsymbol{W}_{\boldsymbol{i}}$. Nesta tese o modelo matemático foi programado em Aimms e resolvido com o solver Knitro 7.0.

O método de Høyland e Wallace (2001) é bastante flexível e permite gerar diferentes árvores de cenários considerando as mesmas propriedades estatísticas da distribuição original $\boldsymbol{T}_{\boldsymbol{i}}$. Isto é feito através de ajustes no tamanho do conjunto de cenários SC, que permite gerar árvores de tamanho diferentes, ou alteração do ponto (ou solução) inicial a ser considerando pelo modelo NLP definido em (8.1), que permite gerar árvores diferentes com o mesmo número de cenários. Um ponto (ou solução) inicial é definido através da inicialização das variáveis de decisão $\boldsymbol{p}_{\boldsymbol{s c}}$ e $\boldsymbol{x}_{\boldsymbol{v}, \boldsymbol{s} \boldsymbol{c}}$ com algum valor escolhido pelo planejador. Devido à complexidade do modelo NLP, Høyland e Wallace (2001) sugerem a inicialização das variáveis $\boldsymbol{p}_{\boldsymbol{s c}}$ e $\boldsymbol{x}_{\boldsymbol{v}, \boldsymbol{s} \boldsymbol{c}}$ para obter melhores resultados com o método. Além disso, o método de Høyland e Wallace (2001) permite a geração de árvores de cenários diferentes com a mesma qualidade estatística. Isto é possível quando as árvores de cenários são geradas pelo o modelo (8.1) assumindo os mesmos valores dos parâmetros $\boldsymbol{T}_{\boldsymbol{i}}$ e $\boldsymbol{W}_{\boldsymbol{i}}$, e obtendo valores iguais (ou muito próximos) de função objetivo.

Nesta tese foram construídas com o método de Høyland e Wallace (2001) dez árvores de cenários que servem de entrada para o modelo estocástico proposto. A Tabela 3.3 identifica as dez árvores de cenários que foram geradas para o problema em estudo. 
Tabela 3.3: Árvores de cenários.

\begin{tabular}{|c|c|}
\hline Árvores de cenários & Nome \\
\hline \multirow{6}{*}{$\begin{array}{l}\text { Solução inicial } \\
\text { (modelos de aproximação } \\
\text { discreta de Keefer, 1994) }\end{array}$} & EP-T \\
\hline & ES-M \\
\hline & $\mathrm{M}-\mathrm{CS}$ \\
\hline & M-RO \\
\hline & Z-DT \\
\hline & Z-DI \\
\hline \multirow{4}{*}{ Sem solução inicial } & 3 cenários \\
\hline & 4 cenários \\
\hline & 5 cenários \\
\hline & 6 cenários \\
\hline
\end{tabular}

Na Tabela 3.3 as árvores de cenários indicadas pelos números $\begin{array}{llllll}1 & \text { a } & \text { são }\end{array}$ compostas por 3 cenários e são geradas a partir de um ponto inicial. O nome de cada árvore refere-se ao modelo de aproximação discreta de três pontos usado como solução inicial e identificado na Tabela 3.4. Estes modelos foram selecionadas com base no trabalho de Keefer (1994), que avaliou aproximações discretas de três pontos considerando os cinco primeiros momentos centrais, a estatística Kolmogorov-Smirnov e o equivalente-certeza (que corresponde a utilidade esperada). Segundo Keefer (1994), estes modelos de aproximação representam bem as propriedades estatísticas da distribuição original.

Ainda na Tabela 3.3 as árvores de cenários indicadas pelos números 7 a 10 não utilizam nenhum ponto inicial conhecido (solução inicial igual a zero) para resolver o modelo NLP proposto Høyland e Wallace (2001). A diferença entre as árvores 7 a 10 é o número de cenários considerados em sua geração: 3, 4, 5 e 6 cenários respectivamente. As soluções obtidas com cada uma das dez árvores de cenário geradas serão avaliadas em função das medidas de qualidade a serem apresentadas a seguir. 
Tabela 3.4: Modelos de aproximação discreta.

\begin{tabular}{lcc}
\hline \multicolumn{1}{c}{ Aproximação } & Valores & Probabilidades \\
\hline \hline Extended Pearson-Tukey (EP-T) & $\mathrm{x}(0.05)$ & 0.185 \\
& $\mathrm{x}(0.50)$ & 0.630 \\
& $\mathrm{x}(0.95)$ & 0.185 \\
\hline Extended Swanson-Megil (ES-M) & $\mathrm{x}(0.10)$ & 0.300 \\
& $\mathrm{x}(0.50)$ & 0.400 \\
McNamee-Celona "Shortcut" (M-CS) & $\mathrm{x}(0.90)$ & 0.300 \\
\hline Miller-Rice "One-Step" (M-RO) & $\mathrm{x}(0.10)$ & 0.250 \\
& $\mathrm{x}(0.50)$ & 0.500 \\
& $\mathrm{x}(0.90)$ & 0.250 \\
\hline Zaino-D'Errico "Taguchi" (Z-DT) & $\mathrm{x}(0.085)$ & 0.248 \\
& $\mathrm{x}(0.50)$ & 0.505 \\
& $\mathrm{x}(0.915)$ & 0.248 \\
\hline Zaino-D'Errico "Improved" (Z-DI) & $\mathrm{x}(0.11)$ & 0.333 \\
& $\mathrm{x}(0.50)$ & 0.333 \\
& $\mathrm{x}(0.89)$ & 0.333 \\
\hline
\end{tabular}

\section{3 \\ Medidas de Qualidade para Árvore de Cenários}

Apesar da sua clara importância para programação estocástica, pouco foi encontrado na literatura sobre a necessidade de avaliar a qualidade da árvore de cenários em função da aproximação fornecida para o problema de programação estocástica. Neste sentido destacamos o trabalho de Kaut e Wallace (2003) que discute a qualidade do método de geração de cenários para um dado modelo de programação estocástica. Os autores propuseram duas medidas para testar se o método geração de cenários leva a melhor decisão do modelo estocástico. As medidas de qualidade são definidas como estabilidade in-sample e out-of-sample; e presença de viés. A estabilidade in-sample é calculada a partir da geração de várias árvores de cenários considerando sempre os mesmos dados de entrada. Se todas as árvores fornecerem valores de função objetivo (FO) próximos, isto indica que há estabilidade in-sample. A estabilidade out-of-sample é verificada quando as decisões obtidas com a árvore de cenários otimiza o que os autores definem como FO "verdadeira”, ou seja, a FO calculada com a distribuição completa das variáveis aleatórias. O teste para presença de viés é feito comparando a FO "verdadeira” com a calculada com a árvore de cenários, o desejável é que a diferença entre elas seja próxima a zero. Em geral não é possível calcular a FO 
“verdadeira” para os casos onde a distribuição é definida a partir de dados históricos uma opção é utilizar toda a série de dados. Parte da metodologia apresentada em Kaut e Wallace (2003) será utilizada nesta seção.

O presente trabalho propõe medir a qualidade da árvore de cenários em função do resultado obtido com o modelo de programação estocástica. O objetivo é definir uma aproximação discreta para uma dada distribuição contínua (ou discreta com muitos pontos) que leve a melhor solução do modelo estocástico. As medidas de qualidade serão úteis para avaliar diferentes árvores de cenários que não precisam, necessariamente, terem sido geradas pelo mesmo método, além de contribuir para definir o tamanho da árvore de cenários (número de cenários) e os pontos a serem selecionados para compor a árvore (valor de cada cenário). As métricas sugeridas ajudarão a quantificar a qualidade da árvore de cenários com base no valor da função objetivo, na decisão de primeiro estágio, e no valor esperado da informação perfeita (EVPI).

Antes de apresentar as medidas de qualidade propostas é necessário formalizar a definição de alguns conceitos. As definições seguem abaixo:

- Distribuição original: distribuição contínua ou discreta com muitos pontos da variável aleatória que representa a incerteza no modelo de programação estocástica ou o parâmetro estocástico;

- Distribuição aproximada: distribuição discreta ou árvore de cenários que fornece uma aproximação discreta para a distribuição original;

- Problema original: modelo de programação estocástico resolvido com a distribuição original do parâmetro estocástico;

- Problema aproximado: modelo de programação estocástico resolvido com a distribuição aproximada do parâmetro estocástico ou árvore de cenários.

A distribuição original é a melhor representação da incerteza, no entanto nem sempre é possível utilizá-la diretamente na solução do modelo de programação estocástica, sendo necessário aproximá-la por uma distribuição discreta (árvore de cenários). Mesmo nos casos onde é possível resolver o modelo de programação estocástica com a distribuição original o tempo de resolução do problema é tão alto que inviabiliza seu uso na prática e novamente se torna necessário aproximar a distribuição original por uma distribuição discreta. Sendo assim, para obter uma boa solução do modelo de programação estocástica é muito 
importante definir a árvore de cenários que não só aproxime bem a distribuição original como também a solução do problema original. O capítulo anterior de geração de cenários já se preocupou com esta primeira característica da árvore de cenários e gerou árvores que aproximam adequadamente a distribuição original com base nos quatro primeiros momentos centrais e na correlação. Este capítulo trata da segunda característica necessária para uma árvore de cenários, a capacidade de a árvore fornecer uma boa solução aproximada para o problema original.

As medidas de qualidade propostas neste trabalho comparam a solução do problema aproximado com a do problema original em função de três critérios: decisão de primeiro estágio, valor da função e objetivo e valor da informação perfeita (Expected Value of Perfect Information - EVPI). A proposta é analisar diferentes árvores de cenários que não precisam, necessariamente, terem sido definidas pelo mesmo método de geração de cenários. As árvores podem variar tanto em relação ao valor do ponto selecionado para aproximação (valor do cenário), quanto em relação à quantidade de pontos selecionados (número de cenários). Neste trabalho o método Høyland e Wallace (2001) foi utilizado para geração de todas as árvores de cenários analisadas.

A crítica com relação às medidas propostas neste capítulo é que na maioria dos casos reais não é possível resolver o problema original, pois a distribuição original é contínua. A solução é construir uma árvore de referência, que deve ter o maior número possível de cenários. No caso de cenários gerados a partir de uma série de dados históricos, o ideal é utilizar todos os valores registrados para calcular a FO do problema original. Outra opção é utilizar o método Sample Average Approximation (SAA) (Kleywegt et al., 2001) para o cálculo da FO verdadeira com 95\% de confiança. Neste trabalho a geração de cenários foi feita a partir da série de fornecimento de petróleo e a FO do problema original foi calculada usando todos os valores da série histórica.

Nesta seção manteremos a mesma notação utilizada ao longo deste capítulo, onde $\xi$ é o vetor de incertezas dada a distribuição contínua de cada parâmetro estocástico, também denominada de distribuição original, e $\xi_{\mathbf{k}}$ é o vetor de incertezas dada a árvore de cenários k que fornece a aproximação discreta para a distribuição original. A distribuição original é dado de entrada do modelo estocástico de dois estágios, que por sua vez fornece para o problema original a 
decisão ótima de primeiro estágio $\mathbf{x}^{*}(\boldsymbol{\xi})$, o valor da função objetivo $\mathbf{z}\left(\mathbf{x}^{*}, \xi\right)$ e 0 valor do $\operatorname{EVPI}(\xi)$. Da mesma forma, quando consideramos a distribuição discreta aproximada $\boldsymbol{\xi}_{\mathbf{k}}$, é possível calcular para o problema aproximado a decisão ótima de primeiro estágio $\mathbf{x}^{*}\left(\boldsymbol{\xi}_{\mathbf{k}}\right)$, o valor da função objetivo $\mathbf{z}\left(\mathbf{x}^{*}, \boldsymbol{\xi}_{\mathbf{k}}\right)$ e o valor do $\operatorname{EVPI}\left(\xi_{\mathbf{k}}\right)$.

A seguir são apresentadas medidas de qualidade para avaliar a árvore de cenários.

\subsection{1}

\section{Decisão de Primeiro Estágio $\left(x^{*}\right)$}

A árvore de cenários deve fornecer uma boa solução para o problema original, sendo assim, a decisão de primeiro estágio encontrada com a árvore de cenários deve ser próxima (ou igual) a decisão tomada no problema original. A medida de qualidade utilizada para avaliar a decisão de primeiro estágio é dada por:

$$
\boldsymbol{x}^{*}\left(\boldsymbol{\zeta}_{\boldsymbol{k}}\right) \approx \boldsymbol{x}^{*}(\xi)
$$

ou pela diferença:

$$
\left|\boldsymbol{x}^{*}(\xi)-\boldsymbol{x}^{*}\left(\xi_{k}\right)\right|
$$

Quanto menor for esta diferença (equação 3.15), melhor será a aproximação do problema original fornecida pela árvore de cenários.

\subsection{2}

\section{Função Objetivo (Z)}

A segunda medida de qualidade baseia-se no trabalho de Kaut e Wallace (2003) e avalia a capacidade da árvore de cenários fornecer uma solução de primeiro estágio que otimize o problema original. Nesta medida a decisão ótima de primeiro estágio $\boldsymbol{x}^{*}\left(\boldsymbol{\xi}_{\boldsymbol{k}}\right)$ calculada usando a distribuição aproximada $\boldsymbol{\xi}_{\boldsymbol{k}}$ será fixada no problema original para obter o seguinte valor de função objetivo $\boldsymbol{z}\left(\boldsymbol{x}^{*}\left(\boldsymbol{\xi}_{\boldsymbol{k}}\right), \boldsymbol{\xi}\right)$. Este valor será comparado com o valor da função objetivo $\boldsymbol{z}\left(\boldsymbol{x}^{*}, \boldsymbol{\xi}\right)$ do problema original pela equação:

$$
z\left(x^{*}\left(\xi_{k}\right), \xi\right) \approx z\left(x^{*}, \xi\right)
$$


ou pela diferença:

$$
\left|z\left(x^{*}, \xi\right)-z\left(x^{*}\left(\xi_{k}\right), \xi\right)\right|
$$

Quanto menor for esta diferença (equação 3.17), melhor será a aproximação fornecida pela árvore de cenários em relação ao problema original.

\subsection{3}

\section{Valor da Informação Perfeita (EVPI)}

O valor da informação perfeita (Expected Value of Perfect Information EVPI) é uma medida bem conhecida e amplamente utilizada para mostrar a utilidade da abordagem estocástica. Outra aplicação para esta medida pode ser vista em Dempster e Thompson (1999), onde o EVPI foi utilizado como critério de otimização da árvore de cenário pelo método de Internal sampling. Levando em conta essas aplicações do EVPI optou-se neste trabalho por também incluí-lo como uma medida de qualidade da árvore de cenários.

A medida de qualidade proposta compara o valor da informação perfeita calculado para o problema original $\boldsymbol{E V P I}(\xi)$ e para o problema aproximado $\boldsymbol{E V P I}\left(\xi_{k}\right)$ conforme segue abaixo:

$$
\operatorname{EVPI}\left(\xi_{k}\right) \approx \operatorname{EVPI}(\xi)
$$

ou pela diferença:

$$
\left|\operatorname{EVPI}(\xi)-\operatorname{EVPI}\left(\xi_{k}\right)\right| \cong 0
$$

Nesta medida o $\boldsymbol{E V P I ( \xi )}$ do problema original é usado como referência para o problema aproximado. O importante sobre esta medida é que nem sempre a árvore de cenários com melhor (menor) EVPI será a melhor aproximação da distribuição original.

Neste ponto vale uma observação com relação à aplicação das medidas de qualidade propostas, na prática não é possível avaliar várias árvores de cenários 
toda vez que o modelo de programação estocástico for utilizado. A sugestão é fazer essa avaliação uma única vez para definir o melhor método de geração de cenários e a melhor forma de configura-lo (ex.: número de cenários, propriedades estatísticas a serem consideradas). Definido isso, a cada nova rodada do modelo estocástico será utilizado o mesmo método de geração de cenários com as mesmas configurações. 


\section{Metodologia}

A pesquisa proposta foi motivada pela necessidade de resolver problemas práticos relacionados ao planejamento operacional de uma refinaria. Atualmente as refinarias brasileiras usam o PIMS (Process Industry Modeling System, 1993) como sistema de planejamento operacional. O PIMS é uma ferramenta determinística que oferece dois módulos de programação: (1) módulo de programação linear (LP) capaz de lidar com elementos não lineares através da técnica SLP (Sucessive Linear Programming), e (2) módulo de programação nãolinear (NLP). O modelo de planejamento das refinarias brasileiras foi desenvolvido com base neste primeiro módulo de programação linear (LP). A partir da análise deste sistema identificou-se a necessidade de revisão e atualização do modelo matemático e do método de solução com o objetivo principal de modelar o problema através de programação não-linear (NLP) e incorporar as incertezas presentes no negócio de refino.

A metodologia adotada nesta pesquisa pode ser definida pelas seguintes etapas (Law e Kelton, 1991; Bertrand e Fransoo, 2002):

Etapa 1 - A coleta de dados históricos: série mensal de fornecimento de petróleo para cada refinaria analisada.

Os atuais planejadores de refino identificaram o fornecimento de petróleo como a incerteza de maior impacto no plano operacional da refinaria. A coleta de dados foi realizada para construir uma série mensal de fornecimento de petróleo com o objetivo de confirmar a presença da incerteza e posteriormente gerar a árvore de cenários.

Etapa 2 - Modelagem Estocástica: representação do modelo conceitual por um modelo científico.

Esta etapa incluiu análise e aprimoramento da modelagem atual. O modelo estocástico de dois estágios com recurso fixo foi formulado em programação não-linear (NLP) no software AIMMS (Advanced Integrated Multidimensional Modeling Software). Os dados de entrada e de saída foram 
administrados através de um banco de dados construído em Access, da Microsoft Office.

Etapa 3 - Experimento com o modelo estocástico: processo de obtenção de uma solução para o modelo científico.

A modelagem estocástica proposta para representar o problema de planejamento operacional de refinarias sob incerteza foi testada utilizando dados reais de três refinarias brasileiras. As refinarias selecionadas possuem diferentes configurações, considerando porte da planta (pequeno, médio e grande), processos químicos e propriedades de produtos finais. As diferentes combinações dessas características levaram a problemas com maior ou menor nível de complexidade. Dois métodos de solução combinados aos principais solvers para resolução de problemas não-linear disponíveis no mercado (KNITRO 7.0, SNOPT 7.2 e CONOPT 3) também foram testados, e aquele que apresentou melhor desempenho foi utilizado.

Nesta etapa os testes foram realizados com diferentes casos compostos de um único cenário (equivalente ao modelo determinístico). O objetivo foi realizar experimentos que mostrassem a aderência do modelo a refinarias reais de diversos tipos e a capacidade do método de solução de resolver casos com diferentes níveis de complexidade.

Etapa 4 - Validação do modelo estocástico: adequação do modelo ao sistema real.

A modelagem estocástica proposta para representar o problema de planejamento operacional de refinarias sob incerteza foi validada utilizando dados reais das mesmas três refinarias nacionais utilizadas na etapa anterior. O fato das refinarias apresentarem diferentes níveis de complexidade permitiu uma avaliação rigorosa do modelo proposto.

A árvore de cenários usada para representar a incerteza nesta etapa foi definida pelos atuais planejadores de refino e serviu para validação do modelo estocástico. Esta etapa incluiu as adaptações necessárias para ajustar o modelo ao sistema real.

Etapa 5 - Geração da árvore de cenários: definição de uma metodologia de geração de cenários adequada ao problema.

A metodologia de geração de cenários foi aplicada à série mensal de fornecimento de petróleo construída a partir dos dados coletados durante a 
Etapa 1. A metodologia selecionada permite a geração de diferentes árvores de cenários a partir da mesma série histórica de dados, sendo assim, foram definidas nesta etapa dez árvores de cenários.

Etapa 6 - Avaliação da árvore de cenários: seleção da melhor árvore de cenários para o modelo estocástico com base em medidas de qualidade.

As árvores de cenários definidas na Etapa 5 foram avaliadas com base nas medidas de qualidade propostas para verificar qual árvore de cenários melhor se adéqua ao modelo estocástico desenvolvido. Devido à grande quantidade de testes realizados e o tempo computacional para solução do modelo estocástico NLP, nesta etapa apenas a refinaria de menor porte foi considerada.

Etapa 7 - Documentação e feedback: análise e documentação da solução obtida.

Validado o modelo estocástico e selecionada a melhor árvore de cenários para representar as incertezas, o plano de refino obtido foi analisado e sua solução documentada. 


\section{Modelo Estocástico para o Planejamento Operacional de Refinaria}

O modelo foi formulado como um programa estocástico de dois estágios com recurso fixo (Dantzig, 1955). As incertezas são discretamente representadas por SC possíveis realizações de cenários e modeladas por uma árvore de cenários. Um cenário é um caminho da raiz até uma folha da árvore. A probabilidade de que o cenário $s c$ irá ocorrer é dada por $p_{s c}\left(p_{s c} \geq 0, \sum_{s c=1}^{S C} p_{s c}=1, s c \in S C\right)$. Assim, o modelo estocástico pode ser representado como segue:

$$
\begin{aligned}
& \operatorname{Max}_{x \in X}\left\{z(x)=c^{T} x+\sum_{s c \in S C} p_{s c} q_{s c}^{T} y_{s c}\right\} \text { sujeito a } \\
& A x \leq b, W y_{s c} \leq h_{s c}-T_{s c} x, x \geq 0, y_{s c} \geq 0 \forall s c \in S C
\end{aligned}
$$

As decisões de primeiro estágio devem ser decididas antes da realização das variáveis aleatórias (here-and-now decisions), representadas por um vetor $x$, enquanto as decisões de segundo estágio, denotadas por $y_{s c}$, são tomadas com informações completas sobre a realização de $s c$, tornando-se variáveis dependentes de cenário.

A função objetivo no modelo (5.1) contém um termo determinístico $c^{t} x$, associado as decisões de compra de petróleo no primeiro estágio, e o valor esperado da função objetivo no segundo estágio $\sum_{s c \in S C} p_{s c} q_{s c}^{T} y_{s c}$, que modela o lucro estocástico da operação devido às decisões de primeiro estágio. Um conjunto de inequações determinísticas $(A x \leq b)$ é usado para modelar as decisões de compra de petróleo. Restrições estocásticas $\left(W y_{s c} \leq h_{s c}-T_{s c} x\right)$ são usadas para representar a quantidade e a qualidade dos fluxos entre as unidades de processo e as relações operacionais entre os petróleos e produtos finais. A incerteza é introduzida no fornecimento de petróleo e na capacidade das unidades de processo considerando a parada para manutenção dos equipamentos. 


\section{1}

\section{Modelo Matemático}

Esta seção apresenta a formulação matemática do modelo de planejamento operacional para refinarias, que se baseia no modelo estocástico multi-período de Neiro e Pinto (2005). Os autores representam a refinaria como um conjunto de unidades conectadas por fluxos em que períodos de tempo são ligados por variáveis de estoque. Preços de petróleo e produtos, bem como a demanda são considerados por Neiro e Pinto (2005) como fatores de incerteza.

A modelagem inicialmente proposta por Neiro e Pinto (2005) foi modificada de forma a incluir importantes aspectos do problema real de planejamento operacional de refinaria, tornando o modelo mais abrangente e completo. A nova modelagem inclui um conjunto de modos de operação das unidades de processo da refinaria e restrições não-lineares para o cálculo de propriedades dos derivados de petróleo em base volumétrica e mássica (usa informação de densidade calculada pelo modelo). O novo modelo trata ainda incertezas identificadas em refinarias reais no Brasil, como o fornecimento de petróleo. Outra contribuição é a adição de uma variável de decisão para representar uma opção de compra de petróleo adicional $\left(c a_{u, c, s}^{t}\right)$. O fornecimento de petróleo para cada refinaria é definido pela companhia. No entanto, como este fornecimento está sujeito a incertezas (alterações na especificação e no volume do petróleo entregue à refinaria), o pedido de petróleo deve sofrer alguma correção, representada pela compra de petróleo adicional $\left(c a_{u, c, s}^{t}\right)$.

As definições dos conjuntos, variáveis e parâmetros do modelo proposto são apresentadas nas Tabelas 5.1 e 5.2, seguidas do modelo matemático. 
Tabela 5.1: Conjuntos e variáveis.

\begin{tabular}{|c|c|c|c|}
\hline \multicolumn{2}{|l|}{ Conjuntos } & \multicolumn{2}{|l|}{ Conjuntos } \\
\hline Unidades de processo $\left(u, u^{\prime}\right)$ & $U$ & Tanques de mistura & $U M \subset U$ \\
\hline Campanhas $\left(c, c^{\prime}\right)$ & C & Tanques de mistura com receita & $U T R \subset U$ \\
\hline Correntes $\left(s, s^{\prime}\right)$ & $S$ & Unidades de processo (separação e conversão) & $U P \subset U$ \\
\hline Utilidades $(I)$ & $L$ & Unidades de conversão & $U P C \subset U$ \\
\hline Propriedades $\left(p, p^{\prime}\right)$ & $P$ & Unidade de separação & $U P S \subset U$ \\
\hline Tempo $\{n \mid n=1, \ldots, T\}$ & $T$ & Unidade de separação por componente & $U P S C \subset U$ \\
\hline Cenários $(s c)$ & $S C$ & $\begin{array}{l}\text { Fluxo }\left(u, c, s, u^{\prime}, c^{\prime}\right) \text {, com origem no par }(u, c) \text { e } \\
\text { destino no par }\left(u^{\prime}, c^{\prime}\right)\end{array}$ & $F \subset S$ \\
\hline Campanhas $c$ associadas à unidade $u$ & $C_{u} \subset C$ & \multicolumn{2}{|l|}{ Variáveis do primeiro estágio } \\
\hline Utilidades I consumidas na campanha $c$ & $L_{c} \subset L$ & Quantidade de óleo $o$ comprado no mercado spot & $c a_{u, c, s}^{t}$ \\
\hline Propriedades $p$ na entrada da unidade $u$ & $P I_{u, c} \subset P$ & \multicolumn{2}{|l|}{ Variáveis do segundo estágio } \\
\hline Propriedades $p$ da corrente s na saída de $u$ & $P O_{u, c, s} \subset P$ & Fluxo da corrente s entre $(u, c)$ e $\left(u^{\prime}, c^{\prime}\right)$ & $q_{u^{\prime}, c^{\prime}, s, u, c}^{t, s c}$ \\
\hline Correntes $s$ na entrada da unidade $u$ & $S I_{u, c} \subset S$ & Nível de estoque em $u$ & $v o_{u, c}^{t, s c}$ \\
\hline Correntes $s$ na saída da unidade $u$ & $S O_{u . c} \subset S$ & Propriedade $p$ na entrada da unidade $u$ & $p i_{u, c, p}^{t, s c}$ \\
\hline Tanques de matéria prima (cesta) & $U C \subset U$ & Propriedade $p$ da corrente s na saída de $u$ & $p o_{u, c, s, p}^{t, s c}$ \\
\hline Unidades de entrega de produto final & $U E \subset U$ & Fluxo de entrada na unidade $u$ & $q i_{u, c}^{t, s c}$ \\
\hline Tanques (armazenagem e mistura) & $U T \subset U$ & Fluxo de saída da corrente $s$ na unidade $u$ & $q i s_{u, c, s}^{t, s c}$ \\
\hline Tanques de armazenagem & $U A \subset U$ & Fluxo de saída da corrente $s$ na unidade $u$ & $q o_{u, c, s}^{t, s c}$ \\
\hline
\end{tabular}

Tabela 5.2: Parâmetros.

\begin{tabular}{|c|c|c|c|}
\hline \multicolumn{2}{|l|}{ Parâmetros } & \multicolumn{2}{|l|}{ Parâmetros } \\
\hline Probabilidade do cenário & $P^{s c}$ & Capacidade mínima de estoque & $V O L L_{u, c}^{t}$ \\
\hline Preço do produto & $P F P_{u, s}^{t}$ & Capacidade máxima de estoque & $V O L U_{u, c}^{t}$ \\
\hline Custo da matéria prima adicional & $C F P A_{u, s}^{t}$ & Demanda mínima & $D E M L_{u, c, s}^{t}$ \\
\hline Custo da matéria prima planejada & $C F P F_{u, s}^{t}$ & Demanda máxima & $D E M U_{u, c, s}^{t}$ \\
\hline Custo das utilidades (gás, água, etc.) & $C U T_{u, s, l}^{t}$ & Valor básico da propriedade $p$ & $\mathrm{PBE}_{\mathrm{u}, \mathrm{c}, \mathrm{p}}$ \\
\hline Custo de estoque & $C I N V_{u, s}^{t}$ & Delta de rendimento na unidade de conversão & $\Delta \mathrm{YP}_{\mathrm{u}, \mathrm{c}, \mathrm{s}, \mathrm{p}}$ \\
\hline Fluxo de entrada mínimo na unidade $u$ campanha $c$ & $Q I L_{u, c}^{t}$ & Delta de propriedade na unidade de conversão & $\Delta \mathrm{PP}_{\mathrm{u}, \mathrm{c}, \mathrm{s}, \mathrm{p}, \mathrm{p}^{\prime}}$ \\
\hline Fluxo de entrada máximo na unidade $u$ campanha $c$ & $Q I U_{u, c}^{t}$ & Limite mínimo da propriedade $p$ na saída de $u$ & $P O L_{u, c, s, p}^{t}$ \\
\hline Fluxo de entrada mínimo da corrente $s$ & $Q I S L_{u, c, s}^{t}$ & Limite máximo da propriedade $p$ na saída de $u$ & $P O U_{u, c, s, p}^{t}$ \\
\hline Fluxo de entrada máximo da corrente $s$ & $Q I S U_{u, c, s}^{t}$ & Propriedade do estoque inicial & $P O I_{u, c, p}^{t}$ \\
\hline Estoque inicial & $V O L I_{u, c}^{t}$ & Propriedade da corrente de saída $s$ na unidade de & $P \cap A S S A Y^{t}$ \\
\hline Rendimento na unidade de separação & $Y U P S_{u, c, s, s^{\prime}}$ & separação $u$ em função da corrente de entrada $s^{\prime}$ & $P U A \triangle \triangle A Y u, c, s, s^{\prime}, p$ \\
\hline Rendimento na unidade de conversão & $Y U P C_{u, c, s}$ & Parâmetros estocásticos & \\
\hline $\begin{array}{l}\text { Rendimento na unidade de separação por } \\
\text { componente }\end{array}$ & $Y U P S C_{u, c, s}$ & Fluxo de entrada mínimo na unidade $u$ & $Q L_{u}^{t, s c}$ \\
\hline Receita de mistura da corrente $s$ & $R U T_{u, c, s}$ & Fluxo de entrada máximo na unidade $u$ & $Q U_{u}^{t, s c}$ \\
\hline Oferta máxima de matéria prima adicional & $Q O C A_{u, c, s}^{t}$ & Fornecimento de matéria prima planejada & $Q O C F_{u, c, s}^{t, s c}$ \\
\hline
\end{tabular}


Função Objetivo

$$
\begin{aligned}
\text { Maximizar } Z= & -\sum_{c \in C_{u}} \sum_{u \in U C} \sum_{s \in S O_{u, c}} \sum_{t \in T} C F P A_{u, s}^{t} c a_{u, c, s}^{t} \\
& +\sum_{s c \in S C} P^{s c}\left(\sum_{c \in C_{u}} \sum_{u \in U E} \sum_{s \in S I_{u, c}} \sum_{t \in T} P F P_{u, s}^{t} q i s_{u, c, s}^{t, s c}\right. \\
& -\sum_{c \in C_{u}} \sum_{u \in U P} \sum_{l \in L_{c}} \sum_{t \in T} C U T_{u, c, l}^{t} q u_{u, c}^{t, s c} \\
& -\sum_{c \in C_{u}} \sum_{u \in U C} \sum_{s \in S S_{u, c}} \sum_{t \in T} C F P F_{u, s}^{t} Q O C F_{u, c, s}^{t, s c} \\
& \left.-\sum_{c \in C_{u}} \sum_{u \in U A} \sum_{s \in S O_{u, c}} \sum_{t \in T} C I N V_{u, s}^{t} v o_{u, c,}^{t, s c}\right)
\end{aligned}
$$

Sujeito a

Capacidade nas unidades de processo

$$
\begin{aligned}
Q I L_{u, c}^{t} \leq q i_{u, c}^{t, s c} \leq Q I U_{u, c}^{t} & \forall u \in U P \cup U T, \forall c \in C_{u}, \forall t \\
& \in T, \forall S C \in S C
\end{aligned} \quad \forall u
$$

$$
Q I S L_{u, c, s}^{t} \leq q i s_{u, c, s}^{t, s c} \leq Q I S U_{u, c, s}^{t} \forall u \in U P S \cup U T, \forall c \in C_{u}, \forall s \in S I_{u, c}, \forall t \in T, \forall s C
$$

$$
\begin{aligned}
& Q L_{u}^{t, s c} \leq \sum_{c \in C_{u}} q i_{u, c}^{t, s c} \leq Q U_{u}^{t, s c} \quad \forall u \in U P \cup U T, \forall t \\
& \in T, \forall s c \in S C
\end{aligned}
$$

$$
Q S L_{u, s}^{t} \leq \sum_{c \in C_{u}} q i S_{u, c, s}^{t, s c} \leq Q S U_{u, s}^{t} \quad \forall u \in U P \cup U T, \forall s \in S I_{u, c}, \forall t \in T, \forall S C
$$

Balanço de material

$$
\begin{aligned}
& q i_{u, c}^{t, s c}=\sum_{\substack{\left(u^{\prime}, c^{\prime}, s, u, c\right) \in F \\
\in S C}} q_{u^{\prime}, c^{\prime}, s, u, c}^{t, s c} \quad \forall u \in U P \cup U T, \forall c \in C_{u}, \forall t \in T, \forall s c \\
& q i s_{u, c}^{t, s c}=\sum_{\left(u^{\prime}, c^{\prime}, s, u, c\right) \in F} q_{u^{\prime}, c^{\prime}, s, u, c}^{t, s c}
\end{aligned}
$$

$\forall u \in U P S \cup U T \cup U E, \forall c \in C_{u}, \forall s \in S I_{u, c}, \forall t \in T, \forall s c \in S C$ 
$q o_{u, c, s}^{t, s c}=\sum_{\left(u, c, s, u^{\prime}, c^{\prime}\right) \in F} q_{u, c, s, u^{\prime}, c^{\prime}}^{t, s c}$

$\forall u \in U P S \cup U T \cup U E, \forall c \in C_{u}, \forall s \in S O_{u, c}, \forall t \in T, \forall s c \in S C$

$v o_{u, c}^{t, s c}=V O L I_{u, c}^{t}+v o_{u, c}^{t-1, s c}+q i_{u, c}^{t, s c}-\sum_{s \in S O_{u, c}} q o_{u, c, s}^{t, s c}$

$\forall u \in U A, \forall c \in C_{u}, \forall t \in T, \forall s c \in S C$

$\sum_{s \in S O_{u, c}} q o_{u, c, s}^{t, s c}=q i_{u, c}^{t, s c} \quad \forall u \in U M, \forall c \in C_{u}, \forall t \in T, \forall s c \in S C$

Balanço na unidade de separação

$q o_{u, c, s}^{t, s c}=\sum_{s^{\prime} \in S I_{u, c}} q i s_{u, c, s^{\prime}}^{t, s c} Y U P S_{u, c, s, s^{\prime}}$

$\forall u \in U P S, \forall c \in C_{u}, \forall s \in S O_{u, c}, \forall t \in T, \forall s c \in S C$

Balanço na unidade de conversão

$q o_{u, c, s}^{t, s c}=q i_{u, c}^{t, s c}\left(Y U P C_{u, c, s}+\sum_{p \in P I_{u, c}} \Delta Y P_{u, c, s, p}\left(p i_{u, c, p}^{t, s c}-P B E_{u, c, p}\right)\right)$

$\forall u \in U P C, \forall c \in C_{u}, \forall s \in S O_{u, c}, \forall t \in T, \forall s c \in S C$

Balanço na unidade de separação por componente

$q o_{u, c, s}^{t, s c}=\sum_{\left(u^{\prime}, c^{\prime}, s^{\prime}, u, c\right) \in F, p \in P O_{u, c, s}} \operatorname{YUPSC}_{u, c, s, p} q_{u^{\prime}, c^{\prime}, s^{\prime}, u, c}^{t, s c} p o_{u^{\prime}, c^{\prime}, s^{\prime}, p}^{t, s c}$

$\forall u \in U P S C, \forall c \in C_{u}, \forall s \in S O_{u, c}, \forall t \in T, \forall s c \in S C$

Balanço no tanque com receita

$\sum_{\left(u^{\prime}, c^{\prime}, s, u, c\right) \in F} q_{u^{\prime}, c^{\prime}, s, u, c}^{t, s c}=R U T_{u, c, s} q i_{u, c}^{t, s c}$

$\forall u \in U T R, \forall c \in C_{u}, \forall s \in S I_{u, c}, \forall t \in T, \forall s c \in S C$

Fornecimento de matéria prima 
$Q O C F_{u, c, s}^{t, s c} \leq q o_{u, c, s}^{t, s c} \leq Q O C F_{u, c, s}^{t, s c}+c a_{u, c, s}^{t}$

$\forall u \in U C, \forall c \in C_{u}, \forall s \in S O_{u, c}, \forall t \in T, \forall s c \in S C$

$c a_{u, c, s}^{t} \leq Q O C A_{u, c, s}^{t} \quad \forall u \in U C, \forall c \in C_{u}, \forall s \in S O_{u, c}, \forall t \in T$

Limite de estoque

$V O L L_{u, c}^{t} \leq v o_{u, c}^{t, s c} \leq V O L U_{u, c}^{t} \quad \forall u \in U A, \forall c \in C_{u}, \forall s \in S O_{u, c}, \forall t \in T, \forall s c \in S C$

Demanda

$D E M L_{u, c, s}^{t} \leq q i s_{u, c, s}^{t, s c} \leq D E M U_{u, c, s}^{t}$

$\forall u \in U E, \forall c \in C_{u}, \forall s \in S I_{u, c}, \forall t \in T, \forall s c \in S C$

Propriedade na saída da unidade de separação

$\begin{aligned} p o_{u, c, s, p}^{t, s c} q o_{u, c, s}^{t, s c}= & \sum_{s^{\prime} \in S I_{u, c}} q i s_{u, c, s}^{t, s c} Y U P S_{u, c, s, s^{\prime}} P O A S S A Y_{u, c, s, s^{\prime}, p}^{t} \\ & \forall u \in U P S, \forall c \in C_{u}, \forall s \in S O_{u, c}, \forall p \in P O_{u, c, s}, \forall t \in T, \forall s c \in S C\end{aligned}$

Propriedade na saída da unidade de conversão

$$
p o_{u, c, s, p}^{t, s c}=P B S_{u, c, s, p}+\sum_{p^{\prime} \in P I_{u, c}} \Delta P P_{u, c, s, p, p^{\prime}}\left(p i_{u, c, p^{\prime}}^{t, s c}-P B E_{u, c, p^{\prime}}\right)
$$

$\forall u \in U P C, \forall c \in C_{u}, \forall s \in S O_{u, c}, \forall p \in P O_{u, c, s}, \forall t \in T, \forall s c \in S C$

Propriedade na saída da unidade de separação por componente

$$
p o_{u, c, s, p}^{t, s c} q o_{u, c, s}^{t, s c}=\sum_{\left(u^{\prime}, c^{\prime}, s^{\prime}, u, c\right) \in F} Y U P S C_{u, c, s, p} q_{u^{\prime}, c^{\prime}, s^{\prime}, u, c}^{t, s c} p o_{u^{\prime}, c^{\prime}, s^{\prime}, p}^{t, s c}
$$

$\forall u \in U P S, \forall c \in C_{u}, \forall s \in S O_{u, c}, \forall p \in P O_{u, c, s}, \forall t \in T, \forall s c \in S C$

Propriedade na saída do tanque de armazenagem

$$
\begin{aligned}
& p o_{u, c, s, p}^{t, s c}\left(V O L I_{u, c}^{t}+\right.\left.v o_{u, c}^{t-1, s c}+q i_{u, c}^{t, s c}\right) \\
&= P O I_{u, c, p}^{t} V O L I_{u, c}^{t, c}+p o_{u, c, s, p}^{t-1, s c} v o_{u, c}^{t-1, s c}+p i_{u, c, p}^{t, s c} q i_{u, c}^{t, s c} \\
& \forall u \in U A, \forall c \in C_{u}, \forall s \in S O_{u, c}, \forall p \in P O_{u, c, s}, \forall t \in T, \forall s c \in S C
\end{aligned}
$$

Propriedade na saída da unidade de mistura 
$p o_{u, c, s, p}^{t, s c}=p i_{u, c, p}^{t, s c}$

$\forall u \in U M, \forall c \in C_{u}, \forall s \in S O_{u, c}, \forall p \in P O_{u, c, s}, \forall t \in T, \forall s c \in S C$

Propriedade na entrada das unidades

$p i_{u, c, p}^{t, s c} q i_{u, c}^{t, s c}=\sum_{\left(u^{\prime}, c^{\prime}, s, u, c\right) \in F} q_{u^{\prime}, c^{\prime}, s, u, c}^{t, c c} p o_{u^{\prime}, c^{\prime}, s, p}^{t, p c}$

$\forall u \in U P \cup U T, \forall c \in C_{u}, \forall p \in P I_{u, c}, \forall t \in T, \forall s c \in S C$

Limite de propriedade

$P O L_{u, c, s, p}^{t} \leq p o_{u, c, s, p}^{t, s c} \leq P O U_{u, c, s, p}^{t}$

$\forall u \in U T, \forall c \in C_{u}, \forall s \in S O_{u, c}, \forall p \in P O_{u, c, s}, \forall t \in T, \forall s c \in S C$

$c a_{u, c, s}^{t}, q_{u^{\prime}, c^{\prime}, s, u, c^{\prime}}^{t, s c} q i s_{u, c, s}^{t, s c} q i_{u, c}^{t, s c}, q o_{u, c, s}^{t, s c}, v o_{u, c}^{t, s c} \in \Re^{+}, p i_{u, c, p}^{t, s c}, p o_{u, c, s, p}^{t, s c} \in \Re$

A função objetivo (5.2) maximiza a margem operacional esperada, que inclui as receitas da venda de produtos menos os custos com matéria-prima e estoque. O fornecimento de petróleo definido pela companhia é representado pelo parâmetro estocástico $\left(Q_{O C F_{u, c, s}^{t, s c}}^{t}\right)$. A compra do petróleo adicional $\left(c a_{u, c, s}^{t}\right)$ representa a decisão de primeiro estágio. As decisões de segundo estágio estão relacionadas às operações da refinaria, como os fluxos entre as unidades $\left(q_{u^{j}, c^{\prime}, s, u, c}^{t, c}\right)$, o nível de estoque $\left(v o_{u, c}^{t, s c}\right)$ e as propriedades de cada produto $\left(p o_{u, c, s, p}^{t, s c}\right)$.

A equação (5.3) restringe a vazão de cada unidade $u$ em cada modo operacional c. A equação (5.4) limita a taxa de fluxo de entrada de fluxo s para a unidade $u$ em cada modo operacional $c$. A equação (5.5) controla a vazão de entrada na unidade $u$ limitada pelos parâmetros estocásticos $\boldsymbol{Q} \boldsymbol{L}_{\boldsymbol{u}}^{\boldsymbol{t} \boldsymbol{s c}}$ e $\boldsymbol{Q} \boldsymbol{U}_{\boldsymbol{u}}^{\boldsymbol{t}, \boldsymbol{s c}}$. A equação (5.6) limita a taxa de fluxo de entrada de fluxo $s$ para a unidade $u$.

A equação (5.7) descreve o balanço do fluxo de entrada na unidade $u\left(q q_{u, c}^{t, s c}\right)$, enquanto a equação (5.8) representa o balanço da corrente de entrada $s$ na unidade $u\left(q i s_{u, c, s}^{t, s c}\right)$. A equação (5.9) descreve o balanço da corrente de saída $s$ da unidade $u$ $\left(q o_{u, c, s}^{t, s c}\right)$. O balanço de estoque na unidade de armazenamento UA é representado pela equação (5.10). A equação (5.11) corresponde ao balanço das unidades de 
mistura UM e dutos UD, já que em ambas não há estoque, portanto a soma dos fluxos de entrada deve ser igual à soma dos fluxos de saída.

A equação (5.12) descreve o processo nas unidades de separação UPS, onde a corrente de saída $s$ é função do petróleo de entrada $s^{\prime}$ e de seu rendimento. A equação (5.13) descreve o processo da unidade de conversão UPC, onde a corrente de saída $s$ é função do fluxo de entrada e do rendimento de conversão $\boldsymbol{Y U P S C}_{\boldsymbol{u}, \boldsymbol{c}, \boldsymbol{s}, \boldsymbol{p}}$ adicionado de um delta $\Delta \boldsymbol{Y} \boldsymbol{P}_{\boldsymbol{u}, \boldsymbol{c}, \boldsymbol{s}, \boldsymbol{p}}$. O delta corresponde a uma variação

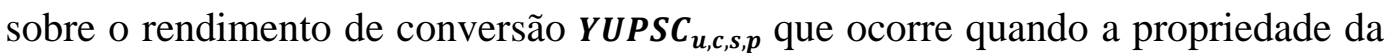
carga de entrada é diferente do valor definido com base $\boldsymbol{P} \boldsymbol{B} \boldsymbol{E}_{\boldsymbol{u}, \boldsymbol{c}, \boldsymbol{p}}$. A equação (5.14) descreve o processo nas unidades de separação por componente UPSC, onde a corrente de saída $s$ é função da propriedade $p$ da corrente de entrada s' e de

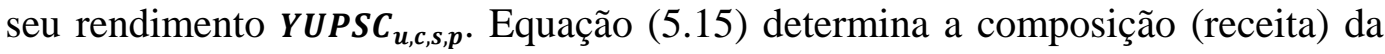
mistura das correntes de entrada $s$ na unidade de tanque UTR em função da vazão de alimentação ( $\left.q i_{u, c}^{t, s c}\right)$ e o parâmetro de receita $R U T_{u, c, s}$.

A equação (5.16) limita o fluxo de saída dos tanques de matéria-prima UC. A equação (5.17) limita a quantidade de matéria-prima adicional disponível. A equação (5.18) representa o nível de estoque a cada período $t$ no cenário sc. A equação (5.18) limita o fluxo de entrada dos produtos finais nas unidades de entrega UE.

As equações (5.20), (5.21) e (5.22) definem as propriedades no fluxo de saída da unidade de separação UPS, da unidade de conversão UPC e da unidade de separação por componente UPSC, respectivamente. Na unidade de separação UPS o calculo da equação (5.20) é feito em função do rendimento da corrente de saída s e do parâmetro $\boldsymbol{P O A S S A Y}_{\boldsymbol{u}, \boldsymbol{c}, \boldsymbol{s}, \boldsymbol{s}, \boldsymbol{p}, \boldsymbol{p}}$ que determina o valor da propriedade transferida do petróleo de entrada $s$ ' para corrente de saída $s$. Na unidade de conversão UPC a equação (5.21) considera um valor base de propriedade $\boldsymbol{P} \boldsymbol{B} \boldsymbol{S}_{\boldsymbol{u}, \boldsymbol{c}, \boldsymbol{s}, \boldsymbol{p}}$ mais um delta de propriedade $\Delta \boldsymbol{P P}_{\boldsymbol{u}, \boldsymbol{c}, \boldsymbol{s}, \boldsymbol{p}, \boldsymbol{p}^{\prime}}$. O delta corresponde a uma variação sobre a propriedade da corrente de entrada e ocorre quando a propriedade calculada para carga de entrada $\boldsymbol{p i}_{\boldsymbol{u}, \boldsymbol{c}, \boldsymbol{p}}^{\boldsymbol{t}, \boldsymbol{s}}$ é diferente do valor definido com base $\boldsymbol{P} \boldsymbol{B} \boldsymbol{E}_{\boldsymbol{u}, \boldsymbol{c}, \boldsymbol{p}}$. Na unidade de separação por componente UPSC a propriedade da corrente de saída $s$ é função da propriedade $p$ da corrente de entrada $s^{\prime}$ e de seu

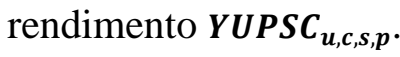


A equação (5.23) refere-se às propriedades nas unidades de armazenamento UA, que considera o estoque no período de tempo anterior $t-1$ e a taxa de fluxo de entrada no período de tempo $t$. A equação (5.24) se refere às propriedades para as unidades de mistura e gasodutos, onde as propriedades do fluxo de saída é igual as propriedades do fluxo de entrada. A equação (5.25) define as propriedades do fluxo de entrada para todos os tipos de unidades. A equação (5.26) especifica a faixa de propriedade. As equações (5.20) a (5.26) são usadas para calculo de propriedade em base volumétrica, como viscosidade e densidade. De forma similar, incluindo a variável de propriedade para $p=$ "densidade” multiplicada a cada termo das equações, é possível calcular as propriedades em base mássica, como é o caso do enxofre. Finalmente, as equações (5.27) definem os limites das variáveis de decisão. 


\section{6}

\section{Método de Solução}

Um estudo com dados reais de três refinarias brasileiras foi conduzido para avaliar o desempenho do modelo matemático proposto para o problema de planejamento operacional de refinarias e identificar o melhor método de solução. A primeira seção apresenta a descrição das três refinarias e a segunda os resultados obtidos com os métodos de solução testados.

\section{1}

\section{Descrição das Refinarias}

As três refinarias consideradas neste estudo foram identificadas em função da capacidade de processamento como Ref. Pequena, Ref. Média e Ref. Grande. As refinarias selecionadas possuem diferentes configurações, considerando porte da planta (pequeno, médio e grande), processos de refino e propriedades de produtos finais. As diferentes combinações dessas características levaram a problemas com maior ou menor nível de complexidade, permitindo uma avaliação rigorosa do modelo matemático proposto.

A Ref. Pequena está localizada na região Nordeste e sua planta foi projetada para fabricar asfaltos, óleos lubrificantes e óleo combustível, processando petróleos do tipo extra pesado e asfáltico específicos para esse fim. Além destes derivados, a Ref. Pequena produz ainda diesel, gás natural, gás liquefeito de petróleo, gasolina, óleo combustível para navios, óleo amaciante de fibras e óleo isolante para transformador. A sua capacidade instalada é de aproximadamente $1.300 \mathrm{~m}^{3} /$ dia (ANP, 2012). O esquema de refino da Ref. Pequena ilustrado na Figura 6.1 é composto pelas unidades de processo: destilação a vácuo, geração de hidrogênio, hidrotratamento e planta de gás natural. A Tabela 6.1 relaciona o código da unidade de processo na Figura 6.1 (Código) com o nome da unidade (Unidade), o tipo de processo de refino (Tipo de Processo) e número de campanhas em que cada unidade pode operar (\# Campanha). 
Tabela 6.1: Unidades de Processo da Ref. Pequena.

\begin{tabular}{lllc}
\hline Código & \multicolumn{1}{c}{ Unidade } & Tipo de Processo & \# Campanha \\
\hline \hline UVAC & Destilação a Vácuo & Separação & 6 \\
UGH & Geração de Hidrogênio & Conversão & 1 \\
UHDT & Hidrotratamento & Tratamento & 4 \\
UPGN & Planta de Gás Natural & Conversão & 1 \\
\hline
\end{tabular}




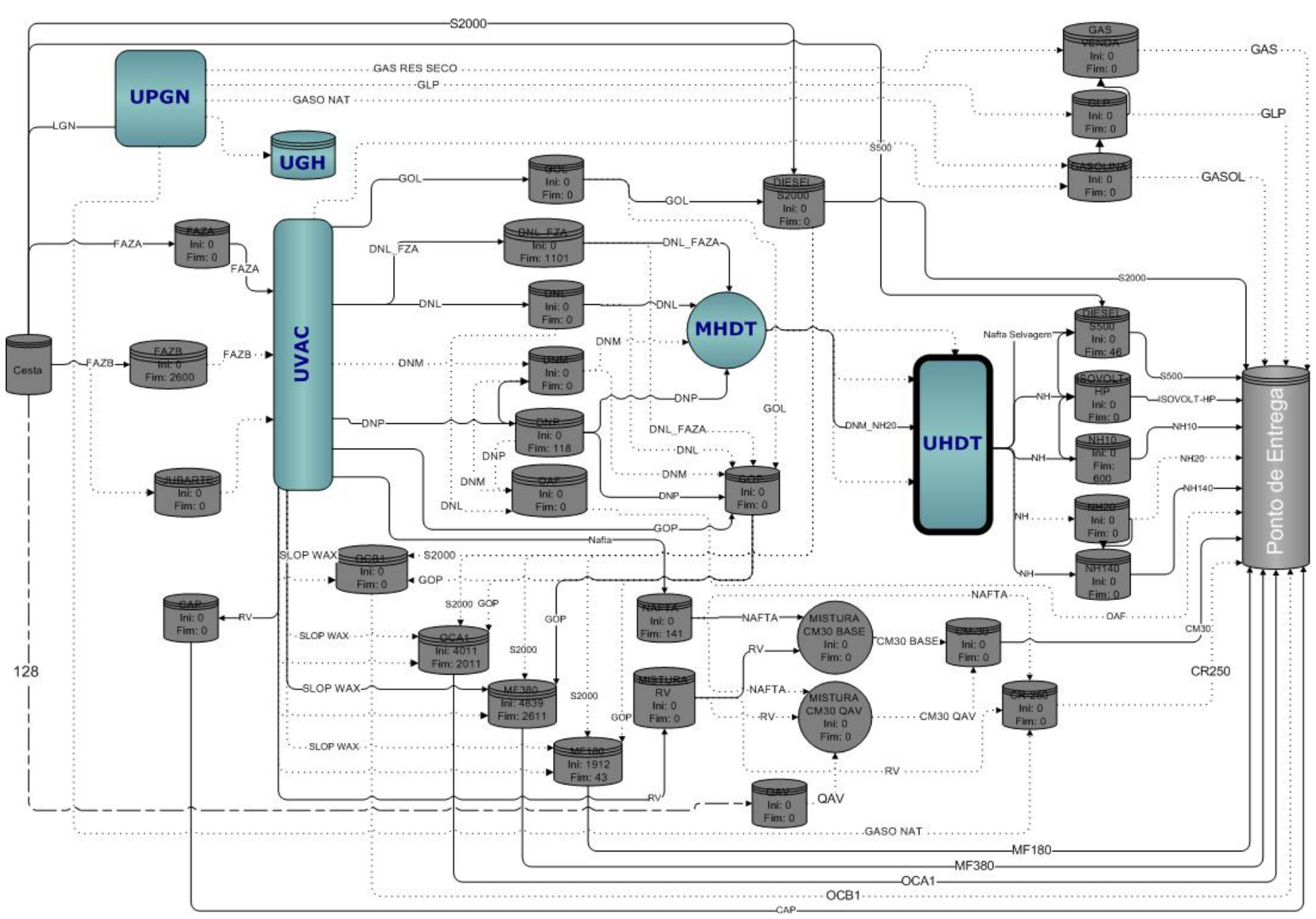

Figura 6.1: Esquema de Refino da Ref. Pequena. 
O esquema de refino da Figura 6.1 mostra todas as unidades modeladas para Ref. Pequena e os possíveis fluxos entre unidades. As unidades ilustradas na Figura 6.1 que não estão identificadas na Tabela 6.1 correspondem ao ponto de oferta de material prima (Cesta), tanques de armazenagem de produtos intermediários e finais, misturadores (círculos em cinza e azul) e o ponto de demanda de produtos finais (Ponto de Entrega). Na Ref. Pequena apenas dois produtos finais são especificados, o combustível marítimo e óleo combustível, que têm seu valor de viscosidade controlado. A Tabela 6.2 indica todos os produtos finais com demanda a ser atendida pela Ref. Pequena e as propriedades a serem especificadas.

Tabela 6.2: Produtos Finais da Ref. Pequena.

\begin{tabular}{ll}
\hline \multicolumn{1}{c}{ Produto Final } & Propriedade \\
\hline \hline Asfalto & \\
\hline Cimento Asfáltico de Petróleo & \\
\hline Combustíveis marítimos & Viscosidade \\
\hline Diesel & \\
\hline Gás Venda & \\
\hline Gasolina & \\
\hline GLP & \\
\hline Óleo Isolante para Transformadores & \\
\hline Lubrificante Naftênico & \\
\hline Óleo Amaciante de Fibras & Viscosidade \\
\hline
\end{tabular}

A Ref. Média está localizada na região Sudeste e processa um blending (mistura) de petróleos do tipo extra pesado, extra leve e médio. A sua capacidade instalada é de $8.500 \mathrm{~m}^{3} /$ dia (ANP, 2012). O esquema de refino da Ref. Média ilustrado na Figura 6.2 é composto pelas unidades de processo: destilação atmosférica, separação de propeno, separação $C_{3}$ e $C_{4}$, recuperação de enxofre, craqueamento catalítico (FCC), área fria do FCC e solvente. A Tabela 6.3 relaciona o código da unidade de processo na Figura 6.1 (Código) com o nome da unidade (Unidade), o tipo de processo de refino (Tipo de Processo) e número de campanhas em que cada unidade pode operar (\# Campanha). 
Tabela 6.3: Unidades de Processo da Ref. Média.

\begin{tabular}{lllr}
\hline \multicolumn{1}{c}{ Código } & \multicolumn{1}{c}{ Unidade } & \multicolumn{1}{c}{ Tipo de Processo } & \# Campanha \\
\hline \hline UDA & Destilação Atmosférica & Separação & 1 \\
PROPENO & Separação de Propeno & Separação por Componente & 1 \\
704 & Separação C e C $_{4}$ & Separação por Componente & 1 \\
ENXOFRE & Recuperação de Enxofre & Conversão & 1 \\
FCC & Craqueamento Catalítico & Conversão & 1 \\
AREA FRIA & Área Fria do FCC & Separação por Componente & 1 \\
SOLV 1 & Solvente - Diluente de Tinta & Conversão & 1 \\
SOLV 2 & Solvente - Borracha & Conversão & 1 \\
\hline
\end{tabular}

O esquema de refino da Figura 6.2 mostra todas as unidades modeladas para Ref. Média e os possíveis fluxos entre unidades. As unidades ilustradas na Figura 6.2 que não estão identificadas na Tabela 6.3 correspondem ao ponto de oferta de material prima (Cesta), tanques de armazenagem de produtos intermediários e finais (tanques em cinza) e misturadores (círculos em azul). Os principais produtos da Ref. Média são: propeno, GLP, gasolina, diesel metropolitano (com baixo teor de enxofre) e solvente. A Ref. Média possui foco em combustíveis e petroquímicos básicos, devido, principalmente, à proximidade a centrais petroquímicas instaladas na região (Tavares, 2005). A Tabela 6.4 indica todos os produtos finais com demanda a ser atendida pela Ref. Média e as propriedades a serem especificadas. 


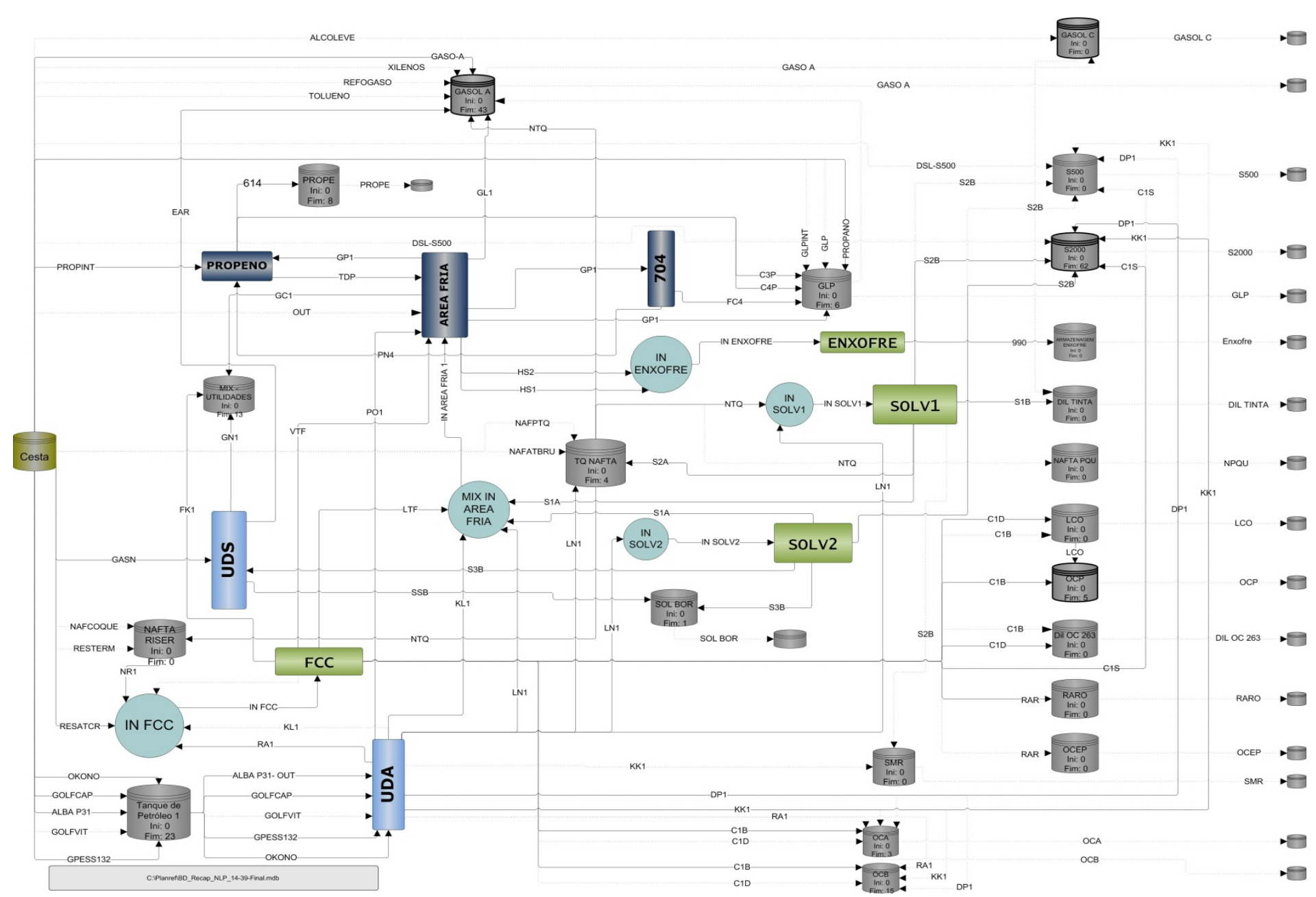

Figura 6.2: Esquema de Refino da Ref. Média. 
Tabela 6.4: Produtos Finais da Ref. Média.

\begin{tabular}{|c|c|}
\hline Produto Final & Propriedade \\
\hline Diesel & $\begin{array}{l}\text { \% Destilação a } 245 \text { C / } 310 \text { C / } 370 \text { C } \\
\% \text { em Volume de LCO } \\
\text { Carbono Ramsbottom } \\
\text { Densidade } \\
\text { Enxofre } \\
\text { Número de Cetano } \\
\text { Ponto de entupimento } \\
\text { Ponto Fulgor } \\
\text { Viscosidade }\end{array}$ \\
\hline Diluente & \\
\hline Diluente de Tinta & \\
\hline Enxofre & \\
\hline Gasolina & $\begin{array}{l}\text { \% Destilação a } 190 \text { C / } 65 \text { C } \\
\text { \% em Volume de Etanol } \\
\text { Aromáticos } \\
\text { Benzeno } \\
\text { Enxofre } \\
\text { Octanagem DON } \\
\text { Octanagem MON } \\
\text { Olefinas } \\
\text { Pressão de Vapor Reid }\end{array}$ \\
\hline GLP & $\begin{array}{l}\text { Densidade } \\
\text { Enxofre } \\
\text { Pressão de Vapor Reid }\end{array}$ \\
\hline Nafta Petroquímica & \\
\hline Óleo Combustível & $\begin{array}{l}\text { Aromáticos } \\
\text { Carbono Conradson } \\
\text { Densidade } \\
\text { Enxofre } \\
\text { Ponto de Fluidez } \\
\text { Ponto de Fulgor } \\
\text { Va } \\
\text { Viscosidade }\end{array}$ \\
\hline Óleo Leve de Reciclo & \\
\hline $\begin{array}{l}\text { Propeno } \\
\text { Raro }\end{array}$ & \\
\hline Solvente & $\begin{array}{l}\text { \% Destilação a } 176 \mathrm{C} \\
\text { Enxofre } \\
\text { Ponto de Fulgor }\end{array}$ \\
\hline
\end{tabular}


A Ref. Grande também está localizada na região Sudeste, e sua capacidade instalada é de $40.000 \mathrm{~m}^{3}$ /dia (ANP, 2012). A Ref. Grande processa petróleos do tipo extra pesado, pesado, médio, leve e extra leve. O esquema de refino da Ref. Grande ilustrado na Figura 6.3 é composto pelas unidades de processo: destilação atmosférica, destilação a vácuo, depropanizadora, solvente, desasfaltação, craqueamento catalítico (FCC), geração de hidrogênio, hidrotratamento (HDT) de diesel, hidrotratamento (HDT) de nafta, hidrotratamento (HDT) de querosene, e unidade de recuperação de enxofre. A Tabela 6.5 relaciona o código da unidade de processo na Figura 6.3 (Código) com o nome da unidade (Unidade), o tipo de processo de refino (Tipo de Processo) e número de campanhas em que cada unidade pode operar (\# Campanha).

Tabela 6.5: Unidades de Processo da Ref. Grande.

\begin{tabular}{lllr}
\hline \multicolumn{1}{c}{ Código } & \multicolumn{1}{c}{ Unidade } & Tipo de Processo & \# Campanha \\
\hline \hline UDA & Destilação Atmosférica & Separação & 1 \\
UVAC & Destilação a Vácuo & Separação & 1 \\
DEPROPANIZADORA & Depropanizadora & Separação & 1 \\
SOLVENTE & Solvente & Separação & 7 \\
DESASFALTACAO & Desasfaltação & Conversão & 2 \\
FCC & Craqueamento Catalítico & Conversão & 3 \\
UGH & Geração de Hidrogênio & Conversão & 1 \\
S72D & HDT Diesel & Tratamento & 2 \\
S72N & HDT Nafta & Tratamento & 1 \\
S72Q & HDT Querosene & Tratamento & 1 \\
URE & Recuperação de Enxofre & Conversão & 1 \\
\hline
\end{tabular}




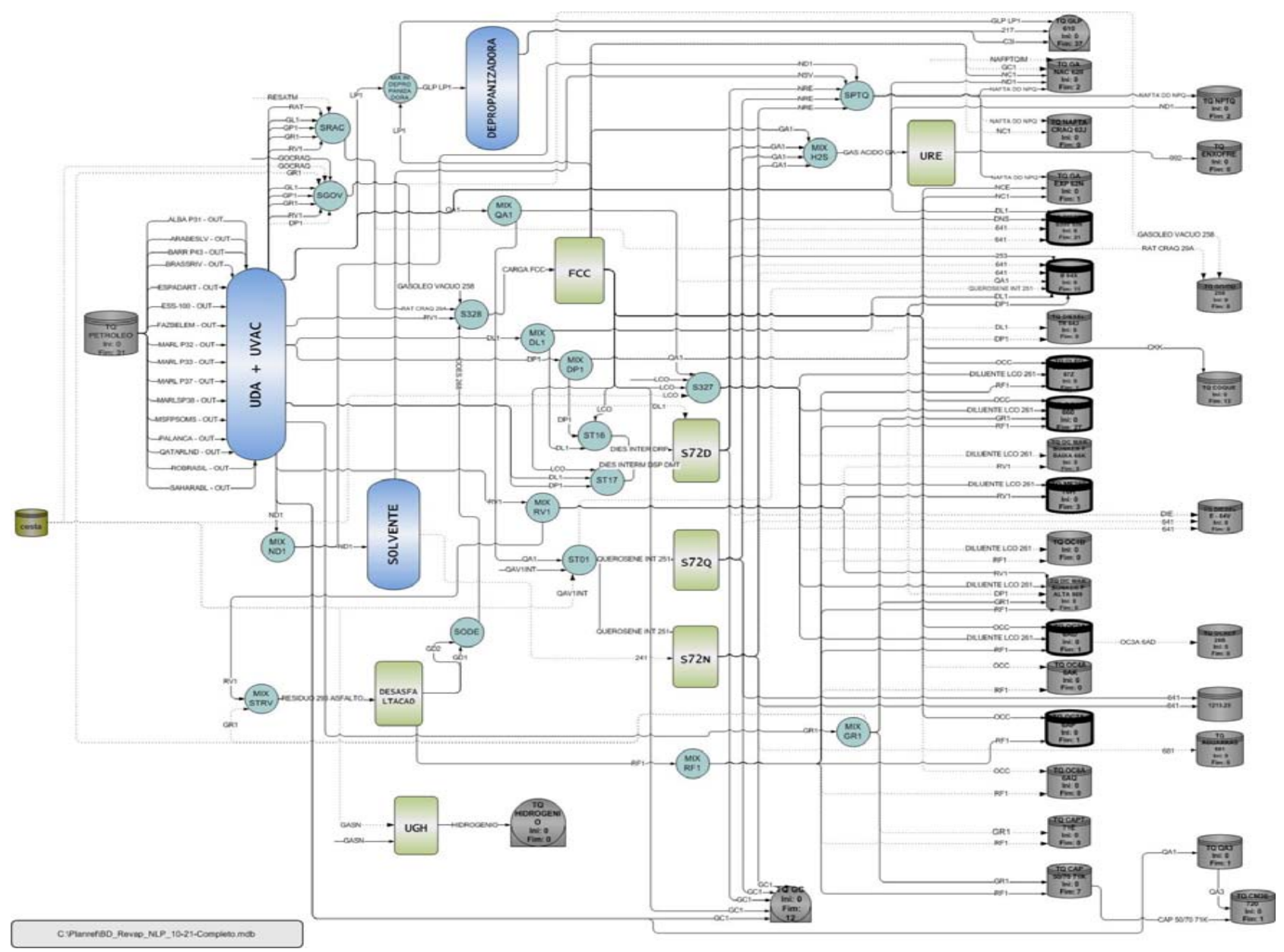

Figura 6.3: Esquema de Refino da Ref. Grande. 
O esquema de refino da Figura 6.3 mostra todas as unidades modeladas para Ref. Grande e os possíveis fluxos entre unidades. As unidades ilustradas na Figura 6.3 que não estão identificadas na Tabela 6.5 correspondem ao ponto de oferta de material prima (Cesta), tanques de armazenagem de produtos intermediários e finais (tanques em cinza) e misturadores (círculos em azul). Os principais produtos da Ref. Grande são: gasolina, diesel, querosene de aviação, GLP, asfalto e enxofre. A Tabela 6.6 indica todos os produtos finais com demanda a ser atendida pela Ref. Grande e as propriedades a serem especificadas.

Tabela 6.6: Produtos Finais da Ref. Grande.

\begin{tabular}{ll}
\hline \multicolumn{1}{c}{ Produto Final } & \multicolumn{1}{c}{ Propriedade } \\
\hline \hline Asfalto & \% em Volume de DP \\
Bunker & \% em Volume de RASFT \\
Bunker & Enxofre \\
Bunker & Viscosidade \\
Bunker & \\
\hline Cimento Asfáltico de Petróleo & \\
\hline Combustíveis marítimos & Densidade \\
Combustíveis marítimos & Enxofre \\
Combustíveis marítimos & Viscosidade \\
\hline Diesel & \% em Volume de QAV \\
Diesel & 85 \%Recuperados \\
Diesel & Densidade \\
Diesel & Enxofre \\
Diesel & Numero de Cetano \\
Diesel & Ponto de entupimento \\
\hline Enxofre & \\
\hline Gás Combustível & \\
\hline Gasolina & \% em Volume de NDD \\
Gasolina & Pressão de Vapor Reid \\
\hline GLP & Densidade \\
\hline Nafta Petroquímica & Densidade \\
Nafta Petroquímica & Parafinas \\
\hline Óleo Combustível & Densidade \\
Óleo Combustível & Enxofre \\
Óleo Combustível & Viscosidade \\
\hline Querosene de Aviação & \\
\hline & \\
\hline & \\
\hline
\end{tabular}

As refinarias Ref. Pequena, Ref. Média e Ref. Grande serão usadas para validar o modelo matemático proposto para o planejamento operacional e para definir o método de solução mais adequado para o problema NLP. Os resultados 
correspondentes a estes testes serão apresentados a seguir. No Capítulo 7 a abordagem estocástica proposta para o para o planejamento operacional de refinarias será testada com dados reais da Ref. Pequena.

\section{2}

\section{Resultados dos Métodos de Solução}

O modelo apresentado do Capítulo 5 foi implementado no software AIMMS (Advanced Integrated Multidimensional Modeling Software - Bisschop e Roelofs, 2007) e os resultados computacionais descritos neste capítulo foram obtidos num computador com processador Intel ${ }^{\circledR}$ Core ${ }^{\text {TM }}$ i5-2400M 3,10GHz e 6Gb RAM. Os testes foram realizados com diferentes casos compostos de um único cenário (equivalente ao modelo determinístico), onde cada caso corresponde a um período de planejamento diferente. A Tabela 6.7 mostra a oferta planejada por tipo de petróleo (A, B, C, D, E ,F, G, H) em cada caso testado, sendo três casos para Ref. Pequena, dois casos para Ref. Média, e três casos para Ref. Grande.

Tabela 6.7: Fornecimento de petróleo planejado (volume).

\begin{tabular}{|c|c|c|c|c|c|c|c|c|c|c|}
\hline \multirow{2}{*}{ Refinaria } & \multirow{2}{*}{ Caso } & \multirow{2}{*}{ Período } & \multicolumn{8}{|c|}{ Oferta Planejada por Tipo de Petróleo (volume) } \\
\hline & & & $\mathrm{A}$ & $\mathrm{B}$ & $\mathrm{C}$ & $\mathrm{D}$ & $\mathrm{E}$ & $\mathrm{F}$ & G & $\mathrm{H}$ \\
\hline \multirow{2}{*}{ Ref. Pequena } & \multirow{2}{*}{ Abr-Mai/2010 } & 1 & 39 & & & & & & & \\
\hline & & 2 & 38 & & & & & & & \\
\hline \multirow{2}{*}{ Ref. Pequena } & \multirow{2}{*}{ Jul-Ago/2010 } & 1 & 38 & 9 & & & & & & \\
\hline & & 2 & 27 & 9 & & & & & & \\
\hline \multirow{2}{*}{ Ref. Pequena } & \multirow{2}{*}{ Ago-Set/2010 } & 1 & 33 & 8 & & & & & & \\
\hline & & 2 & 29 & 8 & & & & & & \\
\hline \multirow{2}{*}{ Ref. Média } & \multirow{2}{*}{ Jun-Jul/2010 } & 1 & & & 4 & & 12 & 8 & & 129 \\
\hline & & 2 & & & 36 & & 20 & 11 & & 156 \\
\hline \multirow{2}{*}{ Ref. Média } & \multirow{2}{*}{ Jul-Ago/2010 } & 1 & & & 65 & & 54 & & & 133 \\
\hline & & 2 & & & 60 & & 30 & & & 150 \\
\hline \multirow{2}{*}{ Ref. Grande } & \multirow{2}{*}{ Fev-Mar/2010 } & 1 & & & 101 & & 120 & 428 & 60 & 121 \\
\hline & & 2 & & & 175 & 220 & & 479 & 85 & 100 \\
\hline \multirow{2}{*}{ Ref. Grande } & \multirow{2}{*}{ Jun-Jul/2010 } & 1 & & & 229 & 38 & 139 & 519 & 200 & \\
\hline & & 2 & & & 20 & 275 & 130 & 745 & 40 & 10 \\
\hline \multirow{2}{*}{ Ref. Grande } & \multirow{2}{*}{ Ago-Set/2010 } & 1 & & & 260 & & 152 & 678 & 230 & \\
\hline & & 2 & & & 155 & 170 & & 610 & 225 & \\
\hline
\end{tabular}


O número total de restrições, de variáveis e de restrições não-lineares geradas para cada refinaria são apresentados na Tabela 6.8.

Tabela 6.8: Descrição das refinarias brasileiras.

\begin{tabular}{lrrr}
\hline \multicolumn{1}{c}{ Refinaria } & \# Restrições & \# Variáveis & \# Rest. NLP \\
\hline \hline Ref. Pequena & 614 & 557 & 200 \\
Ref. Média & 1.859 & 1.651 & 802 \\
Ref. Grande & 1.931 & 1.989 & 838 \\
\hline
\end{tabular}

Os solvers selecionados para otimizar o modelo não-linear foram SNOPT 7.2, CONOPT 3 e KNITRO 7.0. SNOPT 7.2 emprega um algoritmo de programação quadrática sequencial (Sequential quadratic programming - SQP); o CONOPT 3 oferece um algoritmo baseado em GRG (Generalized reduced gradient) especialmente desenvolvido para problemas NLP de grande porte; e o KNITRO 7.0 combina GRG com o método de pontos interiores (ou método de barreira). Os critérios usados para avaliar o desempenho dos métodos de solução propostos para resolver o problema de planejamento operacional de refinarias foram: valor da função objetivo, inviabilidade do problema e tempo de resolução em segundos. A inviabilidade do problema (Inv.) corresponde à soma das inviabilidades encontradas em cada restrição, uma vez que os solvers não-lineares permitem que a solução seja inviável. Neste estudo foi aceito inviabilidade de no máximo $10^{-4}$, soluções com inviabilidade maior que $10^{-4}$ foram declaradas inviáveis.

Inicialmente foi proposto resolver o problema completo, ou seja, considerando todas as restrições e variáveis, e sem nenhuma solução inicial. O problema completo combinado com os solvers SNOPT 7.2, CONOPT 3 e KNITRO 7.0 definem os três primeiros métodos avaliados para resolver o problema estocástico:

I. Problema completo com o solver SNOPT 7.2;

II. Problema completo com o solver CONOPT 3;

III. Problema completo com o solver KNITRO 7.0;

A Tabela 6.9 apresenta os resultados obtidos com os métodos I, II e III com base nos critérios de desempenho: valor da função objetivo (FO), inviabilidade do problema (Inv.) e tempo de resolução em segundos (Tempo). Os resultados mostram que as soluções encontradas com método I (SNOPT 7.2) foram inviáveis 
para a cinco dos oito casos testados. Nos três casos em que o método I chegou a uma solução viável, o valor da função objetivo foi negativo. O método II (CONOPT 3) foi inviável para todos os casos testados. O método III (KNITRO 7.0) encontrou ótimos locais para quatro casos, mas nos demais as soluções foram inviáveis.

Tabela 6.9: Resultados dos Métodos I, II e III.

\begin{tabular}{|c|c|c|c|c|}
\hline $\begin{array}{c}\text { Refinaria } \\
\text { Caso }\end{array}$ & Critério & I. Snopt & II. Conopt & III. Knitro \\
\hline \multirow{3}{*}{$\begin{array}{l}\text { Ref. Pequena } \\
\text { Abr-Mai/2010 }\end{array}$} & FO (\$) & Inviável & Inviável & 12.331 \\
\hline & Inv. & $6,58 \mathrm{E}-01$ & $1,58 \mathrm{E}+01$ & $7,80 \mathrm{E}-07$ \\
\hline & Tempo (s) & 0,06 & 0,03 & $3.446,31$ \\
\hline \multirow{3}{*}{$\begin{array}{l}\text { Ref. Pequena } \\
\text { Jul-Ago/2010 }\end{array}$} & FO (\$) & Inviável & Inviável & 12.512 \\
\hline & $\operatorname{lnf}$ & 6,61E-02 & $1,67 E+01$ & $1,09 E-06$ \\
\hline & Tempo (s) & 0,08 & 0,03 & $3.150,41$ \\
\hline \multirow{3}{*}{$\begin{array}{l}\text { Ref. Pequena } \\
\text { Ago-Set/2010 }\end{array}$} & $\mathrm{FO}(\$)$ & Inviável & Inviável & 12.794 \\
\hline & Inv. & $6,47 \mathrm{E}-02$ & $1,62 E+01$ & $1,29 E-06$ \\
\hline & Tempo (s) & 0,08 & 0,03 & $8.415,52$ \\
\hline \multirow{3}{*}{$\begin{array}{c}\text { Ref. Média } \\
\text { Jun-Jul/2010 }\end{array}$} & FO (\$) & Inviável & Inviável & Inviável \\
\hline & Inv. & $7,24 \mathrm{E}+03$ & $4,84 \mathrm{E}+01$ & $1,27 E+02$ \\
\hline & Tempo (s) & 1,48 & 0,36 & $36.615,76$ \\
\hline \multirow{3}{*}{$\begin{array}{c}\text { Ref. Média } \\
\text { Jul-Ago/2010 }\end{array}$} & $\mathrm{FO}(\$)$ & Inviável & Inviável & 18.537 \\
\hline & Inv. & $2,89 E+02$ & $4,84 \mathrm{E}+01$ & $3,53 \mathrm{E}-06$ \\
\hline & Tempo (s) & 2,60 & 0,06 & $18.300,85$ \\
\hline \multirow{3}{*}{$\begin{array}{c}\text { Ref. Grande } \\
\text { Fev-Mar/2010 }\end{array}$} & $\mathrm{FO}(\$)$ & -157.856 & Inviável & Inviável \\
\hline & Inv. & $0,00 E+00$ & $8,15 E+01$ & $8,46 E+01$ \\
\hline & Tempo (s) & 3,57 & 0,06 & $36.625,51$ \\
\hline \multirow{3}{*}{$\begin{array}{l}\text { Ref. Grande } \\
\text { Jun-Jul/2010 }\end{array}$} & FO (\$) & -159.834 & Inviável & Inviável \\
\hline & Inf & $0,00 E+00$ & $8,24 \mathrm{E}+01$ & $6,03 E+01$ \\
\hline & Tempo (s) & 2,26 & 0,06 & $30.746,22$ \\
\hline \multirow{3}{*}{$\begin{array}{c}\text { Ref. Grande } \\
\text { Ago-Set/2010 }\end{array}$} & FO (\$) & -187.261 & Inviável & Inviável \\
\hline & Inv. & $0,00 E+00$ & $8,37 E+01$ & $5,05 E-03$ \\
\hline & Tempo (s) & 2,11 & 0,58 & $36.694,13$ \\
\hline
\end{tabular}

Na tentativa de encontrar ótimos locais para todos os casos testados outros dois métodos foram propostos. Os métodos seguintes resolvem o problema decomposto em quatro etapas, onde cada etapa serve de inicialização para a seguinte (Figura 6.4). A primeira etapa otimiza o problema de planejamento de refinarias considerando apenas decisões de fluxo entre as unidades operacionais. $\mathrm{Na}$ segunda etapa as equações que calculam as propriedades volumétricas (restrições quadráticas) dos produtos são incluídas. Na terceira, as equações que calculam as propriedades mássicas (restrições cúbicas) são adicionadas ao problema. Na quarta etapa, que corresponde ao problema completo, as 
especificações (limites de propriedade) dos produtos finais são incorporadas. Na prática quatro problemas são otimizados em sequência, e a cada etapa há um incremento na complexidade do modelo.

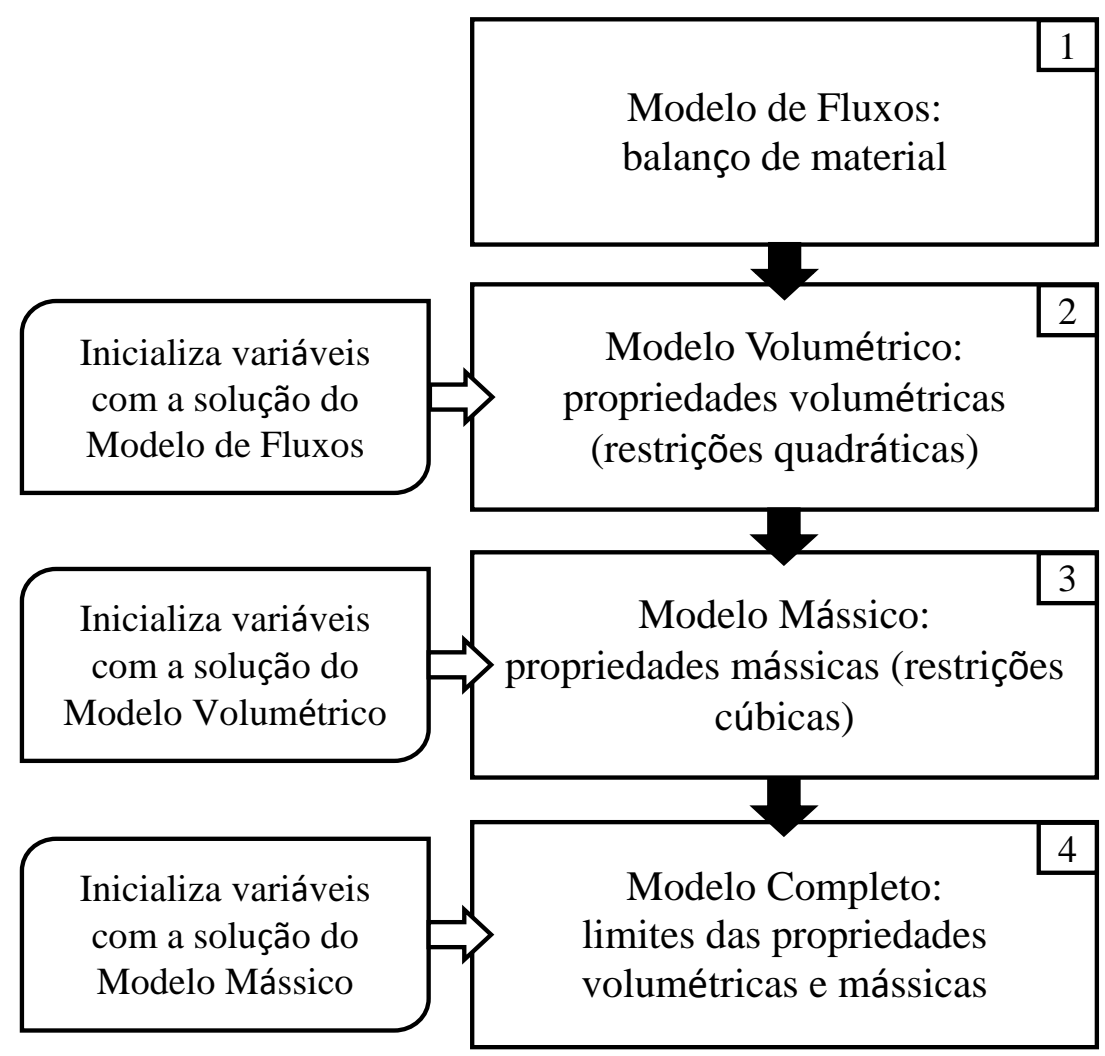

Figura 6.4: Esquema do método de solução em quatro etapas.

Nas refinarias Ref. Pequena e Ref. Grande que não possuem unidade de processo do tipo separação por componente a Etapa 1 corresponde a um problema linear que pode ser resolvido com o solver CPLEX 12. Com base nos resultados da Tabela 7.3 temos que o método II (CONOPT 3) não encontrou solução viável para nenhum dos casos testados e por isso o solver CONOPT 3 não será testado na solução do problema decomposto. O problema decomposto combinado com os solvers CPLEX 12, SNOPT 7.2 e KNITRO 7.0 definem mais dois métodos propostos para resolver o problema estocástico:

IV. Problema decomposto com os solvers SNOPT 7.2 (etapas 1, 2 e 3) e KNITRO 7.0 (etapa 4);

V. Problema decomposto com os solvers CPLEX 12 (etapa 1), SNOPT 7.2 (etapas 2 e 3) e KNITRO 7.0 (etapa 4); 
A Tabela 6.10 apresenta os resultados obtidos com os métodos I, II, III, IV e V com base nos critérios de desempenho: valor da função objetivo (FO), inviabilidade do problema (Inv.) e tempo de resolução em segundos (Tempo).

Tabela 6.10: Resultados dos Métodos I, II, III, IV e V.

\begin{tabular}{|c|c|c|c|c|c|c|}
\hline $\begin{array}{l}\text { Refinaria } \\
\text { Caso }\end{array}$ & Critério & I. Snopt & II. Conopt & III. Knitro & $\begin{array}{l}\text { IV. Snopt } \\
\text { Knitro }\end{array}$ & $\begin{array}{r}\text { V. Cplex } \\
\text { Snopt } \\
\text { Knitro }\end{array}$ \\
\hline \multirow{3}{*}{$\begin{array}{l}\text { Ref. Pequena } \\
\text { Abr-Mai/2010 }\end{array}$} & FO (\$) & Inviável & Inviável & 12.331 & 12.331 & 12.331 \\
\hline & Inv. & $6,58 \mathrm{E}-01$ & $1,58 \mathrm{E}+01$ & $7,80 \mathrm{E}-07$ & 6,27E-07 & $8,70 \mathrm{E}-07$ \\
\hline & Tempo (s) & 0,06 & 0,03 & $3.446,31$ & $2.821,64$ & $3.097,52$ \\
\hline \multirow{3}{*}{$\begin{array}{l}\text { Ref. Pequena } \\
\text { Jul-Ago/2010 }\end{array}$} & $\mathrm{FO}(\$)$ & Inviável & Inviável & 12.512 & 12.512 & 12.512 \\
\hline & Inv. & $6,61 \mathrm{E}-02$ & $1,67 E+01$ & $1,09 E-06$ & 9,79E-07 & $2,49 \mathrm{E}-06$ \\
\hline & Tempo (s) & 0,08 & 0,03 & $3.150,41$ & $2.868,42$ & $5.295,20$ \\
\hline \multirow{3}{*}{$\begin{array}{l}\text { Ref. Pequena } \\
\text { Ago-Set/2010 }\end{array}$} & FO (\$) & Inviável & Inviável & 12.794 & 12.794 & 12.794 \\
\hline & Inv. & $6,47 \mathrm{E}-02$ & $1,62 E+01$ & $1,29 E-06$ & 7,57E-07 & 4,70E-07 \\
\hline & Tempo (s) & 0,08 & 0,03 & $8.415,52$ & $3.965,93$ & $4.380,31$ \\
\hline \multirow{3}{*}{$\begin{array}{c}\text { Ref. Média } \\
\text { Jun-Jul/2010 }\end{array}$} & $\mathrm{FO}(\$)$ & Inviável & Inviável & Inviável & 15.224 & \\
\hline & Inv. & $7,24 \mathrm{E}+03$ & $4,84 \mathrm{E}+01$ & $1,27 E+02$ & 1,62E-06 & \\
\hline & Tempo (s) & 1,48 & 0,36 & $36.615,76$ & 170,48 & \\
\hline \multirow{3}{*}{$\begin{array}{l}\text { Ref. Média } \\
\text { Jul-Ago/2010 }\end{array}$} & FO (\$) & Inviável & Inviável & 18.537 & 18.549 & \\
\hline & Inv. & $2,89 E+02$ & $4,84 \mathrm{E}+01$ & 3,53E-06 & $1,20 \mathrm{E}-06$ & \\
\hline & Tempo (s) & 2,60 & 0,06 & $18.300,85$ & 614,92 & \\
\hline \multirow{3}{*}{$\begin{array}{c}\text { Ref. Grande } \\
\text { Fev-Mar/2010 }\end{array}$} & FO (\$) & -157.856 & Inviável & Inviável & 132.870 & 132.123 \\
\hline & Inv. & $0,00 E+00$ & $8,15 E+01$ & $8,46 \mathrm{E}+01$ & $1,66 \mathrm{E}-06$ & 9,85E-07 \\
\hline & Tempo (s) & 3,57 & 0,06 & $36.625,51$ & 347,32 & $1.004,85$ \\
\hline \multirow{3}{*}{$\begin{array}{c}\text { Ref. Grande } \\
\text { Jun-Jul/2010 }\end{array}$} & FO (\$) & -159.834 & Inviável & Inviável & 147.643 & 44.112 \\
\hline & Inv. & $0,00 E+00$ & $8,24 \mathrm{E}+01$ & $6,03 E+01$ & 1,29E-06 & $3,37 \mathrm{E}-03$ \\
\hline & Tempo (s) & 2,26 & 0,06 & $30.746,22$ & $3.359,25$ & $36.454,31$ \\
\hline \multirow{3}{*}{$\begin{array}{c}\text { Ref. Grande } \\
\text { Ago-Set/2010 }\end{array}$} & FO (\$) & -187.261 & Inviável & Inviável & 110.930 & \\
\hline & Inv. & $0,00 E+00$ & $8,37 E+01$ & 5,05E-03 & 1,15E-06 & $1,72 E+03$ \\
\hline & Tempo (s) & 2,11 & 0,58 & $36.694,13$ & 623,22 & $36.622,45$ \\
\hline
\end{tabular}

O melhor resultado encontrado para cada caso está destacado em negrito na Tabela 6.10. Nos oitos casos analisados o melhor desempenho foi obtido com o método IV. Observa-se que em dois casos (Ref. Pequena Ago-Set/2010 e Ref. Grande Fev-Mar/2010), o método V forneceu uma solução com inviabilidade menor que o método IV. No entanto, todas as soluções do método IV estão dentro do limite de inviabilidade definido como aceitável, e como apresenta FO melhor e tempo menor, o método IV foi identificado como o de melhor desempenho.

O método IV resolve o problema decomposto com os solvers SNOPT 7.2 (três primeiras etapas) e KNITRO 7.0 (etapa final). SNOPT 7.2 foi eficiente em fornecer ótimos locais com poucas iterações e tempo reduzido para as etapas iniciais do problema decomposto, mas com FO muito baixa, havendo ainda 
possibilidade de melhorar a solução. Na etapa final o solver KNITRO 7.0 foi usado para refinar a solução, aumentando valor de FO e reduzindo a inviabilidade. A combinação destes dois solvers forneceu o melhor desempenho com relação a tempo e qualidade de solução. Os resultados estocásticos apresentados no capítulo de resultados foram todos obtidos usando o método IV que resolve o problema decomposto com os solvers SNOPT 7.2 (três primeiras etapas) e KNITRO 7.0 (etapa final). 


\section{Resultados}

Um estudo com base na Refinaria Pequena descrita no Capítulo 6 foi conduzido para avaliar o desempenho do modelo estocástico proposto para o problema de planejamento operacional de refinarias. O modelo foi implementado no software AIMMS (Advanced Integrated Multidimensional Modeling Software Bisschop e Roelofs, 2007) e resolvido com o método de solução apresentado no Capítulo 6 (problema decomposto usando os solvers SNOPT 7.2 nas três primeiras etapas e KNITRO 7.0 na etapa final). Os resultados computacionais descritos neste capítulo foram obtidos num computador com processador Intel ${ }^{\circledR}$ Core TM i5-2400M 3,10GHz e 6Gb RAM.

Os resultados apresentados neste capítulo foram separados em três seções. Na primeira seção será apresentado o processo de geração das árvores de cenários. Na segunda seção as árvores de cenários serão avaliadas com as três medidas de qualidade propostas no Capítulo 3, com o objetivo de selecionar a árvore de cenários que fornece o melhor desempenho ao modelo estocástico desenvolvido. Na terceira seção, identificada a melhor árvore de cenários para representar as incertezas, o modelo estocástico será avaliado em termos do EVPI (valor esperado da informação perfeita) e VSS (valor da solução estocástica).

\section{1}

\section{Geração das Árvores de Cenários}

No problema de planejamento operacional de refinarias foram identificados dois tipos de incerteza: fornecimento de petróleo e capacidade das unidades de processo. Porém apenas o fornecimento de petróleo possuía registro histórico, e como visto no Capítulo 3, a metodologia de geração de cenários escolhida utiliza como dado de entrada as propriedades estatísticas calculadas a partir da série histórica ou da distribuição da variável aleatória. Como não foi possível estimar uma distribuição para o parâmetro estocástico de capacidade das unidades, apenas a incerteza no fornecimento de petróleo foi considerada. A seguir a metodologia 
de geração de cenários descrita no Capítulo 3 será aplicada a série real de fornecimento de petróleo disponibilizada pelos planejadores da refinaria.

O horizonte de tempo do planejamento é de dois meses, porém a cada rodada de planejamento apenas o plano do primeiro mês utilizado. O segundo mês será re-planejado (como primeiro mês) na próxima rodada do planejamento. O segundo mês representa o processo contínuo no qual a refinaria opera, passando a informação para o modelo de que o mês planejado não é o único e nem o último. O horizonte de planejamento com dois períodos permite que as decisões de estoque do primeiro período sejam mais aderentes à realidade da refinaria. Sendo assim, a incerteza esta sendo considerada apenas no primeiro mês de planejamento, bem como a geração de cenários.

A geração de cenários será feita para o fornecimento de petróleo da Refinaria Pequena, uma vez que os resultados tratam apenas desta refinaria. Foram obtidos dados mensais de fornecimento de petróleo planejado e realizado dos últimos três anos de operação da Refinaria Pequena. As séries históricas de fornecimento de petróleo foram inicialmente utilizadas para determinar os tipos de petróleo que mais contribuem para incerteza na operação da refinaria. Selecionados os tipos de petróleo com maior incerteza no fornecimento, foram gerados os cenários com base na metodologia apresentada anteriormente.

O histórico mostrou que a Refinaria Pequena pode ser abastecida por cinco tipos de petróleos diferentes. A incerteza gerada por cada tipo de petróleo foi medida pelo total dos erros absolutos de planejamento, i.e., diferença em valor absoluto entre o volume planejado e o realizado. A contribuição de cada petróleo é dada pela razão entre o total dos erros absolutos de planejamento do petróleo no período ( $n$ observações) e o total dos erros absolutos de todos os petróleos em todos os períodos:

$$
\frac{\sum_{i=1}^{n}\left(\mid \text { Real }_{o, i}-\text { Plan }_{o, i} \mid\right)}{\sum_{o=1}^{O} \sum_{i=1}^{n}\left(\mid \text { Real }_{o, i}-\text { Plan }_{o, i} \mid\right)}, \forall o \in O .
$$

onde Real $_{o, i}$ é o valor do petróleo o efetivamente entregue no período $i$ e $P_{l a n_{o, i}}$ é valor planejado para o fornecimento de petróleo $o$ no período $i$. Três destes petróleos contribuem com 96\% dos erros observados, e por isso somente estes três petróleos, aqui identificados como petróleo A, petróleo B e petróleo $\mathrm{C}$, foram 
considerados para geração de cenários. A oferta dos demais petróleos foi tratada como determinística.

A geração de cenários para os petróleos A, B e C foi feita com base na série dos erros relativos de planejamento:

$$
\text { Erro }_{o, i}=\frac{\text { Real }_{o, i}-\text { Plan }_{o, i}}{\sum_{o=1}^{O} \text { Plan }_{o, i}}
$$

É importante ressaltar que os cenários são gerados a partir da série de $E r o_{o, i}$ e fornecem valores percentuais de $E r O_{o, i, s c}$ que serão utilizados para ajustar o volume de cada petróleo planejado no período em questão. Ao utilizar a série dos erros relativos de planejamento é possível tratar as variações entre o realizado e o planejado com diferentes ordens de grandeza causadas pelo aumento de capacidade da refinaria ao longo do tempo. O volume em cada cenário sc para cada petróleo $o$ é dado por:

$$
\operatorname{Plan}_{o, i, s c}=\operatorname{Plan}_{o, i}+\text { Erro }_{o, i, s c} \cdot \sum_{o=1}^{O} \operatorname{Plan}_{o, i}
$$

Esta fórmula permite ajustar o volume de um petróleo no cenário mesmo quando este não aparece no planejado do período considerado, desde que o Erro $_{o, i, s c}$ seja significativo.

A Figura 7.1 mostra o histograma dos erros de planejamento Erro $_{o, i}$ observados (barras) para os petróleos A, B e C.

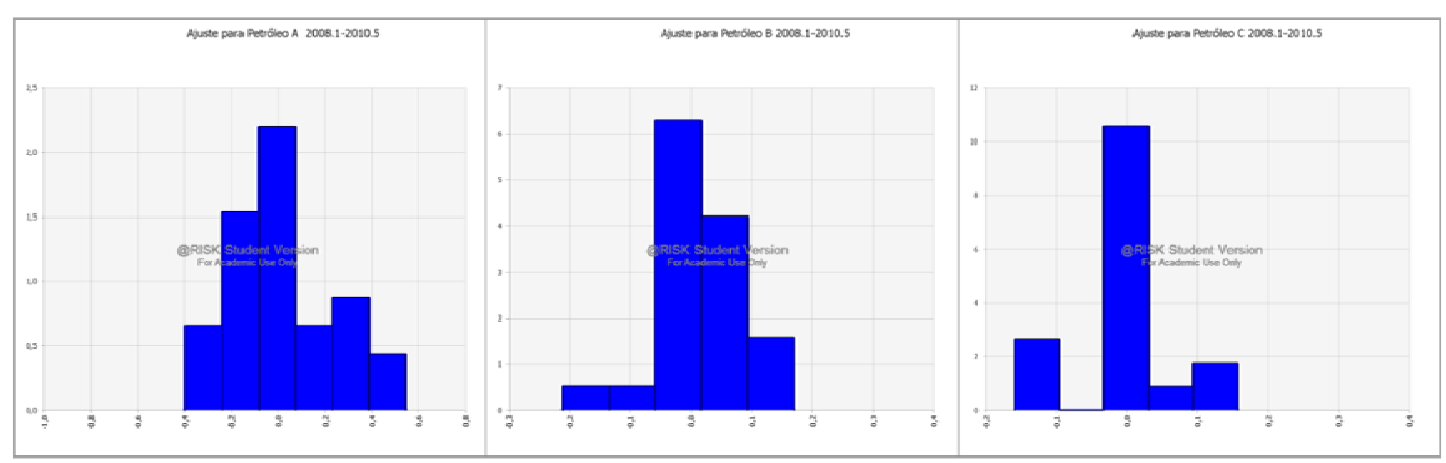

Figura 7.1: Histograma dos erros para os petróleos A, B e C.

Com base nas séries de erros de planejamento Erro $_{o, i}$ dos petróleos A, B e C, foram calculadas as propriedades estatísticas (Tabela 7.1) usadas como entrada para o método de geração de cenários de Høyland e Wallace (2001). As 
propriedades estatísticas: média, variância, curtose e assimetria (quatro primeiros momentos centrais), foram obtidas com o software @Risk e a correlação com a ferramenta de análise do Excel (Correlação).

Tabela 7.1: Propriedades estatísticas das distribuições originais.

\begin{tabular}{crrrrrrrr}
\hline Petróleo & Média & Variância & \multicolumn{1}{c}{ Curtose } & Assimetria Correlação & A & B & C \\
\hline \hline A & 0,012 & 0,050 & 3,032 & 0,310 & A & 1 & & \\
B & 0,013 & 0,006 & 5,611 & $-0,641$ & B & $-0,035$ & 1 & \\
C & $-0,026$ & 0,004 & 8,993 & $-2,448$ & C & $-0,496$ & $-0,116$ & 1 \\
\hline
\end{tabular}

Na geração das árvores de cenários 1 a 6 o método de geração de cenário é inicializado com as aproximações discretas de 3 pontos apresentadas na Tabela 3.4 da metodologia. Os pontos iniciais selecionados da série de Erro $_{o, i}$ para cada um dos petróleos estão na Tabela 7.2.

Tabela 7.2: Solução inicial - Aproximação discreta para os petróleos A, B e C.

\begin{tabular}{|c|c|c|c|c|c|}
\hline Aproximação (Solução inicial) & Valores & Probabilidades & A & B & C \\
\hline \multirow{3}{*}{ Extended Pearson-Tukey (EP-T) } & $x(0.05)$ & $19 \%$ & $-37 \%$ & $-11 \%$ & $-16 \%$ \\
\hline & $x(0.50)$ & $63 \%$ & $-1 \%$ & $1 \%$ & $0 \%$ \\
\hline & $x(0.95)$ & $19 \%$ & $40 \%$ & $14 \%$ & $0 \%$ \\
\hline \multirow{3}{*}{ Extended Swanson-Megil (ES-M) } & $x(0.10)$ & $30 \%$ & $-34 \%$ & $-5 \%$ & $-16 \%$ \\
\hline & $x(0.50)$ & $40 \%$ & $-1 \%$ & $1 \%$ & $0 \%$ \\
\hline & $x(0.90)$ & $30 \%$ & $29 \%$ & $10 \%$ & $0 \%$ \\
\hline \multirow{3}{*}{ McNamee-Celona "Shortcut" (M-CS) } & $x(0.10)$ & $25 \%$ & $-34 \%$ & $-5 \%$ & $-16 \%$ \\
\hline & $x(0.50)$ & $50 \%$ & $-1 \%$ & $1 \%$ & $0 \%$ \\
\hline & $x(0.90)$ & $25 \%$ & $29 \%$ & $10 \%$ & $0 \%$ \\
\hline \multirow{3}{*}{ Miller-Rice "One-Step" (M-RO) } & $x(0.085)$ & $25 \%$ & $-35 \%$ & $-5 \%$ & $-16 \%$ \\
\hline & $x(0.50)$ & $50 \%$ & $-1 \%$ & $1 \%$ & $0 \%$ \\
\hline & $x(0.915)$ & $25 \%$ & $29 \%$ & $10 \%$ & $0 \%$ \\
\hline \multirow{3}{*}{ Zaino-D'Errico "Taguchi" (Z-DT) } & $x(0.11)$ & $33 \%$ & $-19 \%$ & $-5 \%$ & $-16 \%$ \\
\hline & $x(0.50)$ & $33 \%$ & $-1 \%$ & $1 \%$ & $0 \%$ \\
\hline & $x(0.89)$ & $33 \%$ & $28 \%$ & $10 \%$ & $0 \%$ \\
\hline \multirow{3}{*}{ Zaino-D'Errico "Improved" (Z-DI) } & $x(0.042)$ & $17 \%$ & $-37 \%$ & $-11 \%$ & $-16 \%$ \\
\hline & $x(0.50)$ & $67 \%$ & $-1 \%$ & $1 \%$ & $0 \%$ \\
\hline & $x(0.958)$ & $17 \%$ & $40 \%$ & $14 \%$ & $0 \%$ \\
\hline
\end{tabular}

A partir das informações das Tabelas 7.1 e 7.2 as dez árvores de cenários identificadas na Tabela 3.3 foram geradas pelo método de Høyland e Wallace (2001). A distribuição de probabilidade conjunta calculada para o erro de 
planejamento dos petróleos A, B e C é apresentada para cada um dos dez casos na Tabela 7.3.

Tabela 7.3: Árvores de cenário - Método de Høyland e Wallace (2001).

\begin{tabular}{|c|c|c|c|c|c|}
\hline & Nome & Prob. & $A$ & B & $\mathrm{C}$ \\
\hline \multirow[t]{3}{*}{1} & & $24 \%$ & $-31 \%$ & $10 \%$ & $3 \%$ \\
\hline & EP-T & $64 \%$ & $4 \%$ & $-4 \%$ & $-2 \%$ \\
\hline & & $12 \%$ & $46 \%$ & $14 \%$ & $-14 \%$ \\
\hline \multirow[t]{3}{*}{2} & & $29 \%$ & $-28 \%$ & $-5 \%$ & $4 \%$ \\
\hline & ES-M & $62 \%$ & $8 \%$ & $7 \%$ & $-5 \%$ \\
\hline & & $9 \%$ & $51 \%$ & $-17 \%$ & $-11 \%$ \\
\hline \multirow[t]{3}{*}{3} & & $10 \%$ & $-42 \%$ & $-16 \%$ & $8 \%$ \\
\hline & M-CS & $69 \%$ & $-4 \%$ & $6 \%$ & $-2 \%$ \\
\hline & & $21 \%$ & $39 \%$ & $-6 \%$ & $-9 \%$ \\
\hline \multirow[t]{3}{*}{4} & & $29 \%$ & $-28 \%$ & $-5 \%$ & $4 \%$ \\
\hline & M-RO & $62 \%$ & $8 \%$ & $7 \%$ & $-5 \%$ \\
\hline & & $9 \%$ & $51 \%$ & $-17 \%$ & $-11 \%$ \\
\hline \multirow[t]{3}{*}{5} & & $10 \%$ & $-42 \%$ & $-16 \%$ & $8 \%$ \\
\hline & Z-DT & $69 \%$ & $-4 \%$ & $6 \%$ & $-2 \%$ \\
\hline & & $21 \%$ & $39 \%$ & $-6 \%$ & $-9 \%$ \\
\hline \multirow[t]{3}{*}{6} & & $24 \%$ & $-31 \%$ & $10 \%$ & $3 \%$ \\
\hline & Z-DI & $64 \%$ & $4 \%$ & $-4 \%$ & $-2 \%$ \\
\hline & & $12 \%$ & $46 \%$ & $14 \%$ & $-14 \%$ \\
\hline \multirow[t]{3}{*}{7} & & $10 \%$ & $-42 \%$ & $-16 \%$ & $8 \%$ \\
\hline & 3 cenários & $69 \%$ & $-4 \%$ & $6 \%$ & $-2 \%$ \\
\hline & & $21 \%$ & $39 \%$ & $-6 \%$ & $-9 \%$ \\
\hline \multirow[t]{4}{*}{8} & & $7 \%$ & $-34 \%$ & $-19 \%$ & $-1 \%$ \\
\hline & $S$ & $20 \%$ & $-28 \%$ & $13 \%$ & $-1 \%$ \\
\hline & & $62 \%$ & $6 \%$ & $0 \%$ & $0 \%$ \\
\hline & & $11 \%$ & $48 \%$ & $4 \%$ & $-21 \%$ \\
\hline \multirow[t]{5}{*}{9} & & $31 \%$ & $-28 \%$ & $0 \%$ & $0 \%$ \\
\hline & & $15 \%$ & $7 \%$ & $15 \%$ & $-1 \%$ \\
\hline & 5 cenários & $40 \%$ & $10 \%$ & $1 \%$ & $-3 \%$ \\
\hline & & $7 \%$ & $11 \%$ & $-20 \%$ & $7 \%$ \\
\hline & & $8 \%$ & $53 \%$ & $-1 \%$ & $-24 \%$ \\
\hline \multirow[t]{6}{*}{10} & & $19 \%$ & $-34 \%$ & $1 \%$ & $4 \%$ \\
\hline & & $15 \%$ & $0 \%$ & $15 \%$ & $-2 \%$ \\
\hline & 6 cenários & $39 \%$ & $1 \%$ & $1 \%$ & $-1 \%$ \\
\hline & & $8 \%$ & $2 \%$ & $-19 \%$ & $0 \%$ \\
\hline & & $7 \%$ & $24 \%$ & $2 \%$ & $-25 \%$ \\
\hline & & $12 \%$ & $45 \%$ & $0 \%$ & $-7 \%$ \\
\hline
\end{tabular}

Observa-se na Tabela 7.3 que mesmo usando diferentes pontos iniciais o método de Høyland e Wallace (2001) gerou árvores de cenários iguais nos seguintes casos: 1 e 6 (EP-T e Z-DI); 2 e 4 (ES-M e M-RO); 3 , 5 e 7 
(M-CS, Z-DT e 3 cenários). Sendo assim, apenas as árvores $1,2,3,8,9$ e 10 são consideradas neste estudo.

A Tabela 7.4 mostra os ajustes das propriedades estatísticas (média, variância, curtose e assimetria) obtidos pelo método de Høyland e Wallace (2001). O método escolhido teve excelente desempenho na geração de todas as árvores de cenários, independente do uso de ponto inicial. As propriedades estatísticas de todas as árvores de cenários foram iguais às propriedades estatísticas da distribuição original definidas como meta (ver Tabela 7.1) com uma precisão de seis casas decimais. Do ponto de vista estatístico, é possível afirmar que todas as árvores de cenários representam a incerteza observada no fornecimento de petróleo com a mesma qualidade, uma vez que ajustaram propriedades estatísticas da distribuição original com a mesma precisão. No entanto, cada árvore de cenários seleciona pontos bem diferentes da curva de fornecimento de petróleo, logo para o problema de programação estocástica essas árvores não são iguais e podem levar a soluções muito diferentes a serem avaliadas na próxima seção.

Tabela 7.4: Árvores de cenário - Propriedades estatísticas.

\begin{tabular}{cccccccrr}
\hline Petróleo & Média & Variância & Kurtosis & Skewness & Correlação & A & B & C \\
\hline \hline A & 0,012 & 0,050 & 3,032 & 0,309 & A & 1 & & \\
B & 0,013 & 0,006 & 5,611 & $-0,641$ & B & $-0,035$ & 1 & \\
C & $-0,026$ & 0,002 & 8,993 & $-2,448$ & C & $-0,496$ & $-0,116$ & 1 \\
\hline
\end{tabular}

\section{2}

\section{Avaliação das Árvores de Cenários}

Nesta seção as árvores de cenários de fornecimento de petróleo apresentadas na Tabela 7.3 são avaliadas com as três medidas de qualidade propostas no Capítulo 3: decisão de primeiro estágio, função objetivo, e valor esperado da informação perfeita. Neste trabalho todas as medidas de qualidade propostas usam a solução do problema original como referência para a avaliação das diversas árvores de cenários geradas. O problema original foi resolvido usando a distribuição original que corresponde a distribuição completa do parâmetro estocástico fornecimento de petróleo. 
O objetivo desta etapa é selecionar a árvore de cenários que melhor representa as incertezas em função da solução obtida com o modelo estocástico. A avaliação leva em consideração quatro casos da Refinaria Pequena que correspondem aos períodos: Junho-Julho/2010; Julho-Agosto/2010; AgostoSetembro/2010; e Setembro-Outubro/2010. A Tabela 7.5 apresenta o volume de petróleo planejado e realizado para os quatros casos considerados por tipo de petróleo (A, B e C).

Tabela 7.5: Fornecimento de petróleo (volume).

\begin{tabular}{cc|ccc|ccc|ccc}
\hline \multirow{2}{*}{ Caso } & Período & \multicolumn{2}{|c|}{ Planejado } & \multicolumn{2}{|c|}{ Realizado } & \multicolumn{4}{|c}{ Variação } \\
& & A & B & C & A & B & C & A & B & C \\
\hline \hline \multirow{2}{*}{ Jun-Jul/2010 } & 1 & 28 & 8 & 0 & 31 & 5 & 0 & $11 \%$ & $-32 \%$ & $0 \%$ \\
& 2 & 22 & 9 & 0 & 35 & 6 & 0 & $58 \%$ & $-38 \%$ & $0 \%$ \\
\hline \multirow{2}{*}{ Jul-Ago/2010 } & 1 & 38 & 9 & 0 & 35 & 6 & 0 & $-9 \%$ & $-37 \%$ & $0 \%$ \\
& 2 & 27 & 9 & 0 & 29 & 12 & 0 & $5 \%$ & $34 \%$ & $0 \%$ \\
\hline \multirow{2}{*}{ Ago-Set/2010 } & 1 & 33 & 8 & 0 & 29 & 12 & 0 & $-12 \%$ & $40 \%$ & $0 \%$ \\
& 2 & 29 & 8 & 0 & 30 & 4 & 0 & $4 \%$ & $-46 \%$ & $0 \%$ \\
\hline \multirow{2}{*}{ Set-Out/2010 } & 1 & 38 & 8 & 0 & 30 & 4 & 0 & $-21 \%$ & $-46 \%$ & $0 \%$ \\
& 2 & 25 & 9 & 0 & 21 & 12 & 0 & $-17 \%$ & $33 \%$ & $0 \%$ \\
\hline
\end{tabular}

A coluna "Variação" da Tabela 7.5 corresponde à diferença percentual entre a oferta de petróleo planejada e realizada: $\left(\operatorname{Real}_{o, i}-\operatorname{Plan}_{o, i}\right) / \operatorname{Plan}_{o, i}$, onde $\operatorname{Real}_{o, i}$ é o valor do petróleo o efetivamente entregue no período $i$ e Plan $_{o, i}$ é valor planejado para o fornecimento de petróleo o no período $i$. Nota-se que a oferta do petróleo A varia de $-21 \%$ até $58 \%$; a oferta do petróleo B varia de $-46 \%$ até 40\%; e a oferta do petróleo C é zero para todos os casos considerados. Variações na oferta de petróleo desta ordem impactam significativamente no plano de produção da refinaria e devem ser tratados com apoio de um modelo de otimização sob incerteza.

As árvores de cenários apresentadas na Tabela 7.3 correspondem a variações percentuais sobre o fornecimento de petróleo planejado. A construção das árvores de cenários é feita aplicando a variação percentual $\left(\operatorname{Erro}_{o, i, s c}\right)$ calculada pela metodologia de geração de cenários à oferta de petróleo planejada $\left(\operatorname{Plan}_{o, i}\right)$ da Tabela 7.5 conforme a equação (7.3). As árvores de cenários usadas 
como dado de entrada do modelo estocástico em cada um dos quatro casos considerados estão na Tabela 7.6.

Tabela 7.6: Árvores de Cenários (volume).

\begin{tabular}{|c|c|c|c|c|c|c|c|c|c|c|c|c|c|c|c|c|c|c|}
\hline & \multirow{2}{*}{ Nome } & \multirow{2}{*}{ Cenário } & \multirow{2}{*}{ Prob. } & \multicolumn{3}{|c|}{ Variação \% } & \multicolumn{3}{|c|}{ Jun-Jul/2010 } & \multicolumn{3}{|c|}{ Jul-Ago/2010 } & \multicolumn{3}{|c|}{ Ago-Set/2010 } & \multicolumn{3}{|c|}{ Set-Out/2010 } \\
\hline & & & & $\mathrm{A}$ & $\mathrm{B}$ & $\mathrm{C}$ & $\mathrm{A}$ & $\mathrm{B}$ & $\mathrm{C}$ & $\mathrm{A}$ & $\mathrm{B}$ & $\mathrm{C}$ & $\mathrm{A}$ & $\mathrm{B}$ & $\mathrm{C}$ & $\mathrm{A}$ & $\mathrm{B}$ & $\mathrm{C}$ \\
\hline \multirow[t]{3}{*}{1} & \multirow{3}{*}{$\begin{array}{l}\text { EP-T } \\
\text { Z-DI }\end{array}$} & 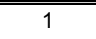 & $24 \%$ & $-31 \%$ & $10 \%$ & $3 \%$ & 17 & 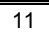 & 1 & 24 & 13 & 1 & 20 & 12 & 1 & 24 & 13 & $\bar{~} 1$ \\
\hline & & 2 & $64 \%$ & $4 \%$ & $-4 \%$ & $-2 \%$ & 30 & 6 & & 41 & 7 & & 34 & 7 & & 40 & 6 & \\
\hline & & 3 & $12 \%$ & $46 \%$ & $14 \%$ & $-14 \%$ & 45 & 13 & & 60 & 15 & & 52 & 14 & & 60 & 15 & \\
\hline \multirow[t]{3}{*}{2} & \multirow{3}{*}{$\begin{array}{l}\text { ES-M } \\
M-R O\end{array}$} & 1 & $29 \%$ & $-28 \%$ & $-5 \%$ & $4 \%$ & 18 & 6 & 2 & 25 & 7 & 2 & 21 & 6 & 2 & 25 & 6 & 2 \\
\hline & & 2 & $62 \%$ & $8 \%$ & $7 \%$ & $-5 \%$ & 31 & 10 & & 42 & 12 & & 36 & 11 & & 42 & 11 & \\
\hline & & 3 & $9 \%$ & $51 \%$ & $-17 \%$ & $-11 \%$ & 46 & 2 & & 63 & 1 & & 54 & 1 & & 62 & 0 & \\
\hline \multirow[t]{3}{*}{3} & $\mathrm{M}-\mathrm{CS}$ & 1 & $10 \%$ & $-42 \%$ & $-16 \%$ & $8 \%$ & 13 & 2 & 3 & 19 & 1 & 4 & 16 & 2 & 3 & 19 & 1 & 4 \\
\hline & Z-DT & 2 & $69 \%$ & $-4 \%$ & $6 \%$ & $-2 \%$ & 26 & 10 & & 36 & 12 & & 31 & 11 & & 36 & 11 & \\
\hline & 3 cenários & 3 & $21 \%$ & $39 \%$ & $-6 \%$ & $-9 \%$ & 42 & 6 & & 57 & 6 & & 49 & 6 & & 57 & 5 & \\
\hline \multirow[t]{4}{*}{8} & & 1 & $7 \%$ & $-34 \%$ & $-19 \%$ & $-1 \%$ & 16 & 1 & & 22 & 0 & & 19 & 0 & & 22 & -1 & \\
\hline & \multirow{3}{*}{4 cenários } & 2 & $20 \%$ & $-28 \%$ & $13 \%$ & $-1 \%$ & 18 & 13 & & 25 & 15 & & 21 & 14 & & 25 & 14 & \\
\hline & & 3 & $62 \%$ & $6 \%$ & $0 \%$ & $0 \%$ & 30 & 8 & & 41 & 9 & & 35 & 8 & & 41 & 8 & \\
\hline & & 4 & $11 \%$ & $48 \%$ & $4 \%$ & $-21 \%$ & 45 & 9 & & 61 & 11 & & 52 & 10 & & 61 & 10 & \\
\hline \multirow[t]{5}{*}{9} & \multirow{5}{*}{5 cenários } & 1 & $31 \%$ & $-28 \%$ & $0 \%$ & $0 \%$ & 18 & 8 & & 25 & 9 & & 21 & 8 & 0 & 25 & 9 & \\
\hline & & 2 & $15 \%$ & $7 \%$ & $15 \%$ & $-1 \%$ & 31 & 13 & & 42 & 16 & & 35 & 14 & & 42 & 15 & \\
\hline & & 3 & $40 \%$ & $10 \%$ & $1 \%$ & $-3 \%$ & 31 & 8 & & 43 & 9 & & 37 & 9 & & 43 & 9 & \\
\hline & & 4 & $7 \%$ & $11 \%$ & $-20 \%$ & $7 \%$ & 32 & 1 & 2 & 44 & & 3 & 37 & 0 & 3 & 43 & & 3 \\
\hline & & 5 & $8 \%$ & $53 \%$ & $-1 \%$ & $-24 \%$ & 47 & 8 & & 63 & 8 & & 54 & 8 & & 63 & 8 & \\
\hline \multirow[t]{6}{*}{10} & \multirow{6}{*}{6 cenários } & 1 & $19 \%$ & $-34 \%$ & $1 \%$ & $4 \%$ & 16 & 8 & 1 & 22 & 9 & 2 & 19 & 9 & 2 & 23 & 9 & 2 \\
\hline & & 2 & $15 \%$ & $0 \%$ & $15 \%$ & $-2 \%$ & 28 & 13 & & 38 & 16 & & 32 & 14 & & 38 & 15 & \\
\hline & & 3 & $39 \%$ & $1 \%$ & $1 \%$ & $-1 \%$ & 28 & 8 & & 39 & 9 & & 33 & 9 & & 39 & 9 & \\
\hline & & 4 & $8 \%$ & $2 \%$ & $-19 \%$ & $0 \%$ & 29 & 1 & & 39 & & & 33 & 0 & & 39 & & \\
\hline & & 5 & $7 \%$ & $24 \%$ & $2 \%$ & $-25 \%$ & 37 & 9 & & 50 & 10 & & 42 & 9 & & 50 & 9 & \\
\hline & & 6 & $12 \%$ & $45 \%$ & $0 \%$ & $-7 \%$ & 44 & 8 & & 60 & 9 & & 51 & 8 & & 60 & 8 & \\
\hline
\end{tabular}

A Tabela 7.6 mostra o nome e o número usado para identificar cada árvore de cenário (Nome); o número de cenários (Cenário); a probabilidade de ocorrência de cada cenário (Prob.); a variação percentual em relação ao volume total de petróleo planejado para cada cenário (Variação \%); e o volume de petróleo planejado para os quatro casos em cada cenário. Observa-se que, mesmo usando diferentes pontos iniciais o método de Høyland e Wallace (2001) gerou árvores de cenários iguais nos seguintes casos: 1 e 6 (EP-T e Z-DI); 2 e 4 (ES-M e M-RO); 3, 5 e 7 (M-CS, Z-DT e 3 cenários). Sendo assim, apenas as árvores $1,2,3,8$, 9 e 10 foram consideradas neste estudo.

A Tabela 7.7 mostra o porte do modelo de programação estocástica e o tempo médio de processamento computacional em função do número de cenários. O caso com 29 cenários corresponde ao problema original, onde todos os registros da série histórica de oferta de petróleo são utilizados como entrada do modelo estocástico. 
Tabela 7.7: Porte do Modelo Estocástico e Tempo Médio de Processamento.

\begin{tabular}{lrrrrr}
$\begin{array}{c}\text { Número de } \\
\text { Cenários }\end{array}$ & Restrições & Variáveis & Não-Zeros & $\begin{array}{c}\text { Restrições } \\
\text { Não-Lineares }\end{array}$ & Tempo (s) \\
\hline \hline 3 cenários & 1.845 & 1.680 & 7.665 & 600 & 2.543 \\
4 cenários & 2.457 & 2.237 & 10.215 & 800 & 15.078 \\
5 cenários & 3.069 & 2.794 & 12.765 & 1.000 & 25.160 \\
6 cenários & 3.681 & 3.351 & 15.315 & 1.200 & 19.154 \\
29 cenários & 17.757 & 16.162 & 73.965 & 5.800 & 34.113 \\
\hline
\end{tabular}

Os resultados desta seção estão separados em: (7.2.1) Árvores de cenários com o mesmo tamanho; (7.2.2) Árvores de cenários com tamanhos diferentes; e (7.2.3) Seleção da melhor árvore de cenário.

\subsection{1}

\section{Árvores de Cenários com o Mesmo Tamanho}

As árvores de cenários 1, 2 e 3 foram geradas pelo método de Høyland e Wallace (2001) a partir de diferentes soluções iniciais, e representam a escolha do planejador entre árvores de mesmo tamanho (3 cenários) com valores distintos. Nesta primeira avalição o objetivo é comparar a solução do modelo de programação estocástica em função de pequenas variações nos valores dos cenários, sem variar a quantidade de pontos usados para aproximar a distribuição original.

A Tabela 7.8 mostra o resultado obtidos para as árvores de cenários 1 (EP-T), 2 (ES-M) e 3 (M-CS), e para a distribuição original (Original). As colunas da Tabela 7.8 indicam o nome do caso (Caso); o número e o nome de cada árvore de cenários (Nome); o valor da função objetivo (Z) e a decisão de primeiro estágio $\left(x^{*}\right)$ para cada problema otimizado; o valor da solução wait-andsee (WS) usada para calcular o valor esperado da informação perfeita (EVPI); o valor da função objetivo $z\left(x^{*}\left(\xi_{k}\right), \xi\right)$ obtida fixando a decisão ótima de primeiro estágio $x^{*}\left(\xi_{k}\right)$ do problema aproximado $\xi_{k}$ no problema original $\xi$; e o valor das três medidas de qualidade. 
Tabela 7.8: Avaliação das Árvores com Três Cenários.

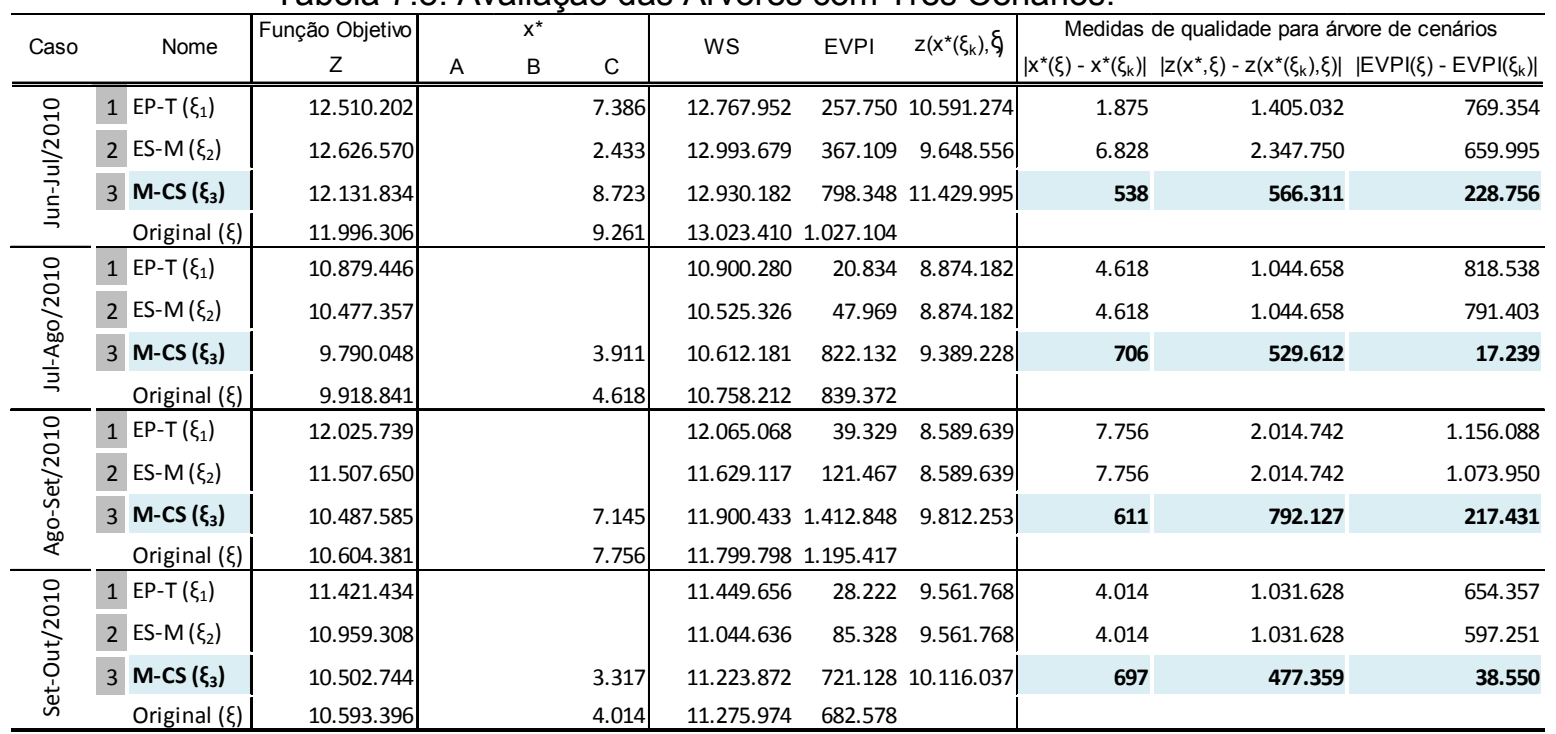

Na Tabela 7.8 destacou-se em negrito a árvore de cenários com melhor desempenho em cada um dos quatros casos. Na comparação entre as árvores de cenários de mesmo tamanho, a árvore 3 apresentou o melhor resultado nos quatros casos para todas as medidas de qualidade. Os resultados obtidos com a árvore 3 no caso Jun-Jul/2010 serão discutidos em detalhe para exemplificar como as medidas de qualidade propostas podem ser interpretadas.

A primeira medida de qualidade trata da decisão de primeiro estágio que corresponde a compra de petróleo. O problema aproximado pela árvore de cenários deve fornecer uma boa solução para o problema original, sendo assim, espera-se que a decisão de primeiro estágio encontrada com a árvore de cenários seja próxima (ou igual) a decisão tomada no problema original. A medida de qualidade utilizada para avaliar a decisão de primeiro estágio é dada por: $\mid x^{*}(\xi)-$ $x^{*}\left(\xi_{k}\right) \mid$, onde $x^{*}(\xi)$ corresponde a decisão de primeiro estágio do problema original e $x^{*}\left(\xi_{k}\right)$ do problema aproximado pela árvore de cenários $k$. No caso JunJul/2010 a decisão de primeiro estágio $x^{*}\left(\xi_{3}\right)$ encontrada com árvore 3 difere apenas em 538 unidades volumétricas $(6 \%)$ da decisão $x^{*}(\xi)$ do problema original. A decisão de primeiro estágio do problema original garante proteção contra todas as possíveis realizações de fornecimento de petróleo dos últimos 3 anos, logo, quanto menor for a diferença $\left|x^{*}(\xi)-x^{*}\left(\xi_{3}\right)\right|$ maior será a proteção contra incerteza fornecida pela árvore de cenários 3 .

A segunda medida de qualidade baseia-se no trabalho de Kaut e Wallace (2003) e avalia a capacidade da árvore de cenários fornecer uma solução de 
primeiro estágio que otimize o problema original. Nesta medida a decisão ótima de primeiro estágio $x^{*}\left(\xi_{k}\right)$ calculada usando a distribuição aproximada $\xi_{k}$ será fixada no problema original para obter o seguinte valor de função objetivo $z\left(x^{*}\left(\xi_{k}\right), \xi\right)$. Este valor será comparado com o valor da função objetivo $z\left(x^{*}, \xi\right)$ do problema original pela equação: $\left|z\left(x^{*}, \xi\right)-z\left(x^{*}\left(\xi_{k}\right), \xi\right)\right|$. No caso JunJul/2010 o valor da função objetivo $z\left(x^{*}\left(\xi_{3}\right), \xi\right)$ fixando a decisão de primeiro estágio $x^{*}\left(\xi_{3}\right)$ encontrada com a árvore 3 foi de 11.429 .995 unidades monetárias, uma diferença de 566.311 unidades monetárias (3\%) da função objetivo $z\left(x^{*}, \xi\right)$ do problema original.

A terceira medida de qualidade proposta compara o valor da informação perfeita (Expected Value of Perfect Information - EVPI) calculado para o problema original $E V P I(\xi)$ e para o problema aproximado $E V P I\left(\xi_{k}\right)$ pela medida dada por: $\left|E V P I(\xi)-E V P I\left(\xi_{k}\right)\right|$. No caso Jun-Jul/2010 o $\operatorname{EVPI}\left(\xi_{3}\right)$ para o problema aproximado por 3 foi de 798.348 unidades monetárias e o $\operatorname{EVPI}(\xi)$ para o problema original foi de 1.027.140 unidades monetárias, uma diferença de 228.756 unidades monetárias (22\%). Na prática as três medidas de qualidade propostas medem a capacidade da árvore de cenários de aproximar o problema original, mas com base em diferentes critérios: decisão de primeiro estágio, valor da função e objetivo e valor do EVPI.

Num primeiro momento, o planejador pode achar que as três árvores de cenários por ajustarem com a mesma qualidade as propriedades estatísticas da distribuição original (ver Tabela 7.4) forneceriam soluções parecidas. No entanto, analisando o valor da função objetivo $(Z)$ e a decisão de primeiro estágio $\left(\boldsymbol{x}^{*}\right)$ observa-se que as árvores de cenários, apesar de serem semelhantes do ponto de vista estatístico, fornecem soluções bem diferentes para modelo de programação estocástica. Outro equivoco que o planejador pode cometer é assumir que a melhor aproximação do problema original é dada pela árvore de cenário que obtiver melhor função objetivo (Z) e/ou melhor (menor) valor esperado da informação perfeita (EVPI). Isto ocorre quando o planejador não possui um valor de referência para verificar a qualidade da aproximação alcançada com uma dada árvore de cenários. Neste trabalho todas as medidas de qualidade propostas usam a solução do problema original como referência para a avaliação das diversas árvores de cenários geradas. 


\subsection{2}

\section{Árvores de Cenários com Tamanhos Diferentes}

As árvores de cenários 3, 8, 9 e 10 foram geradas pelo método de Høyland e Wallace (2001) sem o uso de uma solução inicial, ou seja, foram geradas a partir dos mesmos dados de entrada, e representam a escolha do planejador entre árvores de tamanhos diferentes (3, 4, 5 ou 6 cenários). Lembrando que a árvore 3 , de melhor desempenho na avaliação anterior coincide com a árvore 3 apresentada nesta avaliação. Isto ocorre, pois as árvores 3 , 5 e 7 (M-CS, Z-DT e 3 cenários) geradas pelo método de Høyland e Wallace (2001) são iguais com e sem solução inicial. Nesta segunda avalição o objetivo é comparar a solução do modelo de programação estocástica em função de árvores de cenários geradas pelo mesmo método (Høyland e Wallace, 2001) e nas mesmas condições (sem solução inicial), mas variando a quantidade de pontos usados para aproximar a distribuição original.

A Tabela 7.9 mostra o resultado obtidos para as árvores de cenários 3 , 8 , 9 e 10 , e para a distribuição original. As colunas da Tabela 7.9 indicam o nome do caso (Caso); o número e o nome de cada árvore de cenários (Nome); o valor da função objetivo $(Z)$ e a decisão de primeiro estágio $\left(\boldsymbol{x}^{*}\right)$ para cada problema otimizado; o valor da solução wait-and-see (WS) usada para calcular o valor esperado da informação perfeita (EVPI); o valor da função objetivo $\boldsymbol{z}\left(\boldsymbol{x}^{*}\left(\boldsymbol{\xi}_{\boldsymbol{k}}\right), \boldsymbol{\xi}\right)$ obtida fixando a decisão ótima de primeiro estágio $\boldsymbol{x}^{*}\left(\boldsymbol{\xi}_{\boldsymbol{k}}\right)$ do problema aproximada $\boldsymbol{\xi}_{\boldsymbol{k}}$ no problema original $\xi$; e o valor das três medidas de qualidade. 
Tabela 7.9: Avaliação das Árvores de Cenários com Tamanhos Diferentes.

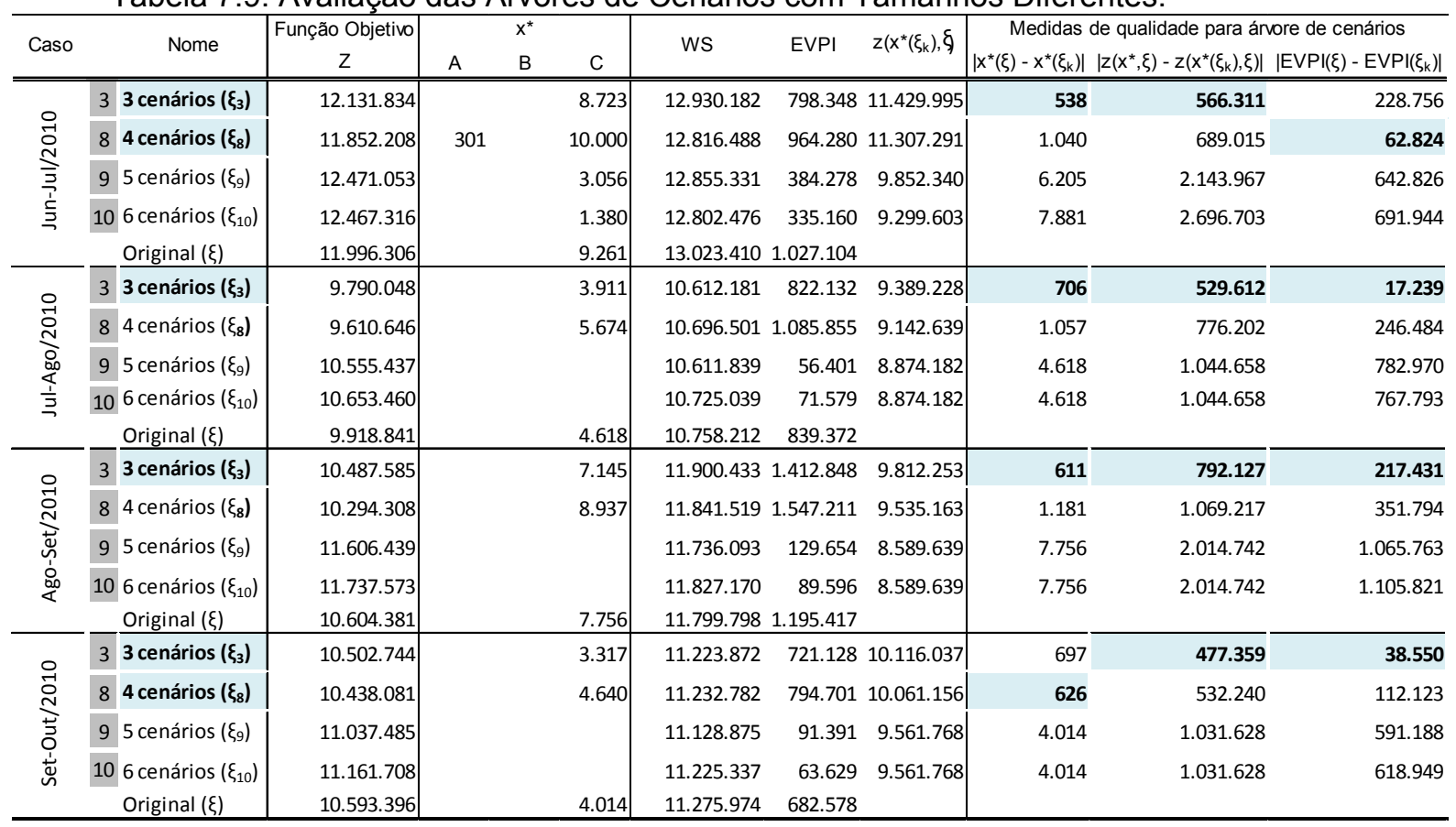

Na Tabela 7.9 destacou-se em negrito a árvore de cenários com melhor desempenho para os quatros casos. Na comparação entre as árvores de cenários de tamanhos diferentes novamente a árvore 3 apresentou o melhor resultado em quase todas as medidas de qualidade, com exceção da medida relativa ao EVPI no caso Jun-Jul/2010 e a decisão de primeiro estágio no caso Set-Out/2010, onde a árvore 4 teve melhor desempenho. Apesar de a árvore 4 apresentar melhor desempenho nestas duas medidas, no geral a árvore 3 foi superior. Com base nas medidas de qualidade propostas entende-se que, dentre as árvores de cenário com tamanhos diferentes (3, 4, 5 e 6 cenários), a árvore 3 forneceu a melhor aproximação para o problema original.

Intuitivamente o planejador avaliaria que um número maior de cenários seria capaz de fornecer uma melhor aproximação para o problema original. No entanto o que observamos neste estudo é que uma distribuição discreta composta de um número maior de pontos pode ajustar melhor a distribuição completa, mas não necessariamente leva a uma melhor solução do problema de programação estocástica. É possível que outros métodos de geração de cenários ou em outros tipos de problema a intuição do planejador esteja correta, e as medidas de qualidade propostas aqui serviriam apenas para confirmar o esperado. Mesmo neste caso, onde uma distribuição discreta com mais pontos fornece uma melhor aproximação para o problema original, existe um trade-off entre tempo de 
processamento do modelo estocástico (ver Tabela 7.7) e qualidade de solução (ver Tabela 7.9), que só poderia ser quantificado com a ajuda de medidas de qualidade como as propostas neste trabalho.

Os resultados mostram que o critério de avaliação melhor função objetivo (Z) e/ou melhor EVPI não é válido para este problema. A árvore 3 em nenhum dos quatro casos apresentou melhor função objetivo (Z) ou melhor EVPI em comparação com as outras árvores avaliadas, no entanto foi a solução que melhor se aproximou da solução do problema original. Com base nas medidas de qualidade propostas entende-se que, dentre as árvores de cenário com mesmo tamanho (3 cenários), a árvore 3 forneceu a melhor aproximação para o problema original.

\subsection{3}

\section{Seleção da Melhor Árvore de Cenário}

Os resultados apontam a árvore de cenários 3 como a melhor distribuição discreta para aproximação do problema original. Nota-se ainda que, segundo as medidas de qualidade propostas, as árvores com melhor função objetivo e menor EVPI não forneceram a melhor aproximação para o problema original. A árvore de cenários 3 , que apresentou melhor desempenho nas medidas de qualidade, teve pior função objetivo e maior EVPI nos quatro casos em comparação com quase todas as árvores. É importante ressaltar que as medidas de qualidade propostas se mostraram bastantes consistentes na avaliação das árvores de cenários, onde uma única árvore apresentou desempenho superior às demais em quase todas as medidas sugeridas. Além disso, nos quatro casos analisados as medidas de qualidade indicaram a mesma árvore como sendo a que melhor representa as incertezas para o modelo de programação estocástica.

As medidas de qualidade apresentadas nas Tabelas 7.8 e 7.9 foram normalizadas em função da solução obtida para problema original e suas médias foram calculadas. A Tabela 7.10 mostra a média das medidas de qualidade normalizadas. 
Tabela 7.10: Média das Medidas de Qualidade Normalizadas.

\begin{tabular}{|c|c|c|c|c|}
\hline & \multirow{2}{*}{ Nome } & \multicolumn{3}{|c|}{$\begin{array}{c}\text { Média \% das medidas de qualidade para árvore de } \\
\text { cenários }\end{array}$} \\
\hline & & $\left|x^{*}(\xi)-x^{*}\left(\xi_{k}\right)\right|$ & $\left|z\left(x^{*}, \xi\right)-z\left(x^{*}\left(\xi_{k}\right), \xi\right)\right|$ & $\left|\mathrm{EVPI}(\xi)-\operatorname{EVPI}\left(\xi_{k}\right)\right|$ \\
\hline 1 & $\mathrm{EP}-\mathrm{T}\left(\xi_{1}\right)$ & $80,06 \%$ & $12,75 \%$ & $91,25 \%$ \\
\hline 2 & ES-M $\left(\xi_{2}\right)$ & $93,43 \%$ & $14,71 \%$ & $83,97 \%$ \\
\hline 3 & M-CS $\left(\xi_{3}\right) / 3$ cenários $\left(\xi_{3}\right)$ & $11,59 \%$ & $5,51 \%$ & $12,04 \%$ \\
\hline 8 & 4 cenários $\left(\xi_{8}\right)$ & $16,23 \%$ & $7,17 \%$ & $20,33 \%$ \\
\hline 9 & 5 cenários $\left(\xi_{9}\right)$ & $91,75 \%$ & $14,29 \%$ & $82,91 \%$ \\
\hline 10 & 6 cenários $\left(\xi_{10}\right)$ & $96,27 \%$ & $15,44 \%$ & $85,51 \%$ \\
\hline
\end{tabular}

Os resultados da Tabela 7.10 confirmam a árvore de cenários 3 como a melhor distribuição discreta para aproximar a solução do problema original e destacam seu desempenho superior às demais árvores geradas. A medida de qualidade calculada com base na decisão de primeiro estágio $\left(x^{*}\right)$ mostra que em média a compra de petróleo adicional do problema aproximado por 3 difere da decisão de primeiro estágio do problema original em apenas 11,59\%. A medida de qualidade baseada na função objetivo mostra que em média a função objetivo aproximada por 3 difere da função objetivo do problema original em apenas $5,51 \%$, em quanto que para as demais árvores a diferença é superior a 7\%. A medida de qualidade em termos do EVPI mostra que em média o EVPI calculado para o problema aproximado com 3 difere em 12,04\% do EVPI calculado para o problema original. A árvore de cenários 4 é única com resultado próximo ao apresentado pela árvore 3 , mas ainda assim significativamente pior.

A próxima seção discute o desempenho do modelo estocástico usando a árvore de cenários 3 para representar as incertezas no fornecimento de petróleo.

\section{3}

\section{Resultados dos Métodos de Solução}

O modelo apresentado do Capítulo Definida a árvore de cenários ( 3 ), o próximo passo é avaliar o modelo de programação estocástica proposto com as medidas EVPI (valor esperado da informação perfeita) e VSS (valor da solução estocástica). O EVPI mede o máximo montante que um tomador de decisão estaria disposto a pagar pela informação perfeita, isto é, o preço a pagar para 
conhecer as realizações futuras. O VSS pode ser interpretado como o benefício esperado do agente que considerou a incerteza, ou ainda, como a perda esperada do agente que optou pela modelagem determinística utilizando o valor esperado da variável aleatória.

A Tabela 7.11 mostra para cada caso o valor da função objetivo (Z), a solução wait-and-see (WS), o valor do EVPI, o EVPI percentual dado pela divisão EVPI/WS (EVPI\%), o valor da função objetivo do modelo estocástico fixando a solução determinística calculada com a média das variáveis aleatórias (EEV); o valor do VSS, e o VSS percentual dado pela divisão VSS/EEV (VSS\%).

Tabela 7.11: EVPI e VSS.

\begin{tabular}{ccccrrrr}
\hline Caso & Z & WS & EVPI & EVPI \% & EEV & VSS & VSS \% \\
\hline \hline Jun-Jul/2010 & 12.131 .834 & 12.930 .182 & 798.348 & $6 \%$ & 9.196 .002 & 2.935 .832 & $32 \%$ \\
Jul-Ago/2010 & 9.790 .048 & 10.612 .181 & 822.132 & $8 \%$ & 9.039 .092 & 750.956 & $8 \%$ \\
Ago-Set/2010 & 10.487 .585 & 11.900 .433 & 1.412 .848 & $12 \%$ & 9.196 .002 & 1.291 .583 & $14 \%$ \\
Set-Out/2010 & 10.502 .744 & 11.223 .872 & 721.128 & $6 \%$ & 9.472 .492 & 1.030 .252 & $11 \%$ \\
\hline Média & & & 938.614 & $8 \%$ & & 1.502 .156 & $16 \%$
\end{tabular}

O EVPI médio de 938.614 unidades monetárias indica que utilizando o modelo estocástico a informação perfeita vale em média 938.614 unidades monetárias ou 8\% da função objetivo do problema de planejamento operacional de refinaria, um valor relativamente baixo em face as incertezas presentes neste problema. O VSS médio de 1.502.156 unidades monetárias indica que o planejador ganha em média 16\% a mais resolvendo o problema estocástico ao invés do determinístico, um ganho que compensa a modelagem estocástica.

O ganho de 1.502.156 unidades monetárias no lucro esperado médio da refinaria dado pelo VSS reforça a utilidade da abordagem estocástica para o problema de planejamento operacional de refinaria. O ganho obtido com a modelagem estocástica é tão expressivo, pois as incertezas observadas no fornecimento de petróleo são igualmente altas. Nos casos analisados para a Ref. Pequena as variações na oferta de matéria prima ficaram entre $+58 \%$ e $-46 \%$ (ver Tabela 7.5). É importante ressaltar que tanto o excesso quanto a falta de petróleo podem impactar significativamente no plano de produção da refinaria. O excesso 
de petróleo gera um custo de estocagem desnecessário, além disso, se o petróleo em excesso for do tipo extrapesado ou asfáltico isso impede a operação normal da refinaria. As refinarias brasileiras operam com misturas (blends) de petróleos e em muitos casos é essa mistura que permite a produção dos derivados dentro das especificações desejadas. A falta de petróleo, por outro lado, subutiliza a capacidade de processamento da refinaria, e novamente se a falta de petróleo for de um tipo especifico, leve ou extra leve, isso impede a operação normal da refinaria. No modelo estocástico proposto a proteção contra as incertezas é feita antecipando a compra de petróleo adicional, definida como decisão de primeiro estágio a ser tomada antes da realização das incertezas. A compra de petróleo adicional complementa o fornecimento de petróleo dado pelo planejamento tático da companhia (parâmetro estocástico), garantindo que a refinaria opere em sua capacidade máxima e produza os derivados dentro das especificações necessárias para atender o mercado consumidor.

Em resumo, a incerteza observada no fornecimento de petróleo (ver exemplos na Tabela 7.5) e os resultados obtidos com o calculo do EVPI e VSS (Tabela 7.11) justificam a modelagem estocástica para o problema de planejamento operacional de refinaria e apontam para grande potencial de ganho. 


\section{Conclusão}

A tese teve como principal objetivo propor uma abordagem estocástica para o problema de planejamento operacional de refinarias, que se diferencia das demais encontradas na literatura. Foi desenvolvido um modelo não-linear de programação estocástica com dois estágios. O modelo proposto representa os processos de natureza não-linear presentes em uma refinaria, como as transformações químicas e o cálculo de qualidade dos derivados. Devido à complexidade do problema NLP formulado, foram avaliados cinco métodos de solução associados aos principais solvers comerciais disponíveis no mercado. O método que apresentou melhor desempenho resolve o problema decomposto em quatro etapas, onde cada etapa serve de inicialização para a seguinte. O método escolhido combina dois solvers na solução do problema, onde as três primeiras etapas são resolvidas com SNOPT 7.2 e a etapa final é resolvida com KNITRO 7.0.

O desempenho do modelo de programação estocástica depende fortemente da árvore de cenários usada para representar a incerteza. Neste sentido é importante que a árvore de cenários aproxime bem a distribuição original do parâmetro estocástico e a solução do modelo de programação estocástica. Neste trabalho foi utilizado o método de geração de cenários proposto por Høyland e Wallace (2001) para representar a incerteza observada no fornecimento de petróleo da refinaria estudada. O método de Høyland e Wallace (2001) gera um número limitado de cenários discretos (árvore de cenários) que satisfazem propriedades estatísticas especificas da distribuição original (neste estudo corresponde a série histórica de fornecimento de petróleo), e assim garantem que a árvore de cenários gerada é uma boa aproximação da distribuição original. Dentre as propriedades estatísticas especificadas, incluiu-se a correlação entre as variáveis aleatórias (os diferentes petróleos) que permitiu o cálculo da distribuição de probabilidade conjunta. Além disso, o método de Høyland e Wallace (2001) foi capaz de gerar árvores de cenários diferentes com a mesma qualidade estatística, pois todas especificaram com a mesma precisão as propriedades estatísticas da 
distribuição original. Ao todo foram geradas neste estudo dez árvores de cenários, mas como algumas deles apresentaram valores de cenários iguais, na prática foram avaliadas seis árvores de cenários diferentes.

Definido o método de geração de cenários, a etapa seguinte avaliou a capacidade da árvore de cenários de aproximar a solução do modelo de programação estocástica obtida com a distribuição original do parâmetro estocástico, ou seja, de aproximar o problema original. As medidas de qualidade propostas neste trabalho comparam a solução do problema aproximado com a do problema original em função de três critérios: decisão de primeiro estágio, valor da função e objetivo e valor da informação perfeita (Expected Value of Perfect Information - EVPI). Os resultados apontaram a árvore de cenários 3 como a melhor distribuição discreta para aproximação do problema original. É importante ressaltar que as medidas de qualidade propostas se mostraram bastantes consistentes na avaliação das árvores de cenários, onde uma única árvore apresentou desempenho bem superior às demais em todas as medidas sugeridas. Além disso, nos quatro casos analisados as medidas de qualidade indicaram a mesma árvore como sendo a que melhor representa as incertezas para o modelo de programação estocástica.

Vale lembrar que na prática não é possível avaliar todas as árvores de cenários cada vez que o modelo de programação estocástico for utilizado. A sugestão é fazer essa avaliação uma única vez para definir o melhor método de geração de cenários e a melhor forma de configurá-lo (ex.: número de cenários). Definido isso, a cada nova rodada do modelo estocástico será utilizado o mesmo método de geração de cenários com as mesmas configurações.

A árvore de cenários 3 foi utilizada para avaliar o modelo de programação estocástica proposto em função das medidas EVPI (valor esperado da informação perfeita) e VSS (valor da solução estocástica). O EVPI médio calculado foi de 8\% e indica que utilizando o modelo estocástico a informação perfeita vale em média 8\% do valor da função objetivo do problema de planejamento operacional de refinaria. O VSS médio foi de $16 \%$ e indica que em média o planejador ganha 16\% a mais resolvendo o problema estocástico ao invés do determinístico, sendo que em um dos casos esse ganho chegou a 32\%. Considerando as altas variações observadas no fornecimento de petróleo, que ficaram entre $+58 \%$ e $-46 \%$ (ver 
Tabela 7.5) para a Ref. Pequena, ambas as medidas justificam a abordagem estocástica para o problema de planejamento operacional de refinaria.

Em resumo, a abordagem estocástica proposta para o problema de planejamento operacional de refinarias é composta por:

- Modelo não-linear estocástico de dois estágios,

- Método de solução para o problema NLP,

- Metodologia de geração de cenários,

- Medidas de qualidade para árvore de cenários,

- Avaliação do modelo estocástico em termos do EVPI e VSS.

Os resultados finais desta pesquisa devem proporcionar avanços no processo de planejamento operacional de refinarias, pois explorou a técnica de programação não-linear (NLP) e os novos solvers disponíveis para problemas do tipo NLP. Pretende-se também gerar contribuições na área de programação estocástica estendendo a abordagem estocástica proposta a outros tipos de problema, principalmente com a disseminação das medidas de qualidade para árvore de cenários que permitem um melhor aproveitamento do modelo de programação estocástica.

\section{1}

\section{Trabalhos Futuros}

Possíveis extensões do presente trabalho são destacadas a seguir:

- Testar a abordagem estocástica proposta nas Ref. Média e Ref. Grande que apresentam diferentes configurações, considerando quantidade de petróleos processados, porte da planta, processos de refino e propriedades de produtos finais.

- Testar a abordagem estocástica proposta considerando diferentes métodos de geração de cenários. O presente trabalho usou um método estatístico para geração de cenários, seria interessante comparar os resultados da abordagem usando também um método de geração por amostragem e de simulação.

- Comparar os resultados obtidos neste trabalho com o método Sample Average Approximation (SAA) (Kleywegt et al., 2001). O SAA calcula 
função objetivo verdadeira com 95\% de confiança, e com isso espera-se que a solução do SAA seja uma boa aproximação para o problema original.

- Propor testes estatísticos para validar as medidas de qualidade usadas na avaliação das árvores de cenários.

- Estender a abordagem estocástica proposta para outros tipos de problemas. 


\section{Referências bibliográficas}

[1] Alhajri, I., Elkamel, A., Albahri, T., Douglas, P.L. (2008), A nonlinear programming model for refinery planning and optimisation with rigorous process models and product quality specifications. International Journal Oil, Gas and Coal Technology, 1, 3, 283-307.

[2] Al-Othman, W., Lababidi, H., Alatiqi, I., Al-Shayji, K., (2008), Supply chain optimization of petroleum organization under uncertainty in market demands and prices. European Journal of Operational Research, 189(3): 822-840.

[3] ANP (2012), Anuário Estatístico Brasileiro do Petróleo, Gás Natural e Biocombustíveis 2012. Acessado em 23 de outubro de 2012: http://www.anp.gov.br/?id=661

[4] Beale, E., (1955), On Minizing A Convex Function Subject to Linear Inequalities, Journal of the Royal Statistical Society, Series B (Methodological), 17, 2, 173-184.

[5] Bellman, R. and Zadeh, L. A. (1970), Decision-making in a fuzzy environment, Management Science, 17, 141-161.

[6] BEN, 2011. Balanço Energético Nacional, 2011. Empresa de pesquisa Energética (EPE), Ministério de Minas e Energia (MME). Disponível em https://ben.epe.gov.br/default2011.aspx acesso em 20/03/2012.

[7] Ben-Tal, A. and Nemirovski, A. (1998), Robust convex optimization, Math. Operations Research, 23, 769-805.

[8] Ben-Tal, A., Nemirovski, A. (1999), Robust solutions of uncertain linear programs, OR Letters, 25, 1-13.

[9] Ben-Tal, A. and Nemirovski, A. (2000), Robust solutions of linear programming problems contaminated with uncertain data, Mathematical Programming, 88, 411-424.

[10] Bertsimas, D. and Sim, M. (2003), Robust discrete optimization and network flows, Mathematical Programming, 98, 43-71.

[11] Bertsimas, D. and Sim, M. (2004), The price of robustness, Operations Research, 52, 35-53.

[12] Bertsimas, D., Pachamanova, D., and Sim, M. (2004), Robust linear optimization under general norms. Operations Research Letters, 32, 6, 510516. 
[13] Beyer, H.-G. and Sendhoff, B. (2007), Robust optimization - a comprehensive survey, Computers Methods in Applied Mechanics Engineering, 196, 3190-3218.

[14] Birge, J.R., and Louveaux, F.V., (1997). Introduction to stochastic programming. New York, NY: Springer.

[15] Bollerslev, T., (1986) Generalized autoregressive conditional heteroskedasticity. Journal Econom., 31, 307-327.

[16] Charnes, A., and Cooper, W., (1959), Chance-constrained programming, Management Science, 6, 1, 73-79.

[17] Dantzig, G. (1955), Linear Programming Under Uncertainty. Management Science, 50, 12 Supplement, 1764-1769.

[18] Dantzig, G.B., and Infanger, G., (1992), Large-scale stochastic linear programs-importance sampling and Benders decomposition. Computational and applied mathematics, I (Dublin 1991), pages 111-120. North-Holland, Amsterdam.

[19] Dempster, M., Hicks Pedron, N., Medova, E., Scott, J., Sembos, A., (2000), Planning logistics operations in the oil industry. Journal of the Operational Research Society, 51(11): 1271-1288.

[20] Dempster, M.A.H., and Thompson, R.T., (1999) EVPI-based importance sampling solution procedures for multistage stochastic linear programmes on parallel MIMD architectures. Annals of Operations Research, 90:161184.

[21] Doucet, A., Freitas, J.F.G., and Gordon, N.J., (2000), Sequential MonteCarlo Methods in Practice. Springer-Verlag.

[22] El-Ghaoui, L. and Lebret, H. (1997), Robust solutions to least-square problems to uncertain data matrices, SIAM Journal on Matrix Analysis and Applications, 18, 1035-1064.

[23] El-Ghaoui, L., Oustry, F., and Lebret, H. (1998), Robust solutions to uncertain semidefinite programs, SIAM Journal on Optimization, 9, 33-52.

[24] Elkamel, A., Ba-Shammakh, M., Douglas, P., and Croiset, E., (2008), An Optimization Approach for Integrating Planning and CO2 Emission Reduction in the Petroleum Refining Industry, Ind. Eng. Chem. Res., 47, 760-776.

[25] Ermoliev, Y.M., and Gaivoronski, A.A., (1992), Stochastic quasigradient methods for optimization of discrete event systems. Ann. Oper. Res., 39(14): 1-39. 
[26] Escudero, L., Quintana, F., Salmerón, J., (1999), CORO, a modeling and an algorithmic framework for oil supply, transformation and distribution optimization under uncertainty. European Journal of Operational Research, 114(3): 638-656.

[27] Fair, R., and Shiller, R., (1990) Comparing information in forecasts from econometric models. Am. Econ. Rev., 80, 375-389.

[28] Freedman, D., (1983) Approximating Countable Markov Chains, 2nd edn. New York: Springer

[29] Gao, Z., Tang, L., Jim, H. and Xu, N. (2008), An Optimization Model for the Production Planning of Overall Refinery. Chinese Journal of Chemical Engineering, Volume 16, Issue 1, Pages 67-7.

[30] Heitsch and Romisch, W. (2005) Scenario tree modelling for multistage stochastic programs, preprint 296, DFG Research Center Matheon (Mathematics for key technologies), Berlin, Germany, (www.matheon.de).

[31] Hoeyland, K., and Wallace, S.W., (2001), Generating Scenario Trees for Multistage Decision Problems. Management Science, 47(2): 295-307.

[32] Infanger, G., (1994), Planning under Uncertainty: Solving Large-Scale Stochastic Linear Programs. Boyd and Fraser, Danvers.

[33] Infanger, G., (1992), Monte Carlo (importance) sampling within a Benders decomposition algorithm or stochastic linear programs. Ann. Oper. Res., 39(1-4): 69-95.

[34] Jerrum, M., and Sinclair, A., (1996), The Markov chain Monte Carlo method: An approach to approximate counting and integration. Approximation Algorithms for NP-hard Problems (Dorit Hochbaum, ed.). PWS Publishing, 482-520.

[35] Jobst, N.J., and Zenios, S.A., (2001) Tracking bond indices in an integrated market and credit risk environment. Working Paper 01-04. Nicosia, Cyprus: HERMES Center of Excellence on Computational Finance \& Economics School of Economics and Management, University of Cyprus.

[36] Kaut, M., and Wallace, S., (2003), Evaluation of scenario-generation methods for stochastic programming. Stochastic Programming E-Print Series, http://www.speps.org.

[37] Kaut M., and Wallace, S.W., (2007) Evaluation of scenario generation methods for stochastic programming. Pac. J. Optim., 3(2): 257-271.

[38] Khor, C.S., Elkamel, A., Douglas, P.L., (2008) Stochastic refinery planning with risk management. Pet. Sci. Technol. 2008, 26, 1726-1740. 
[39] Khor, C., Elkamel, A., Ponnambalam, K., Douglas, P., (2007), Two-stage stochastic programming with fixed recourse via scenario planning with economic and operational risk management for petroleum refinery planning under uncertainty. Chemical Engineering \& Processing: Process Intensification, 47(9-10): 1744-1764.

[40] Khor, C.S., and Nguyen, T.H.N., (2009), Stochastic Programming with Tractable Mean- Risk Objectives for Refinery Planning Under Uncertainty, Computer Aided Chem. Eng., 27, 1965-70.

[41] Kleywegt, A.J., Shapiro, A., Homem-De-Mello, T., (2001), The sample average approximation method for stochastic discrete optimization, SIAM Journal of Optimization 12 479-502.

[42] Kouvelis, P., Yu, G., (1997), Robust Discrete Optimization and its Applications. Dordecht,The Netherlands, Kluwer Academic Publishers.

[43] Lababidi, H., Ahmed, M., Alatiqi, I., Al-Enzi, A., (2004), Optimizing the supply chain of a petrochemical company under uncertain operating and economic conditions. Industrial \& Engineering Chemistry Research, 43(1): 63-73.

[44] Lakkhanawat, H. and Bagajewicz, M.J. (2008), Financial Risk Management with Product Pricing in the Planning of Refinery Operations. Industrial \& Engineering Chemistry Research, 47, 17, 6622-6639.

[45] Leiras, A., Hamacher, S., and Elkamel, A. (2010), Petroleum Refinery Operational Planning using Robust Optimization, Engineering Optimization, in press.

[46] Leiras, A., Ribas, G., Hamacher, S., Elkamel, A., (2011), Literature Review of Oil Refineries Planning under Uncertainty, International Journal of Oil, Gas and Coal Technology, 4, 2, 156-173.

[47] Li, C., He, X., Chen, B., Xu, Q., and Liu, C. (2008), A Hybrid Programming Model for Optimal Production Planning under Demand Uncertainty in Refinery, Chinese Journal of Chemical Engineering, 16, 2, 241-246.

[48] Li, W., Hui, C., Li, P., Li, A., (2004), Refinery Planning under Uncertainty. Industrial and Engineering Chemistry Research 43, 6742-6755.

[49] Li, W., Hui, C., Li, P., and Li, A., (2005), Integrating CDU, FCC and product blending models into refinery planning, Computers and Chemical Engineering, 29, 2010-2028.

[50] Li, C., He, X., Chen, B., Xu, Q., and Liu, C. (2008), A Hybrid Programming Model for Optimal Production Planning under Demand Uncertainty in Refinery, Chinese Journal of Chemical Engineering, 16, 2, 241-246. 
[51] Liu, M., Sahinidis, N., (1996), Optimization in process planning under uncertainty. Industrial \& Engineering Chemistry Research, 35: 4154.

[52] Liu, M.L., and Sahinidis, N., (1997), Process planning in a fuzzy environment, European Journal of Operational Research, 100, 1, 142-169.

[53] Micheletto, S., Carvalho, M., Pinto, J., (2007), Operational optimization of the utility system of an oil refinery. Computers and Chemical Engineering, v.32, n.1-2, p.170-185.

[54] Mitra, S. (2006), Scenario generation for stochastic programming, White paper, Optirisk Systems, UK, 1-34.

[55] Moro, L., Zanin, A., Pinto, J., (1998), A planning model for refinery diesel production. Computers and Chemical Engineering, v.22, p.1039-1042.

[56] Moro, L., (2003), Process Technology in the Petroleum Refining Industry current situation and future trends. Computers and Chemical Engineering, Volume 27, Number 8, 15, pp. 1303-1305(3).

[57] Neiro, S., and Pinto, J., (2004), A general modeling framework for the operational planning of petroleum supply chains. Computers and Chemical Engineering, v.28, n.6-7, p.871-896.

[58] Neiro, S., and Pinto, J., (2005), Multiperiod Optimization for Production Planning of Petroleum Refineries. Chemical Engineering Communications, 192, 1, 62-88.

[59] Neiro, S., and Pinto, J., (2006), Langrangean decomposition applied to multiperiod planning of petroleum refineries under uncertainty. Latin American Applied Research, 36, 4.

[60] Park, J., Park, S., Yun, C., and Kim, Y., (2010), Integrated Model for Financial Risk Management in Refinery Planning, Ind. Eng. Chem. Res., 49, 374-380.

[61] PIMS (1993), Process Industry Modeling System: User's Manual. Version 6.0, Bechtel Corp., Houston.

[62] Pinto, J.M., Joly, M., and Moro, L.F.L., (2000), Planning and scheduling models for refinery operations, Computers and Chemical Engineering, 24, 2259-2276.

[63] Pinto, J., and Moro, L., (2000), A planning model for petroleum refineries. Brazilian Journal of Chemical Engineering 17, 575-586.

[64] Pongsakdi, A., Rangsunvigit, P., Siemanond, K., and Bagajewicz, M.J., (2006), Financial risk management in the planning of refinery operations. International Journal of Production Economics, 103, 64-86. 
[65] Ponnambalam, K., Vannelli, A., and Woo, S., (2002), An interior point method implementation for solving large planning problems in the oil refinery industry, Canadian Journal of Chemical Engineering, 70, 2, 368374.

[66] Ravi, V., and Reddy, P., (1998), Fuzzy linear fractional goal programming applied to refinery operations planning. Fuzzy Sets and Systems, 96(2), 173182.

[67] Ribas, G.P., Hamacher, S., and Street, A., (2010), Optimization of the integrated petroleum supply chain considering uncertainties using stochastic, robust and max-min models, International Transactions in Operational Research, 17: 777-796. doi: 10.1111/j.1475-3995.2009.00756.x

[68] Ribas, G.P., Leiras, A., and Hamacher, S., (2010), Optimization under Uncertainty for Operational Planning of Petroleum Refineries, Simpósio da Sociedade Brasileira de Pesquisa Operacional, 2010. Anais XLII SBPO.

[69] RPMS (1979) Refinery and Petrochemical Modeling Systems: A System Description; Bonner and Moore: Houston, TX.

[70] Rustem B., Gulpinar, N. and Settergren R., (2004), Simulation and optimzation approaches to scenario tree generation. Journal of Economic Dynamics and Control, 28.

[71] Shah, N.K., Li, Z., and Ierapetritou, M.G. (2011), Petroleum Refining Operations: Key Issues, Advances, and Opportunities, Ind. Eng. Chem. Res., 50 (3), 1161-1170.

[72] Sahinidis, V., (2004), Optimization under uncertainty: state-of-the-art and opportunities. Computers and Chemical Engineering, 28, 971-983.

[73] Shapiro, A. and Philpott, A. A Tutorial on Stochastic Programming. Disponível em http://stoprog.org/.

[74] Shapiro, A., Dentcheva, D., and Ruszczynski, A., (2009), Multistage Problems, Lectures on Stochastic Programming: Modeling and Theory, Chapter 3, SIAM, Philadelphia.

[75] Smith, L., (2002), A Tutorial on Principal Components Analysis. http://ranger.uta.edu/ guerra/Smith02tutorial.pdf (Acessado em 17 de julho, 2011).

[76] Soyster, A., (1973), Convex programming with set-inclusive constraints and applications to inexact linear programming. Operations Research, 21, 11541157.

[77] TAVARES, MARINA ELISABETE E. (2005), Análise do Refino no Brasil: estado e perspectivas - uma análise “cross-section” [Rio de Janeiro] 2005. 
XVIII, 384 p. 29,7 cm (COPPE/UFRJ D.Sc., Planejamento Energético, 2005).

[78] Zhang, B.J., and Hua, B., (2007), Effective MILP model for oil refinerywide production planning and better energy utilization, Journal of Cleaner Production, 15, 5, 439-448.

[79] Zhang, N., and Zhu, X.X., (2006), Novel modeling and decomposition strategy for total site optimization, Computers and Chemical Engineering, 30, 765-777.

[80] Zhang, N., Zhu, X.X., and Towler (2001), A Simultaneous Optimization Strategy for Overall Integration in Refinery Planning, Ind. Eng. Chem. Res., 40, 2640-2653.

[81] Zimmermann, H.-J. (1991), Fuzzy set theory and its applications, 2nd ed. Boston, Massachusetts, United States of America: Kluwer Academic Publishers. 